\author{
UnB - UNIVERSIDADE DE BRASÍLIA \\ FGA - FACULDADE GAMA \\ PROGRAMA DE PÓS-GRADUAÇÃO EM ENGENHARIA \\ BIOMÉDICA
}

\title{
PROCESSAMENTO DE SINAIS DE EMG-S POR MEIO DA UTILIZAÇÃO DE COMPRESSIVE SENSING
}

IGOR LUIZ BERNARDES DE MOURA

ORIENTADOR: Dr. FABIANO ARAUJO SOARES

DISSERTAÇÃO DE MESTRADO EM ENGENHARIA BIOMÉDICA

PUBLICAÇÃO: 39A/2015

BRASÍLIA/DF: OUTUBRO - 2015 
UnB - UNIVERSIDADE DE BRASÍLIA

FGA - FACULDADE GAMA

PROGRAMA DE PÓS-GRADUAÇÃO EM ENGENHARIA

BIOMÉDICA

\section{PROCESSAMENTO DE SINAIS DE EMG-S POR MEIO DA UTILIZAÇÃO DE COMPRESSIVE SENSING}

\section{IGOR LUIZ BERNARDES DE MOURA}

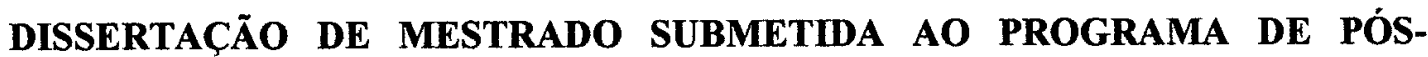
GRADUAÇÃO EM ENGENHARIA BIOMÉDICA DA FACULDADE GAMA DA UNIVERSIDADE DE BRASÍLIA, COMO PARTE DOS REQUISITOS NECESSÁRIOS PARA A OBTENÇÃo DO GRAU DE MESTRE EM ENGENHARIA BIOMÉDICA.

APROVADA POR:

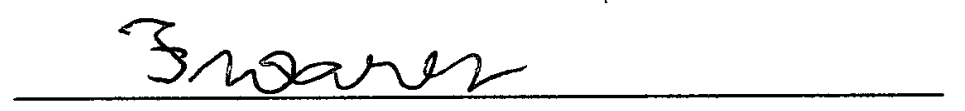

Prof. Dr. Fabiano Araujo Soares - FGA/UnB (Orientador)

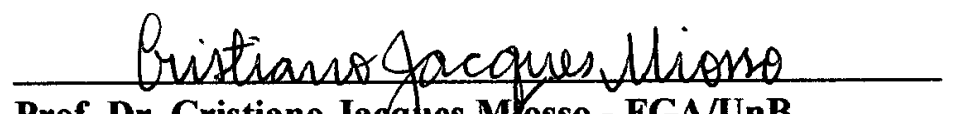

Prof. Dr. Cristiano Jac(q)es Mosso - FGA/UnB

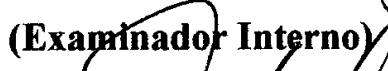

Prof. Dr. Jake do Carmo - FEF/UnB

(Expminador Externo)

BRASÍLIA/DF, 16 DE OUTUBRO DE 2015. 


\section{FICHA CATALOGRÁFICA}

IGOR LUIZ BERNARDES DE MOURA

Processamento De Sinais De EMG-S Por Meio Da Utilização De Compressive Sensing, [Distrito Federal] 2015.

80.p., 210 x 297 mm (FGA/UnB Gama, Mestre, Engenharia Biomédica, 2015). Dissertação de Mestrado - Universidade de Brasília. Faculdade Gama. Programa de Pós-Graduação em Engenharia Biomédica.

1. COMPRESSIVE SENSING

2. ELETROMIOGRAFIA / EMG-S

3. SIMULADOR DE EMG-S 2D

4. PROCESSAMENTO DE SINAIS

I. FGA UnB Gama/ UnB.

\section{REFERÊNCIA BIBLIOGRÁFICA}

MOURA, I. L. B. (2015). PROCESSAMENTO DE SINAIS DE EMG-S POR MEIO DA UTILIZAÇÃO DE COMPRESSIVE SENSING. Dissertação de Mestrado em Engenharia Biomédica, Publicação 39A/2015, Programa de Pós-Graduação em Engenharia Biomédica, Faculdade Gama, Universidade de Brasília, Brasília, DF, 80p.

\section{CESSÃO DE DIREITOS}

AUTOR: IGOR LUIZ BERNARDES DE MOURA

TÍTULO: PROCESSAMENTO DE SINAIS DE EMG-S POR MEIO DA UTILIZAÇÃO DE COMPRESSIVE SENSING

GRAU: Mestre

ANO: 2015

É concedida à Universidade de Brasília permissão para reproduzir cópias desta dissertação de mestrado e para emprestar ou vender tais cópias somente para propósitos acadêmicos e científicos. O autor reserva outros direitos de publicação e nenhuma parte desta dissertação de mestrado pode ser reproduzida sem a autorização por escrito do autor.

ENDEREÇO

SQN 112 BLOCO F APT 506.

ASA NORTE - BRASÍLIA, DF - CEP: 70762060 


\section{Agradecimentos}

Primeiramente a Deus.

Agradeço a minha familia por todo amor e apoio.

À minha amiga e companheira Isabella Cintra, por todo amor e carinho, e a sua família que sempre me acolheu de braços abertos.

Aos meus amigos Auber Alves, Luan Ozelim, Matheus Bichara e Filipe Tomé.

Ao meu professor orientador, Fabiano A. Soares, pelos ensinamentos e oportunidades.

Ao professor Ricardo v.Borries, por me receber na UTEP no período de intercâmbio.

A Universidade de Brasília pelo mestrado e por toda infraestrutura oferecida.

Igor Luiz Bernardes de Moura 


\section{RESUMO}

O Compressive Sensing ( $C S$ ) é uma técnica recente que explora a esparsidade de um sinal para realizar a amostragem em uma taxa inferior à de Nyquist. Ainda incipientes, pesquisas que relacionam o $C S$ à reconstrução de sinais de Eletromiografia de Superfície (EMG-S) indicam possibilidade de utilização desta técnica no processamento e recuperação de dados. Este trabalho tem como proposta a realização de um teste computacional para avaliar múltiplas combinações dos parâmetros: intervalos máximo de perdas para reconstrução, métrica $l_{p}$ a ser minimizada, menor percentual de amostras para uso do $C S$ e tipo de matriz de aquisição (binária ou aleatória). Espera-se determinar quais os melhores valores para recuperação e reconstrução de sinais de EMG-S através do uso de $C S$, de modo que na etapa de pós processamento seja possível recuperar trechos danificados do sinal.

Utilizou-se um sinal simulado para os testes, de modo que este serviu para comparação com os que foram reconstruídos experimentalmente. Por serem naturalmente não-esparsos, os sinais de EMG-S foram esparsificados através da utilização de um banco de filtros de 32 canais, sendo o CS aplicado em cada uma das componentes. Um laço de repetição foi implementado para determinar qual a melhor combinação entre o tamanho máximo do intervalo, a métrica $l_{p}$ a ser minimizada, o percentual de amostras e o tipo de matriz de aquisição utilizado. Uma vez determinados, os resultados foram aplicados em múltiplos intervalos distribuídos pelo sinal, com intuito de avaliar a capacidade da técnica em recuperar um sinal altamente comprometido.

Os resultados indicaram uma relação entre o sinal reconstruído e o original de aproximadamente $29.59 \mathrm{~dB}$, para o caso em que um intervalo de 40 pontos foi recuperado, e 25.01 para o caso de cinco intervalos. Considerando que o sinal de testes tinha 1025 amostras, foi possível reconstruir aproximadamente $20 \%$ deste com o CS. Uma vez que na análise de sinais de EMG-S micro-oscilações na curva do sinal não são comprometedoras, e que outros parâmetros/características possuem uma relevância maior (ex: RMS, ARV, MNF, MDF, CV), o objetivo foi alcançado e a utilização do CS mostrou-se bastante promissor. 


\begin{abstract}
The Compressive Sensing $(C S)$ is a recent technique that exploits the sparsity of a signal to sample it at a rate under the proposed by Nyquist. Still incipient, research linking the $C S$ reconstruction of surface electromyography signals $(E M G-S)$ indicate the possibility of using this technic for the processing and data recovery. This paper aims to carry out a computer test to evaluate multiple combinations of parameters: maximum reconstruction intervals, metric $L_{p}$ to be minimized, minimal percentage of samples and type of acquisition matrix (binary or random). It is expected to determine the best values for the recovery and reconstruction S-EMG signals through the use of $C S$, so in the post processing step, will be possible to recover damaged sections of the signal.

It was used a simulated signal for the tests, so this was used to compare with those reconstructed experimentally. Due the characteristic of been naturally non-sparse, the S-EMG signals were sparsified by using a 32-channel filter bank, and the $C S$ was applied to each of the components. A repeating loop was implemented to determine the best combination between the maximum size of the interval, the metric $L_{p}$ to be minimized, the percentage of samples and the type of acquisition matrix used. Once determined, the results were applied in multiple intervals distributed by the signal, in order to verify the technique's ability to recover a highly compromised signal.

The results indicate a relationship between the reconstructed signal and the original of approximately $29.59 \mathrm{~dB}$ for the case in which an interval of 40 points was recovered and 25.01 for the case of five intervals. Whereas the test signal had 1025 samples, it was possible to reconstruct about $20 \%$ of this with the CS. Once the analysis of EMG-S micro-oscillation signals in the signal curve are not compromising, and other parameters/features have greater relevance ( $R M S, A R V, M N F, M D F, C V)$, the objective has been achieved and using the $C S$ proved very promising.
\end{abstract}




\section{SUMÁRIO}

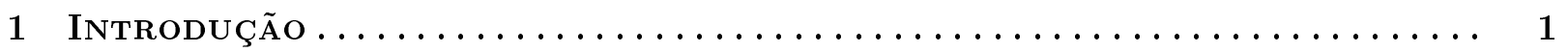

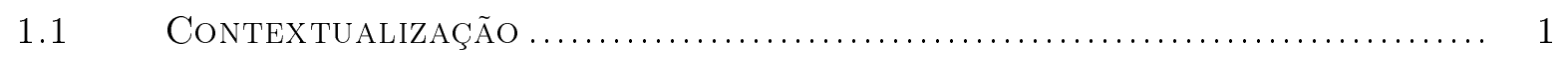

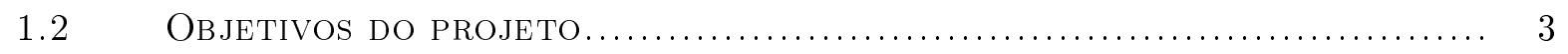

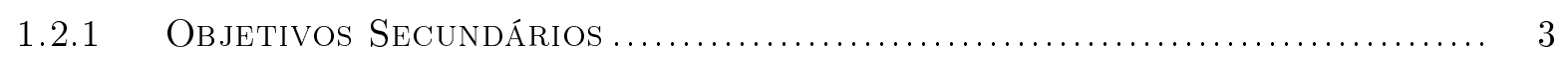

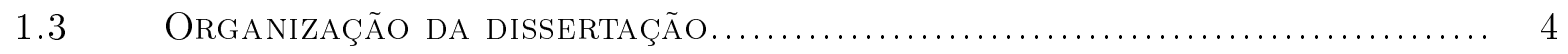

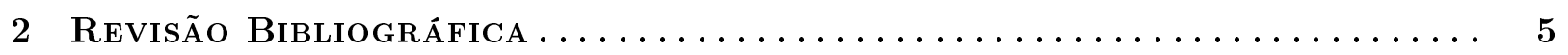

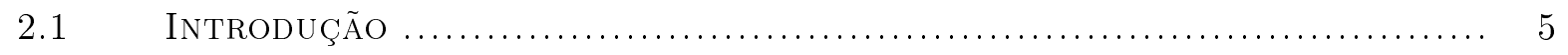

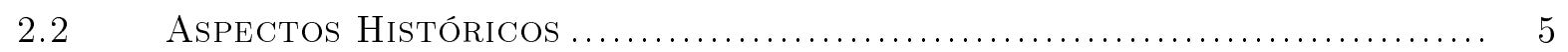

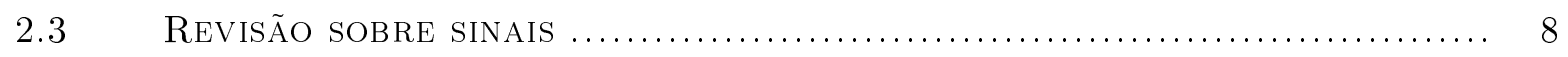

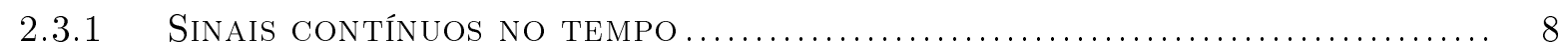

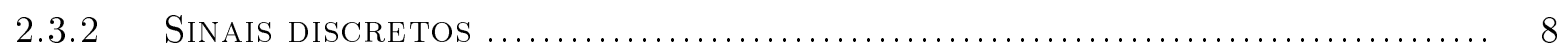

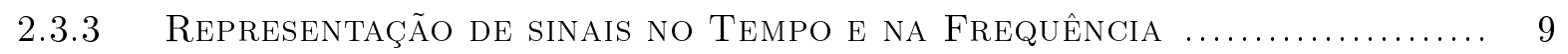

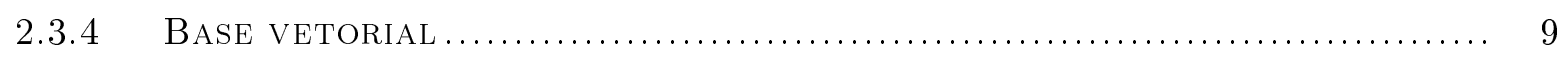

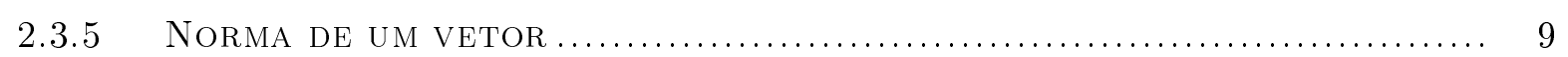

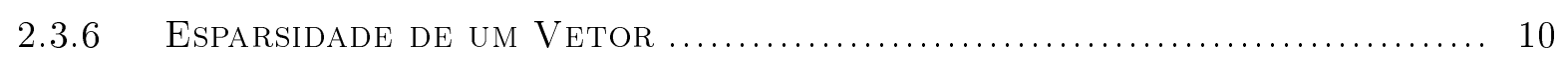

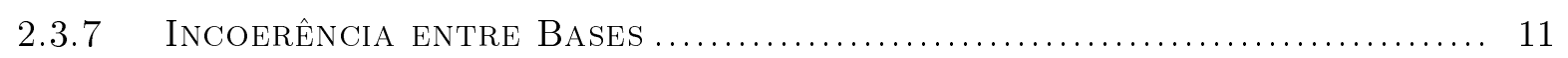

2.3 .8 Técnicas de Amostragem........................................ 11

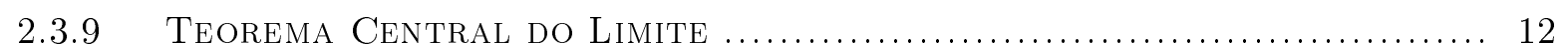

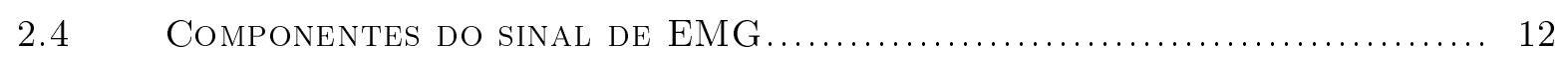

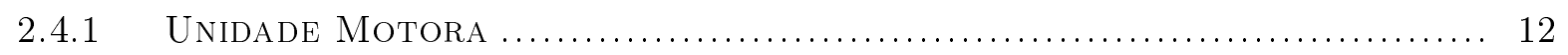

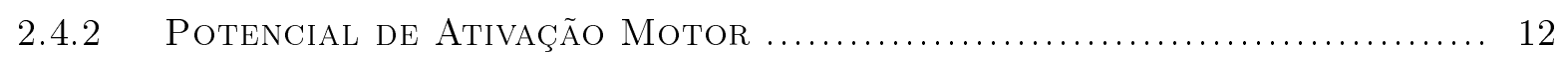

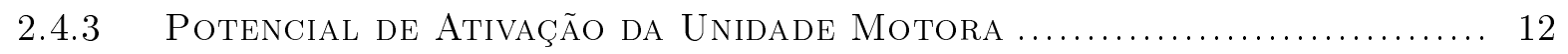

2.4.4 Trem de Potenciais de AtivaÇão da Unidade Motora $\ldots . . . . . . . . . . . . . . . .13$

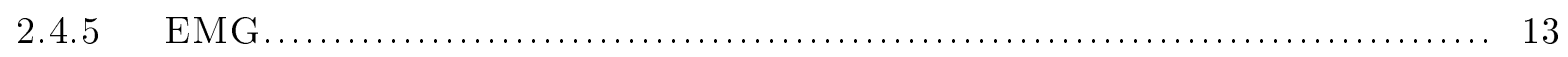

2.4.6 Ruídos E INTERFERÊnCIAS nos SINAL DE EMG .......................... 13

2.5 Filtragem e Banco de Filtros ..................................... 14

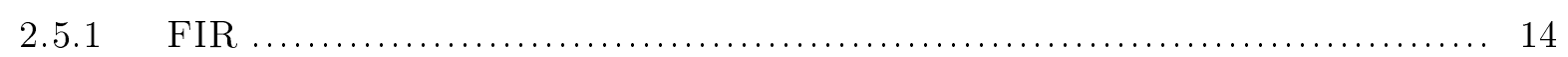

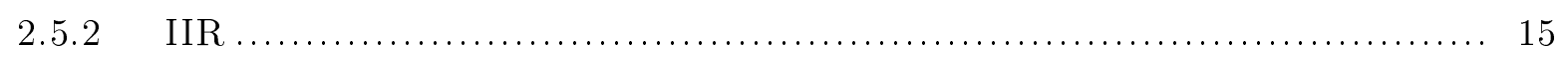

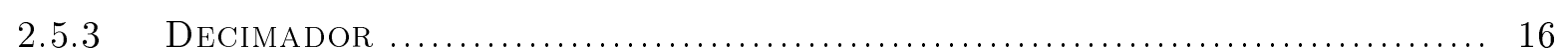

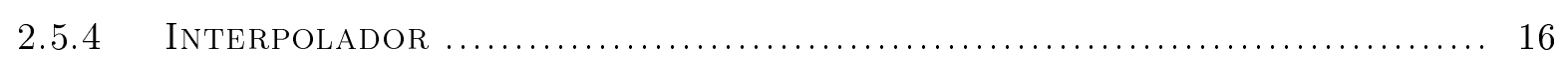

2.5.5 BAnCo de Filtros ......................................................... 17

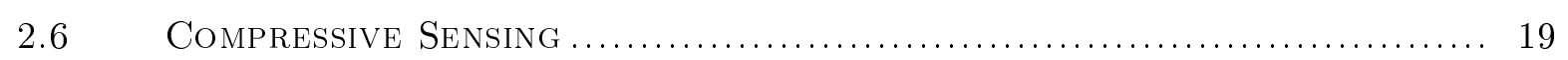




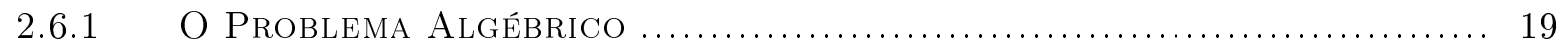

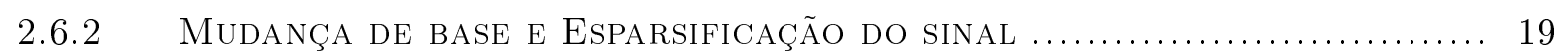

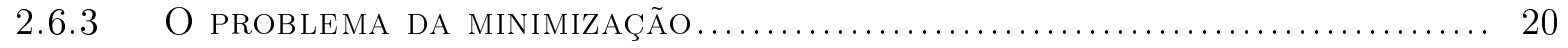

2.6.4 Requisitos Para o funcionamento do Compressive Sensing ............... 22

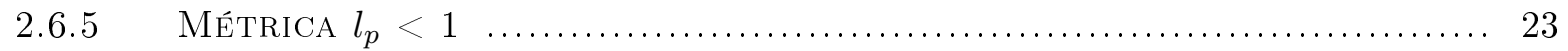

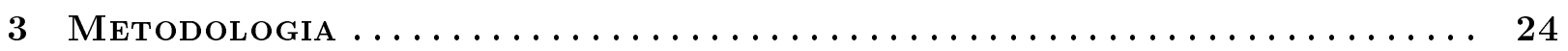

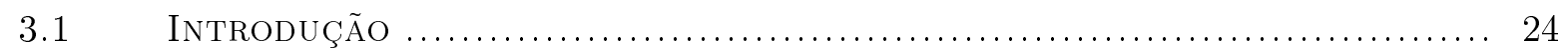

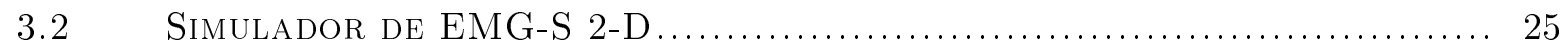

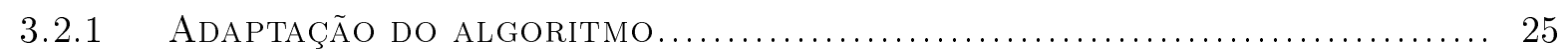

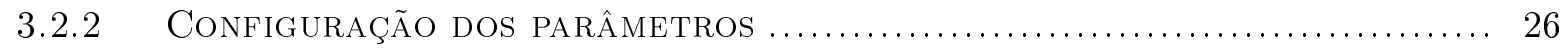

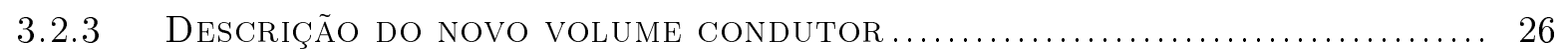

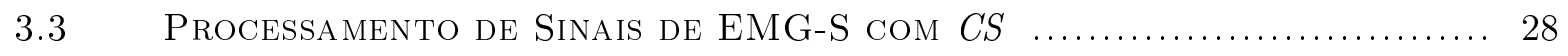

3.3.1 Banco de Filtros de AnÁlise.......................................... 28

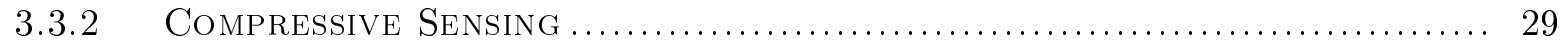

3.3.3 Banco de Filtros de Síntese ........................................ 32

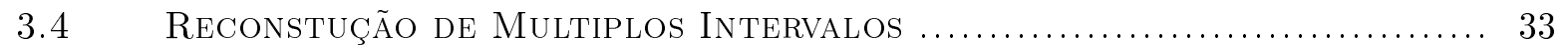

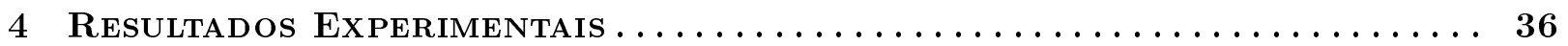

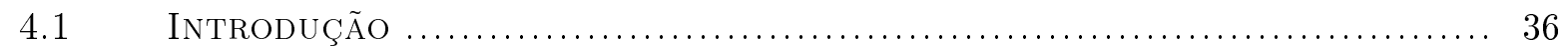

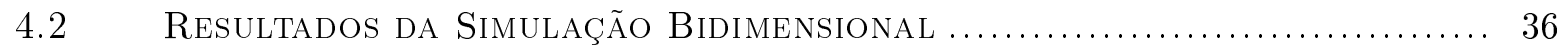

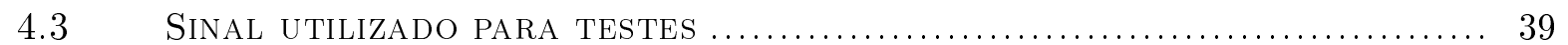

4.4 Decomposição do sinal Em 32 sub-Bandas de frequÊnCIA............... 40

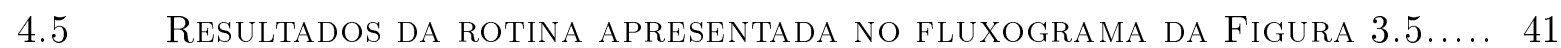

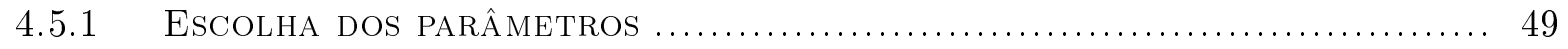

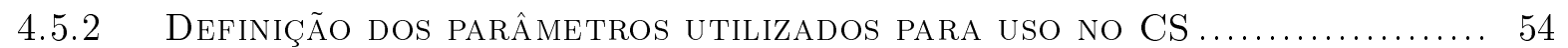

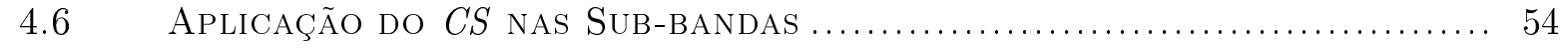

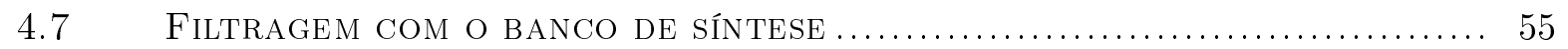

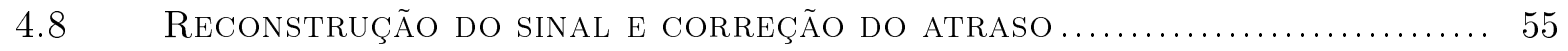

4.9 ReconstruÇÃo de Múltiplos intervalos .............................. 57

4.10 RELAÇÃo SSR ENTRE O SinAL original E O RECONSTRUÍdo ................ 59

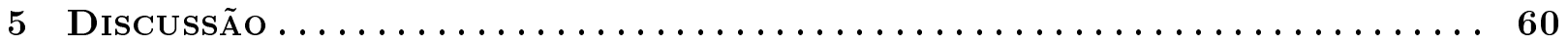

5.1 Discussão SOBRE O SIMUlador DE EMG-S BIDIMENSIONAL $\ldots \ldots \ldots \ldots \ldots \ldots \ldots$

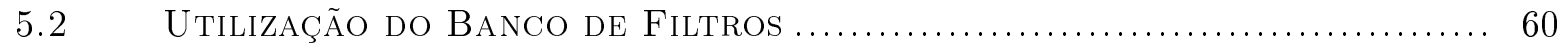

5.3 Rotina PARA DELIMITAÇ̃̃o dos PARÂMETROS ................................ 61

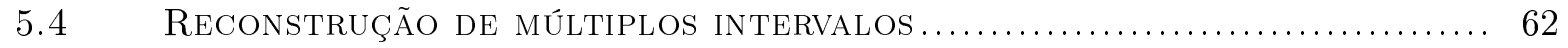

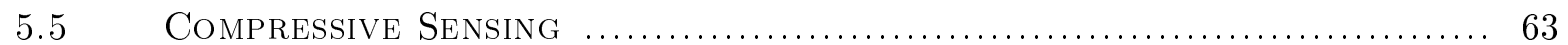

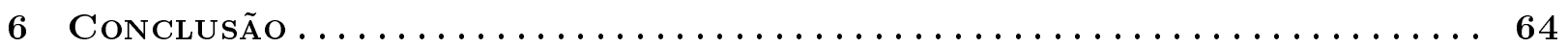

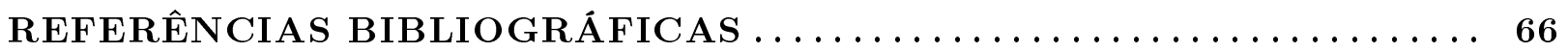




\section{LISTA DE FIGURAS}

2.1 Representação de um sinal no domínio do tempo e no domínio da frequência. A figura ilustra a decomposição de um sinal em senóides e a representação de cada uma destas no domínio transformado. Fonte: http://www.sabereletronica.com.br/artigos/1918anlise-de-vibraes-mecnica-com-fpga

2.2 Descreve brevemente todas os passos para formação do sinal de EMG. Inicia com a formação da unidade motora e segue para a geração do potencial de ativação. Mostra o potencial sendo repetido inúmeras vezes e finaliza com a formação do sinal de EMG a partir do somatório de todos os potenciais. ............................ 13

2.3 Exemplo da configuração de um filtro FIR de ordem N. .......................... 15

2.4 Exemplo de configuração de um filtro IIR. Adaptado de [1] ........................ 15

2.5 Diagrama de bloco de um Decimador ........................................... 16

2.6 Exemplo do efeito da decimação de um sinal $x(n)$ por um fator $2 \ldots \ldots \ldots \ldots \ldots \ldots \ldots \ldots \ldots \ldots \ldots$

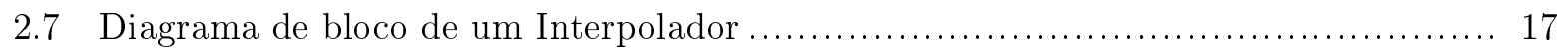

2.8 Exemplo do efeito da interpolação de um sinal $x(n)$ por um fator $2 \ldots \ldots \ldots \ldots \ldots \ldots \ldots \ldots \ldots \ldots \ldots$

2.9 Exemplo da estrutura de um Banco de Filtros. a)Filtro de Análise. Um sinal $x(n)$ é decomposto em $M$ sub-bandas. b)Filtro de Síntese. As sub-bandas $y(k)$ são

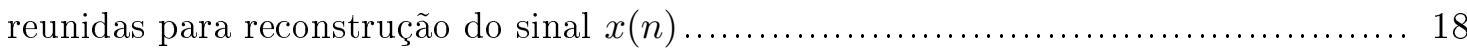

2.10 Matriz de Sensoriamento. É a representação gráfica da Equação (2.14), e ilustra a obtenção do sinal $y$ a partir da multiplicação matricial de $\Phi$ e de $x$. .................. 20

2.11 Matriz de Aquisição e de Mudança de base. É a representação gráfica da Equação (2.17), e ilustra a obtenção do sinal $y$ a partir da multiplicação matricial de $\Phi, \Psi^{T}$ e $s$. Permite a obtenção de $y$ a partir do sinal esparso $s$

2.12 Comparativo entre o comportamento das 3 principais normas envolvidas com o $C S$. Nota-se que todos os pontos que não estão sobre os eixos são as soluções não esparsas e portanto, não devem ser utilizadas.Fonte: http://www.amepc.org-qims-articleviewFile-2233-3083-8679

2.13 Comparativo entre normas L1 e L2. Com base na Figura 2.12, a norma $L_{2}$ coincide com a reta dos possíveis resultados fora dos eixos, o que implica em uma solução não esparsa. Já a norma $L_{1}$ encontra a reta exatamente sobre do eixo, justificando assim sua utilização. Adapatado de [2]

3.1 Diagrama de blocos das etapas de recuperação do sinal de EMG. O sinal é decomposto em 32 sub-bandas de frequências através de um banco de filtros de análise, processado com o uso do $C S$ e reconstruído com o uso do banco de filtros de síntese. 25 
3.2 (a) Volume condutor utilizado no simulador original. O eixo $\mathrm{x}$, que representa a camada onde estão posicionados os eletrodos, é considerado infinito e plano. As camadas $d$ e $h_{1}$ são fixas e independem da posição do eletrodo. Adaptado de [3]. (b) Volume condutor utilizado como referência para elaboração do simulador. As camadas de pele e gordura são descritas como funções do angulo $\alpha$ e variam conforme o eletrodo se distância horizontalmente da fibra muscular.

3.3 Função que descreve o comportamento das camadas de pele e de gordura. Na origem do sistema, os parâmetros $d$ e $h$ tem o valor original, que foi estabelecido pelo usuário. Conforme a coluna de eletrodo é deslocada na direção $x$, os parâmetros são alterados seguindo a função que descreve o volume condutor a ser simulado, considerando assim o efeito da distância na captação dos sinais.

3.4 Resposta do banco de análise projetado. Na figura estão representados os 32 filtros passa-banda que compõem o banco de filtros. Observa-se que existe grande atenuação fora da banda de passagem.

3.5 Fluxograma utilizado como referência para determinação dos melhores parâmetros ... 31

3.6 Simulação de dois intervalos de perdas no sinal. Estão circuladas as 2 falhas inseridas no sinal, localizadas entre os pontos 200-240 e entre 680-720. Cada trecho foi substituído por 40 elementos nulos.

3.7 Simulação de três intervalos de perdas no sinal. Estão circuladas as 3 falhas inseridas no sinal, localizadas entre os pontos 200-240, 440-480 e entre 680-720. Cada trecho foi substituído por 40 elementos nulos.

3.8 Simulação de quatro intervalos de perdas no sinal. Estão circuladas as 4 falhas inseridas no sinal, localizadas entre os pontos 200-240, 440-480, 680-720 e entre 920-960. Cada trecho foi substituído por 40 elementos nulos.

3.9 Simulação de cinco intervalos de perdas no sinal. Estão circuladas as 5 falhas inseridas no sinal, localizadas entre os pontos 160-200, 360-400, 560-600, 760-800 e entre 960-1000. Cada trecho foi substituído por 40 elementos nulos.

4.1 Representação dos resultados para a primeira coluna de eletrodos, posicionada paralela às fibras musculares e sobre o eixo Z. Existe pouca variação na amplitude $\mathrm{e}$ ocorre atraso em função da distância entre os eletrodos.

4.2 Representação dos resultados para a primeira linha de eletrodos, posicionada perpendicular às fibras musculares e sobre o eixo x. Existe grande variação na amplitude em função das variações no volume condutor.

4.3 Representação 2-D da simulação de uma matriz 4x5, utilizando os parâmetros estabelecidos na Tabela 3.1. Cada conjunto de sinais representa uma mesma linha de eletrodos, onde os sinais das 5 colunas estão reunidos. Os sinais de maior amplitude são os posicionados diretamente sobre a fibra muscular. 
4.4 Resultados da simulação de uma matriz 4x5, utilizando os parâmetros estabelecidos na Tabela 3.1. Cada plano apresenta o resultado de um linha de cinco eletrodos, onde o primeiro está posicionado com distância horizontal nula, enquanto o quinto elemento está a $12 \mathrm{~mm}$ na direção $x$. O decaimento da amplitude do sinal é resultado da variação das camadas do volume condutor em função do angulo $\alpha$. A tonalidade escura indica os pontos em que a amplitude do sinal de EMG é máxima, enquanto a cor branca indica os pontos de mínimo. Os potenciais de ação estão se propagando da esquerda para a direita.

4.5 Sinal utilizado como referência para os testes. O sinal possui 1025 amostras e foi obtido através de simulação. Os parâmetros característicos do sinal estão apresentados na Tabela 3.1

4.6 Decomposição do sinal em sub-bandas de frequência para esparsificação. Cada componente equivale a uma largura de banda de $15 \mathrm{~Hz}$. a) Representação temporal das primeiras 15 sub-bandas do sinal de EMG-S. b) Representação no domínio da frequência, onde é possível observar que a resposta se aproxima de um impulso, que pode ser assumido como esparso.

4.7 Representação do comportamento da medida de SSR em função do percentual de amostras utilizada. Representa-se também em cada uma das figuras, o efeito do aumento do numero de pontos perdidos. As Figuras a,c,e,g,i,k,m representam os resultados obtidos com a amostragem padrão, enquanto as Figuras b,d,f,h,j,l,n apresentam os resultados da amostragem ponderada.

4.8 Visualização do comportamento das normas em função do aumento do número de pontos reconstruídos. A metrica $L_{p}=0.0005$ apresenta os melhores resultados em quase todos os casa, com exceção do caso em que é utilizado $5 \%$ das amostras. Neste caso, não existe definição clara do comportamento em decorrência do baixo numero de pontos utilizados e da reconstrução não ser ter qualidade satisfatória.

4.932 sub-bandas processadas com o CS. Nesta etapa as componentes apresentam atraso em função do filtro de análise utilizado. Nota-se que as componentes iniciais possuem a maior parte das informações, enquanto que as últimas pouco influenciam. 54

4.1032 sub-bandas processadas com o $C S$ e convoluídas com o filtro de síntese. Após essa etapa, o sinal está pronto para ser reconstruído, sendo este processo a soma linear de todas as componentes. O atraso ainda não é corrigido.

4.11 Reconstrução sinal e correção do atraso inserido pelo banco de filtros. O sinal original é representado em azul, enquanto que o reconstruído está em vermelho.a) Antes da remoção do atraso. b) Sinal recuperado e deslocado em 191 pontos para remoção do atraso introduzido pelo banco de filtros.

4.12 Recuperação do sinal com múltiplos intervalos de falhas, com posições estabelecidas na Tabela 3.2. Cada intervalo representa 40 pontos de perda de informações. a) Dois intervalos. b) Três intervalos. c) Quatro intervalos. d) Cinco intervalos. 


\section{LISTA DE TABELAS}

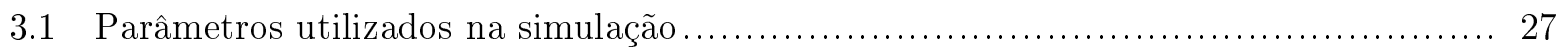

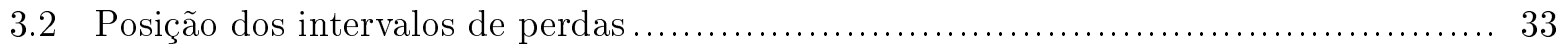

4.1 Resultados da rotina apresentada na Figura 3.5 para um intervalo de 5 pontos ....... 42

4.2 Resultados da rotina apresentada na Figura 3.5 para um intervalo de 10 pontos...... 43

4.3 Resultados da rotina apresentada na Figura 3.5 para um intervalo de 20 pontos...... 44

4.4 Resultados da rotina apresentada na Figura 3.5 para um intervalo de 30 pontos...... 45

4.5 Resultados da rotina apresentada na Figura 3.5 para um intervalo de 40 pontos...... 46

4.6 Resultados da rotina apresentada na Figura 3.5 para um intervalo de 50 pontos ...... 47

4.7 Resultados da rotina apresentada na Figura 3.5 para um intervalo de 100 pontos .... 48

4.8 Parâmetros escolhidos após o fim dos testes experimentais .......................... 54

4.9 Resultados dos cálculos de SRR do sinal reconstruído e o do sinal original para

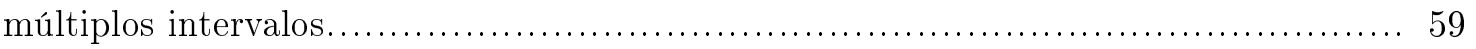




\section{Capítulo 1}

\section{Introdução}

\subsection{Contextualização}

A Eletromiografia é uma técnica para aquisição dos sinais elétricos gerados nas fibras musculares, que são responsáveis pela contração muscular, e que contêm informações sobre os sinais neurais que controlam os músculos [4]. O sinal de eletromiografia é o resultado de um longo processo, que se origina no cérebro ou na medula e termina com a contração muscular. Os sinais de EMG podem ser utilizados em diversas aplicações, como por exemplo, no diagnóstico de doenças neuromusculares [5] e no controle de próteses ativas [6]. Além dessas aplicações, sinais com propriedades específicas podem vir a ser utilizadas no teste e na validação de equipamentos médicos [7].

Os sinais de EMG são afetados por diversos fatores como a fadiga muscular, quantidade de força aplicada, quantidade de fibras musculares e a posição do eletrodo de captação. Os sinais de EMG possuem um comportamento aleatório [8], o que impossibilita a aquisição de sinais iguais, ainda que para a mesma atividade motora, em intervalos de tempo distintos. Em situações reais a aquisição de sinais com características específicas ou com alta densidade de pontos pode não ser viável, seja pelo custo elevado ou por questões técnicas. A utilização de modelos e simuladores apresenta-se como uma boa alternativa para a obtenção dos sinais, uma vez que todo processo pode ser feito em laboratório e não existe a necessidade de voluntários para aquisição.

Com a modelagem matemática de fenômenos naturais, é possível o estudo e a simulação dos eventos que ocorrem no ambiente, sejam eles físicos ou biológicos. Os modelos gerados podem ser utilizados na criação de simuladores e, através destes, avaliar o efeito de determinados fatores sobre o sistema que está sendo reproduzido. Um bom simulador deve garantir ao usuário o controle total dos parâmetros que influenciam no resultado da simulação, de forma que a simulação se torne tão precisa quanto seja requerido.

Segundo Mesin [9], os modelos matemáticos para sinais de EMG podem ser fenomenológicos ou baseados na estrutura física do músculo. Para a construção de simuladores de EMG baseados na segunda opção, o modelo deve abranger informações como a descrição da fonte do sinal, descrição matemática das propriedades dos tecidos, modelo do sistema de detecção (arranjo e propriedade dos eletrodos), bem como a descrição das unidades motoras (MU) e seu comportamento espacial 
e temporal [9].

Farina e Merletti listaram os pontos que são considerados importantes em um modelo para representação dos sinais de eletromiografia de superfície (EMG-S) [3]. Eles desenvolveram um modelo matemático abrangendo todos esses pontos [3]. A partir deste modelo, foi desenvolvido um simulador de EMG-S unidimensional que oferecia a opção de configuração do volume condutor e das características dos eletrodos. Embora o simulador apresentado tenha significado um grande avanço, ele estava limitado à criação de um vetor de eletrodos.

Com a adaptação para duas dimensões do simulador proposto por Farina et al. [3], torna-se possível a aquisição de sinais de forma matricial, onde uma malha de eletrodos pode ser simulada de acordo com especificações do usuário. O aumento da resolução espacial é de grande interesse para alguns pesquisadores, uma vez que pode contribuir na determinação mais precisa de pontos de interesse do músculo e no fornecimento de mais informações para o reconhecimento de padrões. Uma aplicação é no controle de próteses ativas [10, 5], onde uma quantidade maior de informações pode resultar em um controle mais preciso.

A vantagem de trabalhar com sinais simulados mais realistas é a possibilidade de testar novos procedimentos de modo que, embora estejam sendo testados em sinais simulados, existe a possibilidade de futuras aplicações com sinais reais. Dentre as técnicas de processamento de sinais existentes, uma que vem ganhando espaço no meio científico é o Compressive Sensing/Sampling (CS) [11]. Esta é uma ferramenta matemática que explora a esparsidade de um sinal, em determinado domínio, para realizar aquisições a uma taxa de amostragem inferior à taxa de Nyquist [12].

A teoria do $C S$ foi proposta inicialmente por Candès et al. [13] e por Donoho [14], e assegura que, caso sejam atendidas algumas condições, é possível realizar a reconstrução de sinais com um número bastante reduzido de pontos, o que reduz a taxa de amostragem, o consumo computacional e o tempo de processamento.

Candès e Wakin [11] citam que na maioria das aplicações não é necessária a aquisição de todos os dados para representar com qualidade um sinal, e que o principio de Nyquist ${ }^{1}$ é utilizado devido a amostragem estar sendo realizada de maneira clássica. Donoho [14] apresenta uma frase em seu trabalho que pode ser utilizada para sintetizar a ideia central do $C S$ :

Por quê fazer tanto esforço para adquirir todos os dados quando a maior parte deles será descartada? Não podemos simplesmente medir diretamente a parte que não será descartada? [14]

A ideia principal do $C S$ é a combinação das etapas de aquisição e compressão de dados, focando na aquisição de apenas as amostras que contenham informações relevantes para a reconstrução do sinal. Uma das condições para o funcionamento do $C S$ é que o sinal seja esparso em pelo menos um domínio. Os sinais de EMG são naturalmente não esparsos, entretanto é possível forçar tal condição a partir da utilização de bancos de filtros. A teoria apresentada no livro de

\footnotetext{
${ }^{1} \mathrm{O}$ princípio de Nyquist estabelece que para um sinal ser reconstruído sem perdas, é necessário que a frequência de amostragem seja pelo menos 2 vezes maior que a máxima frequência apresentada pelo sinal.
} 
Vaidyanathan [15] abarca os fundamentos para a interpretação do problema. Um sinal não esparso pode ser decomposto em $n$ componentes, tornando cada uma esparsa em um novo domínio.

Pode ocorrer de alguns pontos destoarem completamente do restante dos demais, e no pósprocessamento resultarem em inferências incorretas. Um exemplo prático é na determinação dos estimadores do sinal de EMG-S (RMS, ARV, MNF, MDF), onde são considerados todos os pontos do sinal. Valores errados podem resultar no comprometimento da curva característica destes estimadores e comprometer a correta interpretação dos dados. Com a utilização do $C S$, existe a possibilidade que tais pontos não sejam utilizados na amostragem, e que na etapa de reconstrução, estes sejam reconstruídos da maneira correta.

Nesta dissertação de mestrado será avaliado a utilização das técnicas acima citadas para o processamento e recuperação de sinais de EMG-S. Espera-se verificar a possibilidade de reconstrução de sinais com um número pequeno de amostras, de modo a reduzir o consumo computacional e o tempo de processamento. Sendo capaz de recuperar um trecho danificado, a técnica mostra-se-á uma importante ferramenta no tratamento de ruídos e interferências. Além disso, espera-se recuperar trechos de informações que venham a ser perdidas dentro do sinal. Esse procedimento é de grande importância não apenas na eletromiografia, mas também para diversos sinais biológicos que são comprometidos por vários fatores, como por exemplo: mau contato entre eletrodo e pele, interferências externas e internas, ruído, posicionamento dos eletrodos, temperatura ambiente.

\subsection{Objetivos do projeto}

Este trabalho tem como objetivo avaliar o uso do $C S$ na reconstrução de sinais de EMGS. Espera-se que, a partir de um número reduzido de amostras, seja possível recuperar o sinal por completo. Será simulada a perda de informações em partes do sinal, de modo a verificar a capacidade da técnica em recuperar os trechos com uma qualidade satisfatória. Deseja-se verificar quais os melhores parâmetros de configuração que devem ser utilizados, sendo estes:

- Maior intervalo de pontos que pode ser recuperado

- Menor percentual de amostras para aplicação do $C S$

- Norma (Métrica) $L_{p}$ que apresenta melhor aproximação

Uma vez que poucas pesquisas estão disponíveis a respeito da utilização do $C S$ aplicado à sinais de EMG-S, espera-se que, ao final do trabalho, um ponto de partida para novos estudos seja criado.

\subsubsection{Objetivos Secundários}

Para atingir os objetivos, algumas sub-etapas necessitam ser desenvolvidas, sendo estas os objetivos secundários deste trabalho. Algumas serão realizas por simulação computacional, enquanto outras serão obtidas a partir de experimentos e observação. As propostas secundárias são: 
1‥ Adaptação para duas dimensões de um simulador de sinais de EMG-S

$\mathbf{2}^{\mathbf{a}}$. Utilização de bancos de Filtros para esparsificação de sinais

$\mathbf{3}^{\mathbf{a}}$. Determinação do maior intervalo de pontos que pode ser recuperado

$4^{\mathbf{a}}$. Determinação do melhor norma a ser minimizada

$5^{\mathbf{a}}$. Determinação do menor percentual de amostras para o uso do $C S$

$6^{\mathbf{a}}$. Escolha do tipo de amostragem que será realizada (Tradicional Binária ou Aleatória Ponderada)

$7^{\mathbf{a}}$. Verificar a possibilidade de reconstrução de mais de um intervalo

\subsection{Organização da dissertação}

Esta dissertação se organiza da seguinte maneira. No Capítulo 2 será apresentado uma revisão bibliográfica sobre os principais temas abordados nesse trabalho. O conceito de banco de filtros e Compressive Sensing são introduzidos e são ilustradas algumas situações em que podem ser utilizados em conjunto. No Capítulo 3 será feita a fundamentação da metodologia utilizada, de modo a relacionar os conhecimentos apresentados no Capítulo 2 e demonstrar a rotina de determinação dos melhores parâmetros para o uso CS em sinais de EMG-S.

No Capítulo 4 são apresentados os resultados dos testes e da reconstrução de múltiplos intervalos com os parâmetros escolhidos. No Capítulo 5 os resultados são debatidos individualmente, apresentando as observações realizadas durante a pesquisa. Por fim, o Capítulo 6 apresenta as conclusões obtidas acerca do trabalho realizado e dos resultados obtidos, para então finalizar o entendimento de como CS pode ser utilizado para reconstrução de sinais de EMG-S e outros sinais biológicos. São apresentadas também propostas para trabalhos futuros. 


\section{Capítulo 2}

\section{Revisão Bibliográfica}

Capítulo destinado a revisão teórica dos conhecimentos fundamentais para entendimento do trabalho.

\subsection{Introdução}

Neste capítulo será feita uma revisão dos conceitos e definições essenciais para a compreensão do trabalho desenvolvido. Cada tópico foi concebido de modo a apresentar o conteúdo direcionado para as demandas da pesquisa. Os tópicos serão apresentados na seguinte ordem:

1. Aspectos Históricos

2. Revisão sobre sinais

3. Componentes do sinal de EMG

4. Filtragem e Banco de Filtros

5. Compressive Sensing

\subsection{Aspectos Históricos}

Com o desenvolvimento da tecnologia eletrônica, a sociedade ganhou uma forte aliada para o aprimoramento dos estudos científicos. Dentre as pesquisas realizadas no campo da ciência, tem-se a eletromiografia (EMG) que auxilia nos estudos do funcionamento do tecido muscular. A eletromiografia pode ser entendida como a representação gráfica da atividade elétrica do músculo esquelético [16].

Historicamente, a eletromiografia é constantemente influenciada pelo avanço tecnológico. Erasistratis (280 A.C) já possuía o conhecimento de que o músculo é um órgão de contração. Registros datados do Renascimento (séc. XV) demonstravam o interesse técnico pelo estudo dos músculos. Por exemplo, Leonardo Da Vinci teve importante contribuição no estudo dos músculos e sua funcionalidade [17]. 
Os primeiros experimentos na área, realizados em animais, em meados do século XVII, por Francesco Redi apontaram que a fonte de energia de um determinado peixe tinha origem muscular. Em 1786, durante a dissecação de uma rã, o então anatomista e cirurgião da Universidade de Bolonha Luigi Galvani, descobriu acidentalmente o que viria a ser conhecido como "eletricidade animal", que era o fenômeno de contração muscular na presença de correntes elétricas. Inquieto pelo ocorrido, Galvani realizou experimentos que relacionavam o movimento muscular e eletricidade. Ao alterar as condições da pesquisa, ele observou o movimento dos músculos sob a influência das fagulhas elétricas vindas de um eletróforo, eletricidade atmosférica ou a própria eletricidade do animal.

Baseando-se nos trabalhos de Galvani, Alessandro Volta notou algo que passou despercebido pelo colega: ele entendeu que a energia era gerada por meio das reações químicas. Este fenômeno foi chamado posteriormente de "galvanismo" em homenagem ao amigo Luigi Galvani.

Carlo Mateucci, em 1830, deu início aos experimentos que envolviam a eletricidade animal questionada por Galvani. A partir de então, com o auxílio de um galvanômetro de Nobeli, Carlo observou que tecidos musculares quando excitados, geravam fluxo contínuo de corrente elétrica. O Kymiógrafo foi desenvolvido por Carlo, posteriormente, para registrar um deslocamento físico originado de uma contração muscular.

Tempos depois, já no ano de 1849, uma pesquisa feita por Mateucci, inspirou Dubois-Reymon [17] a realizar as primeiras deteç̧ões de sinal elétrico em músculos humanos durante contração voluntária. Entre os anos de 1831 e 1875, o neurofisiologista Guillaume Benjamin Amand Duchenne analisou os efeitos dos estímulos elétricos em músculos e nervos com alguma anomalia (como paralisia ou atrofia) advinda de alterações nervosas.

Até então, os valores em termos quantitativos dos músculos humanos eram desconhecidos, mas Piper [18], um cientista alemão, inventou eletrodos metálicos superficiais que revolucionaram a captação dos sinais eletromiográficos. Em 1918 já se discutia o melhor tratamento e quais técnicas deveriam ser conduzidas antes de obter e analisar os dados relativos aos fenômenos eletrofisiológicos.

Neste contexto, destaca-se o engenheiro elétrico Baines, cujas publicações já abordavam essa temática. Este pesquisador foi o primeiro a modelar partes do sistema nervoso através de circuitos elétricos, com o intuito de explicar seu comportamento. Para tanto, Baines comparou a propagação de pulsos em um conjunto de nervos a um cabo elétrico, sendo este estudo denominado teoria do "cabo".

Por volta de 1920, foi possível observar os sinais musculares com o auxílio de um microscópio de raios catódicos [19]. Oito anos depois, o primeiro experimento bem sucedido de detecção de sinais de um músculo foi realizado por Proebster (1928) que obteve traços de um músculo com paralisia periférica [17].

O avanço nos estudos sobre os sinais musculares fizeram com que, em 1945, Reinhold Reiter registrasse a primeira patente de utilização de próteses controladas por sinais eletromiográficos. Tal feito foi observado, aproximadamente quinze anos depois, quando o experimento realizado por Kobrinsk de uma prótese da mão foi controlada por sinais de EMG advindos do antebraço do 
paciente [17].

Em meados de 1960 houve a expansão da utilização da eletromiografia (invasiva e de superfície), e a expressão biofeedback ganhou destaque no estudo de patologias e incômodos na coluna. Hardyck e sua equipe, em 1966, foram os primeiros médicos a utilizar os sinais mioelétricos [17].

A década de 80 foi marcada pela utilização de eletrodos, por parte de Cream e Steger, que se beneficiaram dessa ferramenta para analisar outros tipos de músculos. Com o desenvolvimento de memórias eletrônicas, foi possível expandir a modelagem e a criação de sistemas de eletromiografia. Tal fato permitiu a efetiva produção comercial de eletrodos, dispositivos e amplificadores com custos mais baixos.

A partir de 1990, com o avanço da informática, houve a possibilidade de transmitir o sinal mioelétrico para equipamentos computacionais, que propiciavam uma maior capacidade de armazenamento de dados e informações, processamento real dos sinais captados e ilustração visual dos resultados colhidos.

Atualmente, a evolução da tecnologia possibilitou o aprimoramento na análise espectral e em outros procedimentos de processos dos sinais eletromiográficos, os quais são fonte basilar para a compreensão da fisiologia, fadigas, disfunções, estratégias de recrutamento e mialgias musculares [20].

Nota-se, portanto, as inúmeras aplicações da eletromiografia, que vão desde a área da saúde (como em aplicações de próteses) até a prática desportiva, a exemplo da análise de fadiga muscular e da determinação da força de um atleta. Seja em qual for o caso, é necessário que os sinais sejam processados. Para isso, os sinais precisam ser amostrados e transferidos para um processador.

A teoria de amostragem permite a ligação entre os domínios contínuos e discretos. Tido como pressuposto fundamental, o Teorema de Nyquist propôs, em 1929, a base para determinação da taxa mais adequada para amostragem de sinais. Segundo o teorema, para reconstrução perfeita das informações, é necessária que a amostragem seja realizada com no mínimo duas vezes a máxima frequência apresentada pelo sinal [21]. Tal teoria só foi demonstrada vinte anos mais tarde, quando Shannon [22] apresentou sua comprovação matemática. Desde então, apenas melhorias foram apresentadas ao trabalho de Nyquist [21], as quais podem ser encontradas em um acervo feito por Jerri [23].

No começo do século XXI surgiram contribuições fundamentadas em modelos teóricos cujo desenvolvimento baseou-se, por exemplo, nos estudos sobre esparsidade e compressão de dados. Um dos primeiros trabalhos acadêmicos relacionados ao Compressive Sensing (CS) teve origem nas pesquisas elaboradas pela Rice University [24] cuja proposta era a criação de um imageador mono-sensor [25]. Neste contexto, outros pesquisadores ganharam destaque no tema em questão. Dentre os autores, pode-se citar Donoho [14], Candés et al.[13], [11], Baraniuk [26], Lee e Bresler [27], alem de diversos outros que continuam a pesquisar na área [28].

Com o intuito de se tornar uma alternativa para aquisição e compressão de dados, o CS permite a reconstrução perfeita dos sinais utilizando-se uma quantidade de amostras bem inferior ao sugerido pelo critério de Nyquist. Tal feito proporciona um decréscimo na taxa de amostragem, 
na utilização de energia e na complexidade computacional exigida para se adquirir e representar um sinal esparso quando comparada a métodos tradicionais[11].

Em 2006, o Instituto de Tecnologia da Califórnia (Caltech) iniciou um projeto na área de reconstrução de imagens em exames de Ressonância Magnética. Esta pesquisa teve como fundamentação teórica os princípios do CS, uma vez que a problemática do projeto girava em reconstruir imagens utilizando-se apenas $5 \%$ da amostra. O ponto chave deste trabalho tinha por objetivo reduzir o tempo de exposição do paciente ao equipamento sem comprometer a qualidade das imagens obtidas.

Ainda no campo do CS, pesquisas realizadas por Candès, Romberg e Tao demonstram a utilização de bases incoerentes para amostragem dos sinais esparsos [13]. Tal feito possibilitou que outros trabalhos fossem desenvolvidos a partir de uma nova abordagem acerca da amostragem e reconstrução dos sinais.

Pesquisas na área biomédica demonstram a importância da aquisição, transmissão e reconstrução dos sinais fisiológicos para o auxílio do tratamento de doenças, prevenção de patologias, desenvolvimento de próteses, dentre outros. Dado que este conhecimento é relativamente recente, pouco material relacionando CS e sinais de EMG-S foi produzido até o momento. Sabe-se que sinais de EMG possuem boa esparsidade no domínio da frequência [29], [30], o que significa em termos práticos que apenas alguns pontos contêm as principais informações sobre o sinal. Desta forma, parte do esforço despendido atualmente para aquisição e processamento de todos os pontos se mostra ineficiente. A aplicação do CS para o tratamento de sinais de EMG-S talvez apresente melhorias no processo, sendo este o tema a ser debatido nesta dissertação.

\subsection{Revisão sobre sinais}

Segundo Oppenheim [12], um sinal pode ser compreendido como a reunião de informações sobre o comportamento de algum fenômeno. Para representar os sinais que ocorrem na natureza, pode-se classificar-los em discretos ou contínuos, isto é, os sinais estão definidos para um número contável de pontos ou para intervalos infinitos.

\subsubsection{Sinais contínuos no tempo}

Define-se por um sinal contínuo no tempo todo aquele que está definido para um intervalo infinito de pontos, sendo o valor em cada instante uma função do tempo.

\subsubsection{Sinais discretos}

Os sinais discretos são definidos apenas em instantes de tempo discretos, ou seja, apenas em determinados momentos o sinal possui valores. Diferentemente do sinal de tempo contínuo, a variável independente é denominada $n$, que pode assumir qualquer valor inteiro. 


\subsubsection{Representação de sinais no Tempo e na Frequência}

Além do tempo, existem outros domínios onde pode ser feita a representação de uma informação. Um destes é o domínio da frequência, que permite a análise matemática e o processamento das informações de maneira diferenciada em relação ao tempo. Através da análise em frequência de um sinal é possível avaliar a distribuição das informações por faixas (ou sub-bandas), o que resulta em uma avaliação mais detalhada das informações. Outra característica é a redução do número de pontos que contêm informações relevantes do sinal. A Figura 2.1 ilustra este característica. Um onda senoidal no domínio do tempo possui como representação no domínio da frequência um impulso, o que, em adição ao fato de sinais poderem ser representados como um somatório de senoides, possibilita que um sinal com muitas informações no tempo seja representado por uma quantidade pequena de impulsos na frequência.

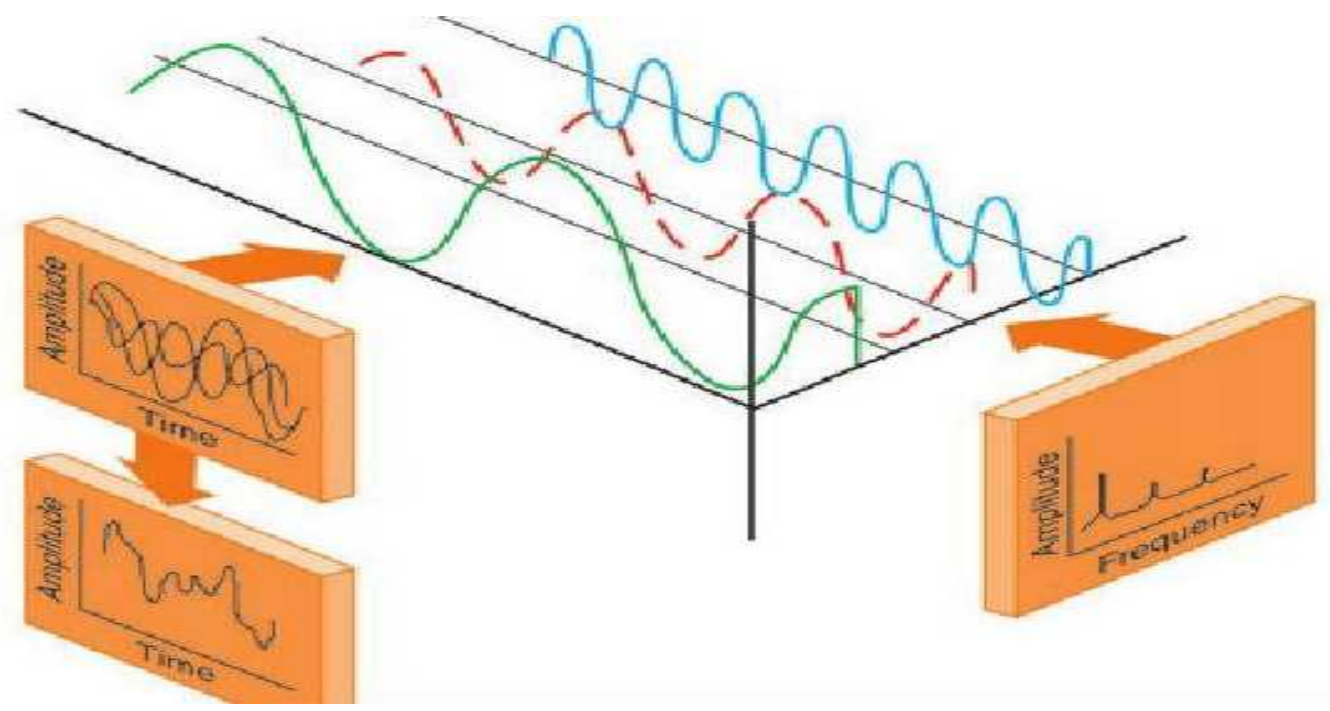

Figura 2.1: Representação de um sinal no domínio do tempo e no domínio da frequência. A figura ilustra a decomposição de um sinal em senóides e a representação de cada uma destas no domínio transformado. Fonte: http://www.sabereletronica.com.br/artigos/1918-anlise-de-vibraes-mecnica-com-fpga

\subsubsection{Base vetorial}

Uma base vetorial $\Phi$ é o conjunto de vetores $\theta_{1}, \theta_{2}, \ldots, \theta_{N}$, cada um com $\mathrm{N}$ elementos, em que os vetores são linearmente independentes. Isto significa dizer que, qualquer vetor do espaço vetorial $V$ com dimensão $\mathrm{N}$ pode ser representado como uma combinação linear dos vetores da base $\Phi$.

\subsubsection{Norma de um vetor}

Define-se por Norma de um vetor $x$, com representação matemática $\|x\|$, como a operação que realiza a análise métrica sobre o vetor $x$. A norma é uma métrica/medida realizada sobre um vetor, e pode ter múltiplas formas de ser calculada. As três que serão apresentadas a seguir são $l_{0}$, $l_{1}, l_{2}$. 


\subsubsection{Métrica $l_{0}$}

A métrica $l_{0}$ pode ser definida como o somatório de elementos não nulos de um vetor. Considerando a seguinte função $z[k]=\left\{\begin{array}{l}0, \text { se } x[k]=0 \\ 1, \text { se } x[k]=1\end{array}\right.$

A expressão matemática que ilustra a métrica $l_{0}$ é dada por

$$
l_{0}=\|x\|_{0}=\sum_{k=0}^{N-1} z[k]
$$

\subsubsection{Norma $l_{1}$}

A norma $l_{1}$ é definida como o somatório dos valores absolutos dos elementos do vetor x. Sua definição matemática é dada pela equação

$$
l_{1}=\|x\|_{1}=\sum_{i=0}^{N-1}|x[i]|
$$

\subsubsection{Norma $l_{2}$}

A norma $l_{2}$ é provavelmente a mais conhecida de todas, uma vez que também é chamada de norma Euclidiana. Esta calcula o comprimento de um vetor, e é expressa matematicamente por

$$
l_{2}=\|x\|_{2}=\left(\sum_{i=0}^{N-1}|x[i]|^{2}\right)^{1 / 2}
$$

\subsubsection{Métrica $l_{p}$}

Por definição, a métrica $L p$ é representada de acordo com a equação

$$
\|x\|_{p}=\left(\sum_{i=0}^{N-1}\left|x[i]^{p}\right|\right)^{\frac{1}{p}}
$$

onde $p$ é $\geq 1$. Para valores de $0<p<1$, entretanto, Chartrand [31] afirma que $L_{p}$ não é considerado uma norma, mas por satisfazer os requisitos da desigualdade triangular, pode ser considerado uma métrica do vetor. Para os valores de $0<p<1$, o cálculo de $l_{p}$ se dá pela equação

$$
l_{p}=\|x\|_{p}=\sum_{i=0}^{N}|x[i]|^{p}
$$

\subsubsection{Esparsidade de um Vetor}

A esparsidade de um vetor pode ser definida por $K(x)=\|x\|_{0}$. Devido a possibilidade de representação de um vetor em diferentes bases vetoriais, a esparsidade pode ser alterada para mais 
ou para menos. Um exemplo disso é a representação de sinais no domínio de Fourier, onde sinais periódicos são representados por impulsos e reduzem significativamente o número de pontos que contém informação sobre o sinal. Devido a esta característica, a base de Fourier é chamada de base de esparsidade para sinais periódicos [32].

Quando a mudança de bases permite uma redução considerável no número de pontos, e ao mesmo tempo não gera perda de informações, esse processo recebe o nome de compressão de dados. Desta forma, quanto maior for a esparsidade do sinal $(K(x)$ pequeno) mais compressível será o sinal.

\subsubsection{Incoerência entre Bases}

A incoerência entre duas bases ortonormais $\Psi$ e $\Phi$ pode ser matematicamente definida por

$$
\mu(\Psi, \Phi)=\sqrt{N} \cdot \max \left\{\Phi^{T} \Psi\right\}
$$

Em outras palavras, a incoerência pode ser entendida como a maior correlação entre dois elementos das bases $\Psi$ e $\Phi$. Um exemplo prático que pode ser mencionado é caso em que $\Psi$ é a base de representação no domínio do tempo e $\Phi$ a base no domínio da frequência. Neste exemplo, o valor de $\mu=1$, o que indica o mínimo de coerência entre as bases (também chamada de máxima incoerência). Caso seja calculado a incoerência de uma base com ela mesma, a coerência será máxima (incoerência mínima).

\subsubsection{Técnicas de Amostragem}

Considere uma matriz com $M_{\text {linhas }}$ e $N_{\text {colunas }}$, que é ortonormal e é denominada $\Phi$. Esta é responsável por amostrar um sinal $Y$, de modo que o resultado da amostragem é dado por

$$
Y_{\text {amostrado }}=\Phi \cdot Y
$$

A matriz $\Phi$ pode ser obtida de diversas formas, sendo que a reconstrução do sinal está diretamente relacionada com esta escolha. Quando o processo que está sendo executado é a amostragem tradicional, a matriz $\Phi$ é a identidade, com dimensões $N_{\text {linhas }}$ x $N_{\text {colunas. }}$ A multiplicação da identidade com um sinal, conforme apresentado na (2.7), resulta na escolha de todos os pontos. Não ocorre alteração no domínio do sinal, portanto a esparsidade não se altera. Se for utilizada uma matriz "tipo identidade", com dimensões $M_{\text {linhas }}$ x $N_{\text {colunas }}$ e com $\mathrm{M}<\mathrm{N}$, será realizada a escolha de apenas M pontos.

Já no caso de ser utilizada para amostragem uma matriz composta pelos coeficientes de Fourier, ao mesmo tempo que o sinal é amostrado ocorre a alteração da base vetorial, levando o sinal resultante para o domínio da frequência. Este processo possui a vantagem de alterar a esparsidade do sinal, reduzindo o número de pontos e consequentemente comprimindo as informações. 


\subsubsection{Teorema Central do Limite}

Muitas vezes não é possível a aquisição de um número elevado de amostras, o que compromete a inferência de parâmetros estatísticos (média e desvio padrão). Entretanto, o Teorema Central do Limite estabelece que qualquer distribuição da variável aleatória pode ser adequadamente aproximada a uma distribuição normal, desde que possua um número mínimo de amostras.

Criado por William Gosset, estabelece que para um número de amostras igual ou superior a 30, a distribuição amostral tende a se comportar como uma distribuição normal de média $\mu$ (igual a média da população) e com desvio padrão $\frac{\sigma}{N}$ ( $\sigma$ é o desvio padrão da população e N o número de amostras). Os resultados são representativos, e ilustram com bastante proximidade os parâmetros populacionais.

\subsection{Componentes do sinal de EMG}

Nesta secção serão apresentados os conceitos fundamentais para a compreensão de como são formados os sinais de EMG, sendo cada etapa apresentada adiante. Para um melhor detalhamento quanto a questões fisiológicas, recomenda-se a leitura do livro de fisiologia [33].

\subsubsection{Unidade Motora}

Os impulsos elétricos provenientes do Sistema Nervoso Central (SNC) não realizam a contração muscular diretamente. O sinal chega através do neurônio motor $\alpha$, que se inerva à diversas fibras musculares e promove a contração destas quando um sinal elétrico está presente. O conjunto formado pelo neurônio e pelas fibras por ele inervadas recebe o nome de Unidade Motora (MU), sendo esta a menor unidade do sistema neuromotor.

\subsubsection{Potencial de Ativação Motor}

Para que ocorra a contração, um sinal elétrico deve se propagar por todo o comprimento da fibra muscular. Este sinal recebe o nome de Potencial de Ativação Motor (MAP), e tem sua amplitude proporcional ao diâmetro da fibra.

\subsubsection{Potencial de Ativação da Unidade Motora}

Quando um impulso elétrico chega até a zona de inervação, a acetilcolina (ACh) é liberada dos neurônios motores, ocasionando a geração de um MAP, que se desloca ao longo da membrana plasmática da fibra muscular. A soma espacial e temporal de todos os potenciais de ação relacionados com uma mesma unidade motora recebe o nome de Potencial de Ação de Unidade Motora (MUAP). Os MUAPS possuem duração curta e na maioria das vezes se apresenta na configuração de dipolo [17]. A propagação dos potenciais ao longo dos túbulos $t$ provoca a liberação do íon 
Ca2+. Após uma série de eventos químicos, ocorre a ligação da miosina com a actina, gerando a movimentação muscular. Mais detalhes disponíveis em [33].

\subsubsection{Trem de Potenciais de Ativação da Unidade Motora}

Apenas um MUAP não é suficiente para gerar e manter uma contração muscular. Desta forma, a unidade motora é constantemente ativada por meio de uma sequência de MUAPS, sendo esta denominada Trem de Potenciais de Ativação da Unidade Motora (MUAPT). Quando um MUAPT é observado, verifica-se que o sinal não é igualmente espaçado e sua amplitude não é constante.

\subsubsection{EMG}

Define-se EMG como o somatório linear de todos os MUAPT's captados pelo eletrodo. Uma vez que existem dezenas de fibras musculares e diversas MU, não é possível determinar com exatidão qual a origem do sinal, pois o EMG é a sobreposição de diversos MUAPT's.

A Figura 2.2 ilustra de forma resumida o processo de formação do sinal de EMG, desde a recepção do sinal da unidade motora até a somatória dos MUAPT para geração do sinal de EMG.

\section{Unidade Motora $\Rightarrow$ MUAP $\Rightarrow$ MUAPTS $\Rightarrow$ EMG}

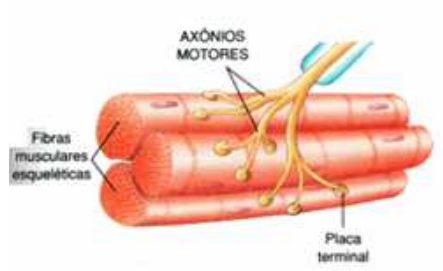

Conjunto formado por um único neurônio motor $\alpha$ e as fibras musculares por ele inervadas

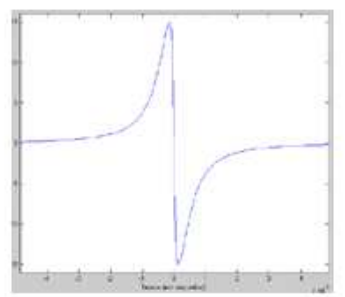

Soma espacial e temporal de todos os potenciais de ação relacionados com uma mesma UM

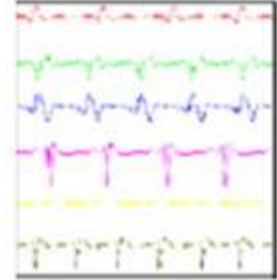

Sequência de MUAPS

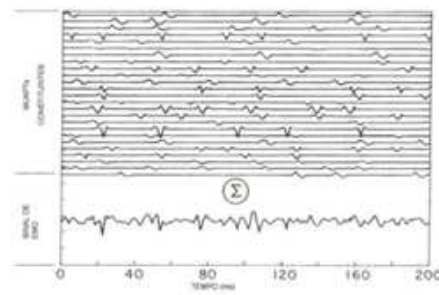

Somatório linear de todos os MUAPTs captados pelo eletrodo

Figura 2.2: Descreve brevemente todas os passos para formação do sinal de EMG. Inicia com a formação da unidade motora e segue para a geração do potencial de ativação. Mostra o potencial sendo repetido inúmeras vezes e finaliza com a formação do sinal de EMG a partir do somatório de todos os potenciais.

\subsubsection{Ruídos e Interferências nos sinal de EMG}

Segundo DeLuca [34], os sinais de EMG-S são inevitavelmente contaminados com diversas fontes de ruídos, podendo estas serem oriundas da movimentação eletrodo-pele, dos equipamentos eletrônicos responsáveis pela amplificação do sinal, além de outras fontes. Embora muitos avanços tenham ocorridos, alguns tipos de interferência não são possíveis de serem removidos. Um exemplo 
é o ruído de artefato, proveniente da movimentação eletrodo-pele ou da movimentação do cabo conectado ao eletrodo. Esse tipo de ruído compromete a amplitude do sinal, além de alterar as componentes em frequência. Com a utilização do $C S$, espera-se que a amostragem seja feita fora do intervalo de pontos com ruído, de modo que quando ocorra a recuperação, o trecho seja corrigido.

\subsection{Filtragem e Banco de Filtros}

A filtragem é uma etapa do processamento dos sinais de grande importância, pois permite a separação do sinal desejado de outras fontes de informações que não precisam ser processadas, evitando-se a contaminação do resultado final com dados indesejáveis. A filtragem pode ser realizada de forma analógica, por meio de componentes eletrônicos em um circuito elétrico, ou ser realizada de forma digital, através de equações discretas. No processamento digital, o sinal se torna a entrada de um sistema, que após ser operado matematicamente, gera uma saída correspondente ao sinal filtrado. Os filtros digitais podem ser classificados como FIR (finite impulse response) ou IIR (infinite impulse response). Esta classificação se dá em função da recursividade ou não do filtro, como será visto a seguir.

\subsubsection{FIR}

Este tipo de filtro possui a característica de apresentar uma resposta finita para um sinal de entrada. É classificado como um filtro não recursivo, uma vez que a saída depende exclusivamente da entrada atual e de entradas anteriores, não sofrendo realimentação das saídas anteriores. Sua função de transferência é feita pela equação

$$
H(z)=\sum_{k=0}^{N-1} h[k] \cdot z^{-k}
$$

A determinação do sinal de saída se dá pela convolução do sinal de entrada x[n] com a função de transferência do filtro. Este somatório está descrito pela equação

$$
y[n]=\sum_{k=0}^{N-1} h[k] \cdot x[n-k]
$$

Onde cada termo $x[n-k]$ representa um atraso em relação ao sinal de entrada. A configuração de um filtro FIR segue a descrição feita na Figura 2.3, sendo a equação característica dada por

$$
y[n]=X_{n} \cdot C_{0}+X_{n-1} \cdot C_{1}+X_{n-2} \cdot C_{2}+\ldots+X_{1} \cdot C_{N}
$$




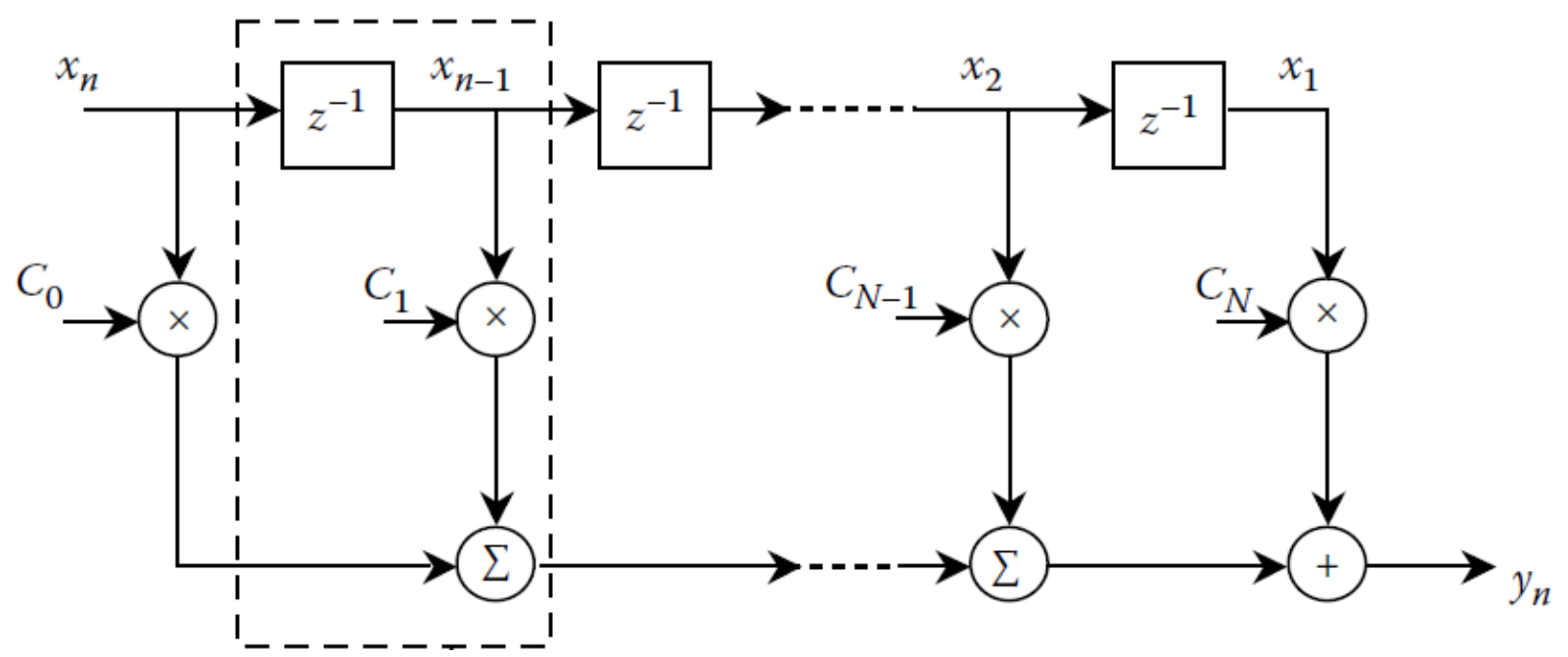

Figura 2.3: Exemplo da configuração de um filtro FIR de ordem N.

\subsubsection{IIR}

Estes são filtros que possuem a resposta infinita para uma entrada impulsional, sendo caracterizados como filtros recursivos uma vez que sua saída depende não apenas do sinal de entrada, como também das saídas anteriores. A configuração de um filtro do tipo IRR está representada na Figura 2.4 , sendo a equação que descreve a saída $y[n]$ do sistema é dada por

$$
y[n]=\sum_{k=0}^{N-1} a_{k}[n] \cdot x[n-k]+\sum_{k=0}^{M-1} b_{k}[n] \cdot y[n-k]
$$

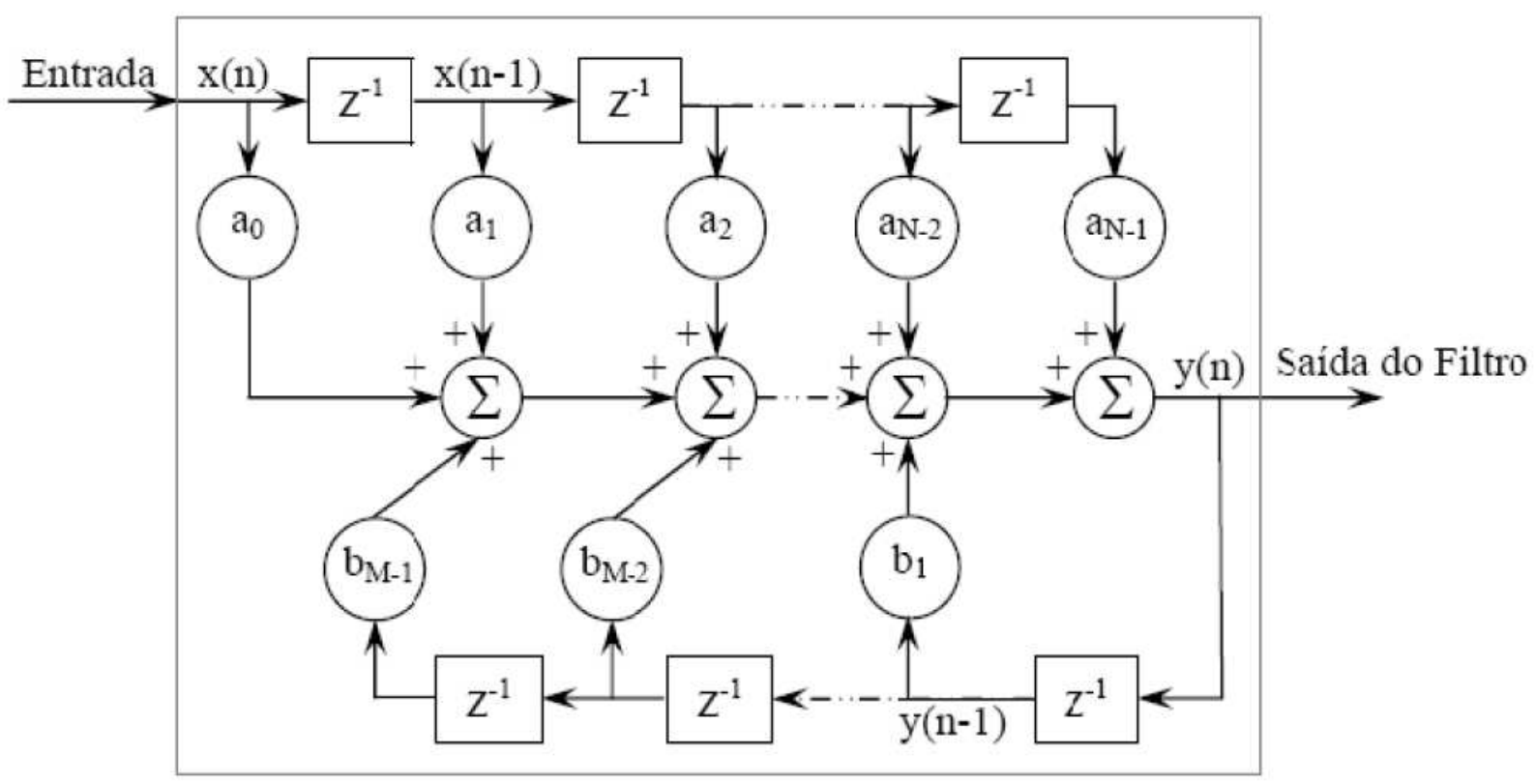

Figura 2.4: Exemplo de configuração de um filtro IIR. Adaptado de [1] 


\subsubsection{Decimador}

O operador de decimação, também chamado de Down-Sampler, realiza a diminuição da frequência de amostragem de um sinal por um fator M, estando sua estrutura de bloco representada na Figura 2.5. Para uma determinada sequência de entrada $\mathrm{x}(\mathrm{n})$, a saída $\mathrm{y}(\mathrm{n})$ é dada pela equação

$$
y[n]=x[M \cdot n]
$$

Onde $\mathrm{M}$ é um número inteiro que representa a proporção do sinal que será sub-amostrada. Apenas para amostras do sinal de entrada $\mathrm{x}(\mathrm{n})$ em que $n$ é múltiplo de $\mathrm{M}$ o sinal será mantido. Em todos os outros casos, os valores serão descartados.

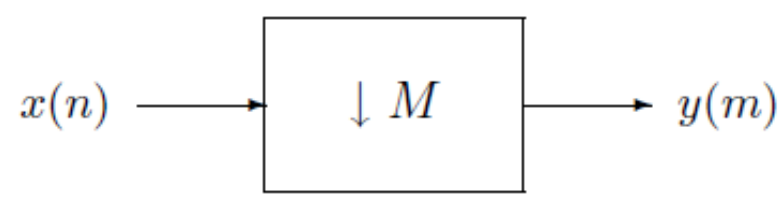

Figura 2.5: Diagrama de bloco de um Decimador

Para ilustrar o funcionamento do decimador, é apresentado na Figura 2.6 um sinal $x(n)$ que passa por um decimador de modulo 2, resultando em um sinal $y(n)$ sub-amostrado. É possível observar que apenas os pontos $-2,0$ e 2 foram mantidos, uma vez que são os múltiplos inteiros de $M=2$. Verifica-se também que o sinal diminuiu a quantidade de amostras, passando de 5 para 3 .
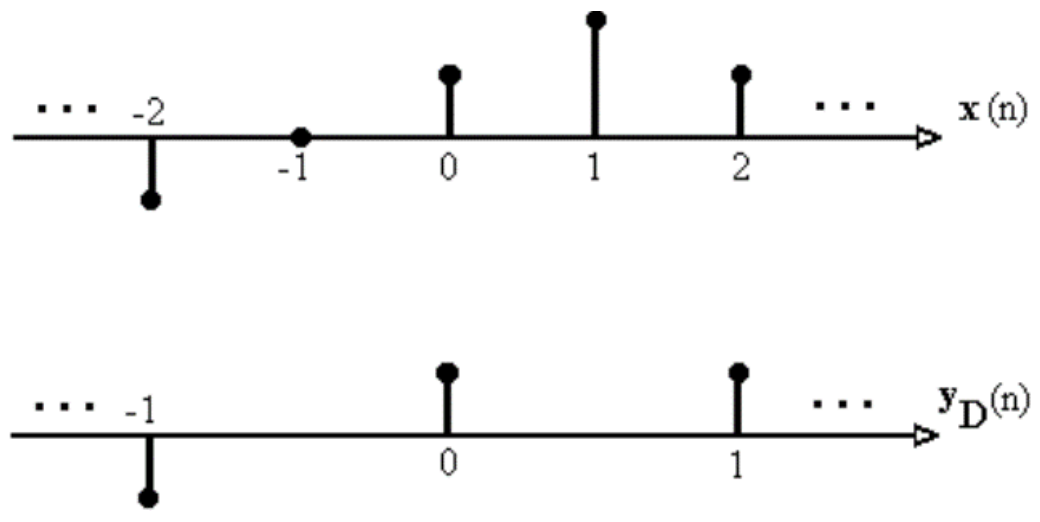

Figura 2.6: Exemplo do efeito da decimação de um sinal $x(n)$ por um fator 2

Usualmente o operador de decimação é precedido por um filtro anti-aliasing para evitar que ocorram sobreposições de espectros no domínio da frequência. Estes filtros normalmente são passabaixa, possuem ganho unitário e frequência de corte de $\frac{\pi}{m}$

\subsubsection{Interpolador}

O procedimento inverso à Decimação é denominado interpolação ou Up-Sampler. Através deste, realiza-se o aumento da frequência de amostragem por um fator $L$, que resulta na expansão da 
quantidade de amostras de um sinal. Este processo está ilustrado na Figura 2.7.

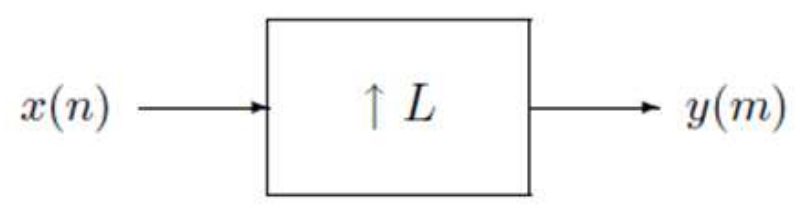

Figura 2.7: Diagrama de bloco de um Interpolador

Para uma determinada sequência de entrada $x[n]$, a saída correspondente ao sinal após o interpolador é dado por

$$
y[n]=\left\{\begin{array}{c}
x\left[\frac{n}{L}\right], \quad n=0, \pm L, \pm 2 L, \pm 3 L \\
0, \quad n \neq 0, \pm L, \pm 2 L, \pm 3 L
\end{array}\right.
$$

Onde L é um número inteiro. A saída resultante será um uma cópia do sinal de entrada nos pontos onde $\mathrm{n}$ é múltiplo de $\mathrm{L}$, e será nula para todos os outros pontos. Em termos práticos, a utilização de expansores introduz zeros entre os pontos do sinal de entrada, proporcionando um aumento da frequência de amostragem. A Figura 2.8 ilustra o processo de expansão por um fator de 2 , onde é possível verificar a inclusão de zeros entre as amostras

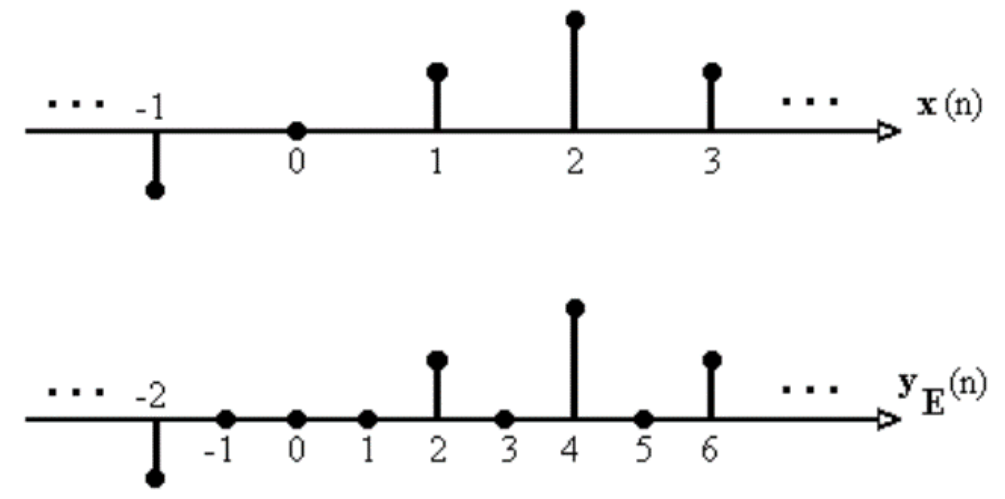

Figura 2.8: Exemplo do efeito da interpolação de um sinal $x(n)$ por um fator 2

\subsubsection{Banco de Filtros}

Segundo Vaidyanathan [15], um conjunto de filtros que compartilham uma entrada comum ou uma saída comum recebe o nome de banco de filtros. A Figura 2.9 ilustra estas duas possibilidades. O sistema apresentado na Figura 2.9(a) é denominado banco de filtros de análise, onde cada componente $G k(z)$ é um filtro de análise. Esse sistema divide o sinal de entrada em M sub-bandas de frequências, produzindo $y_{M-1}(k)$ saídas. O sistema apresentado na Figura 2.9(b) é denominado banco de síntese, que ao contrário do banco de análise, recebe as $y_{M-1}(k)$ entradas e as reúne em uma única saída. 
Observa-se que os dois filtros implementam os blocos básicos de decimação e interpolação para trabalhar com os sinais nas sub-bandas determinadas. Para evitar perdas no processo de decomposição e reconstrução, busca-se criar um banco de filtros que seja de reconstrução perfeita, conforme apresentado na próxima secção.

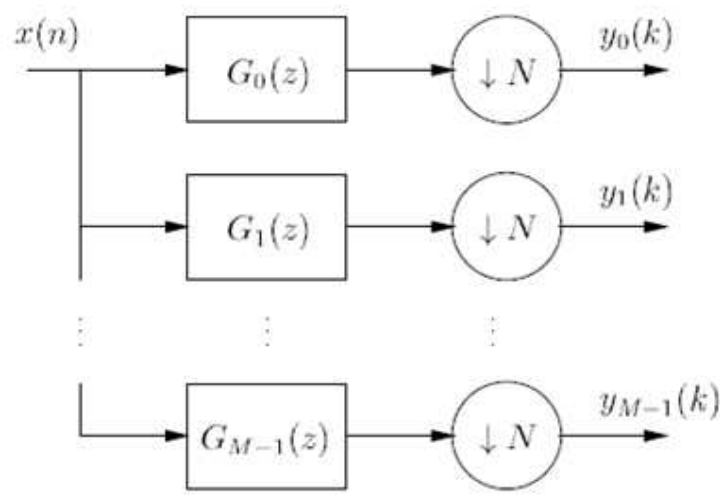

(a)

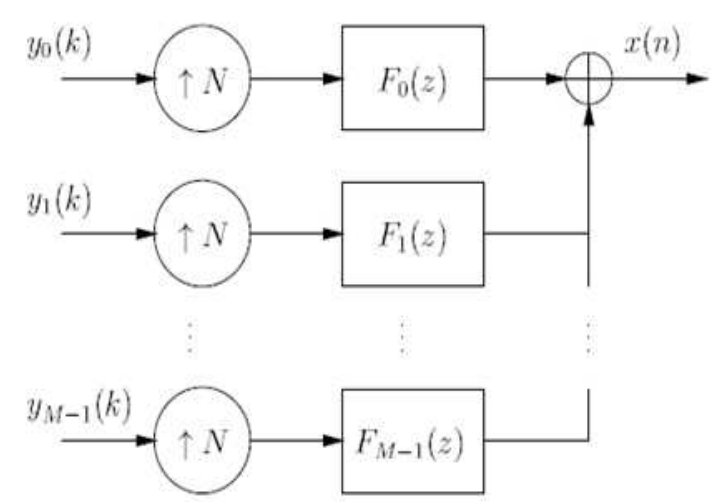

(b)

(a) Filtro de Analise

(b) Filtro de Síntese

Figura 2.9: Exemplo da estrutura de um Banco de Filtros. a)Filtro de Análise. Um sinal $x(n)$ é decomposto em $M$ sub-bandas. b)Filtro de Síntese. As sub-bandas $y(k)$ são reunidas para reconstrução do sinal $x(n)$

\subsubsection{Banco de Filtros de Reconstrução Perfeita}

Os filtros $G(z)$ e $F(z)$ apresentados na Figura 2.9 podem ser projetados de forma que, caso aplique-se um sinal no filtro de análise e os sinais resultantes da decomposição em sub-bandas sejam injetados no filtro de síntese, o sinal resultante é o próprio sinal original. Neste caso, o banco de filtros possui a característica de reconstrução perfeita. Caso contrário, existem três fontes de erro que comprometem a qualidade do sinal:

1. Aliasing

2. Distorção de amplitude

3. Distorção de fase

Entretanto, filtros de reconstrução perfeita apresentam a desvantagem de possuírem a resposta em frequência dos filtros limitada, de modo que uma atenuação na banda de rejeição e uma demora na faixa de transição podem ocorrer. 


\subsection{Compressive Sensing}

A aquisição e reconstrução de sinais são os principais objetivos das pesquisas em processamento de sinais. Na maioria destes pesquisas, o teorema de Nyquist [12] é utilizado com alicerce para determinação da taxa de amostragem correta a ser utilizada. Este garante que, para um sinal limitado em banda, a perfeita reconstrução será obtida caso a frequência de amostragem seja de, no mínimo, duas vezes a máxima frequência do sinal.

Entretanto, o Teorema de Nyquist não considera outros fatores além do pior caso de frequência. Ou seja, não considera se o sinal pode ser comprimido ou se existem informações redundantes. Outro fator não considerado é a esparsidade do sinal, que diminui consideravelmente o número pontos quando representando em uma base esparsa.

Tendo essa lacuna de conhecimentos aberta, pesquisas começaram a ser desenvolvidas, buscando uma nova alternativa para a aquisição de sinais onde fosse possivel explorar sua esparsidade. Neste contexto, surgiu a teoria do Compressive Sensing (CS), desenvolvida inicialmente por Candès, Romberg e Tao [13] e por Donoho[14], que assegura que é possível a reconstrução de sinais com um número bem menor de amostras que o usado por métodos tradicionais. Além disso, possibilita em alguns casos que o sinal seja amostrado e comprimido ao mesmo tempo, o que pode resultar em uma melhora no desempenho computacional.

\subsubsection{O Problema Algébrico}

Considere um vetor $x$, que possui $N$ amostras e que tenha esparsidade $k$. Para realizar a amostragem deste sinal, utiliza-se uma matriz de aquisição (também chamada de matriz de sensoriamento) $\Phi$, que possui $m$ linhas e $n$ colunas. Considere também que $m<n$ e que nenhuma coluna da matriz $\Phi$ é nula. O problema algébrico pode então ser expresso como

$$
y=\Phi . x
$$

onde $y$ são as amostras coletadas, $\Phi$ é a matriz de sensoriamento e $x$ é o sinal original. Observase então que a Equação (2.14) é um sistema indeterminado, onde, sem o fornecimento de informações adicionais, é impossível a recuperação do sinal $x$ a partir das amostras $y$. Dentre as possíveis soluções, busca-se a solução mais esparsa, e ainda assim, poderá ocorrer de existirem múltiplas soluções. A opção correta será determinada pela escolha de matrizes de sensoriamento e de transformação de bases incoerentes entre si, conforme será visto adiante. A Figura 2.10 ilustra a Equação (2.14), onde é possível visualizar a amostragem do vetor x.

\subsubsection{Mudança de base e Esparsificação do sinal}

Considere agora $\Psi$ uma matriz de mudança de base, cuja inversa é dada por $\Psi^{T}$, responsável por alterar a base do vetor $x$ e leva-lo para um domínio onde ele é esparso. A representação do vetor $x$ no domínio esparso é dado por $s$, e pode ser expresso pela multiplicação matricial 


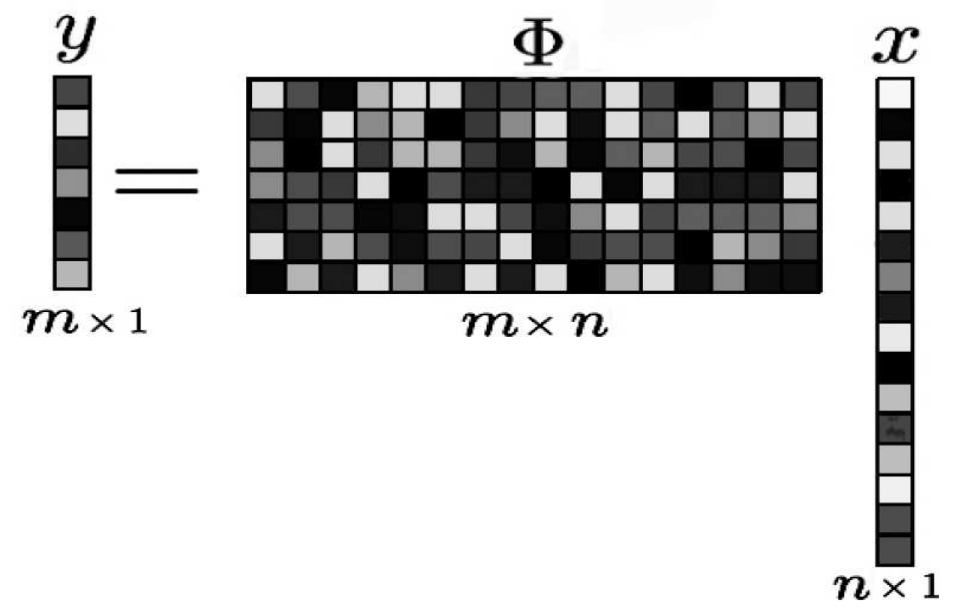

Figura 2.10: Matriz de Sensoriamento. É a representação gráfica da Equação (2.14), e ilustra a obtenção do sinal $y$ a partir da multiplicação matricial de $\Phi$ e de $x$.

$$
s=\Psi \cdot x
$$

Tal condição implica que o processo inverso também é válido, resultando em

$$
x=\Psi^{T} . s
$$

Substituindo o resultado de (2.16) na Equação (2.14), o vetor de amostras y pode ser reescrito como

$$
y=\Phi \cdot \Psi^{T} . s
$$

A representação matricial está representada pela Figura 2.11, onde é possível visualizar representação do vetor x como $\Psi^{T} . s$

\subsubsection{O problema da minimização}

O problema pode ser resumido em, a partir do vetor de amostras $y$, reconstruir o sinal original com a melhor qualidade possível. Para isso, faz-se uso da esparsidade do sinal em algum domínio, calcula-se o vetor mais esparso possível $(s)$ e que atenda Equação (2.17). Este vetor pode ser entendido como o que possui menor número de elementos significativos (ou o maior número de zeros) em sua composição. Isso é um problema de minimização, e conforme visto na secção 2.3.5.1, minimizar o número de elementos significativos é similar à minimizar a norma $l_{0}$. Este problema pode ser representado matematicamente por

$$
\min _{s}\|s\|_{l_{0}} \text { sujeito a } \Phi \cdot \Psi^{*} \cdot s=y
$$




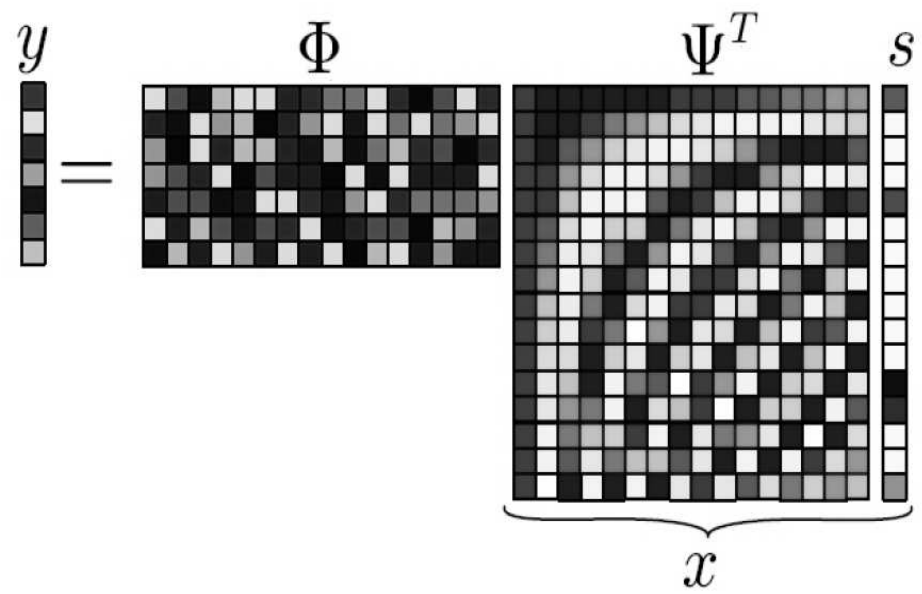

Figura 2.11: Matriz de Aquisição e de Mudança de base. É a representação gráfica da Equação (2.17), e ilustra a obtenção do sinal y a partir da multiplicação matricial de $\Phi, \Psi^{T}$ e $s$. Permite a obtenção de $y$ a partir do sinal esparso $s$

A minimização da norma $l_{0}$ pode ser interpretada como um busca combinatória, onde seu resultado depende de encontrar dentre todos os possíveis resultados esparsos, o que melhor representa o sinal. Em termos práticos, isso é inviável computacionalmente, pois demandaria muito esforço de máquina.

A solução adotada mais comumente é a substituição de $l_{0}$ pela norma convexa mais próxima, no caso, $l_{1}$. O problema de minimização se torna então

$$
\min _{s}\|s\|_{l_{1}} \text { sujeito a } \Phi \cdot \Psi^{*} \cdot s=y
$$

Para justificar a escolha de $l_{1}$ em detrimento de outras opções, a Figura 2.12 apresenta um comparativo entre as normas $l_{0}, l_{1}$ e $l_{2}$. Já a Figura 2.13 apresenta as normas $l_{1}$ e $l_{2}$, onde a reta representa todas as possíveis soluções de $y=\Phi \cdot \Psi^{T} \cdot s$. As normas $l_{2}$ e $l_{1}$ podem ser individualmente representadas por vetores na superfície de um círculo e um losango, respectivamente. Analisando a norma $l_{2}$, observa-se que esta toca o eixo dos resultados primeiramente no ponto $\hat{x}$, que é um ponto onde nenhuma das componentes é nula. Por outro lado, analisando a representação de $l_{1}$, o ponto de encontro com a reta dos resultados é exatamente sobre o eixo, no ponto $x$, que é a solução mais esparsa. 
$L_{2}$ norm

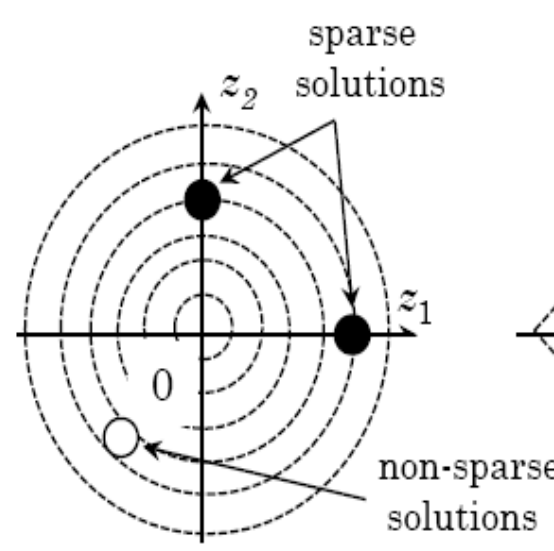

$L_{1}$ norm

sparse

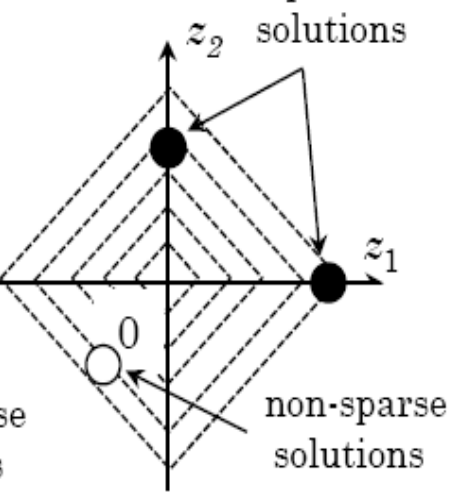

$L_{0}$ norm

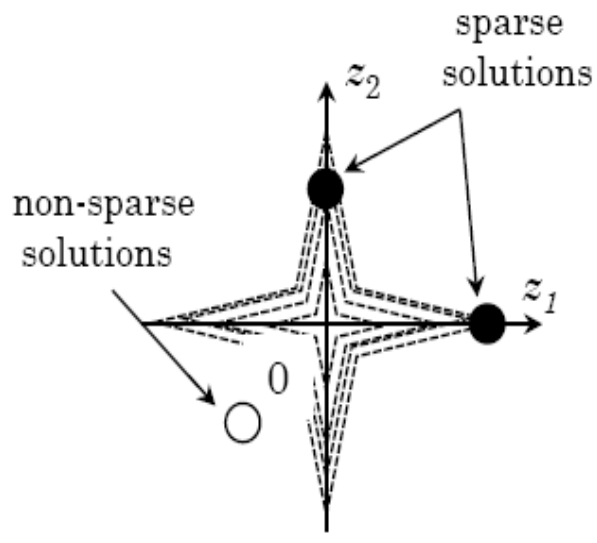

Figura 2.12: Comparativo entre o comportamento das 3 principais normas envolvidas com o CS. Nota-se que todos os pontos que não estão sobre os eixos são as soluções não esparsas e portanto, não devem ser utilizadas.Fonte: http://www.amepc.org-qims-article-viewFile-2233-3083-8679
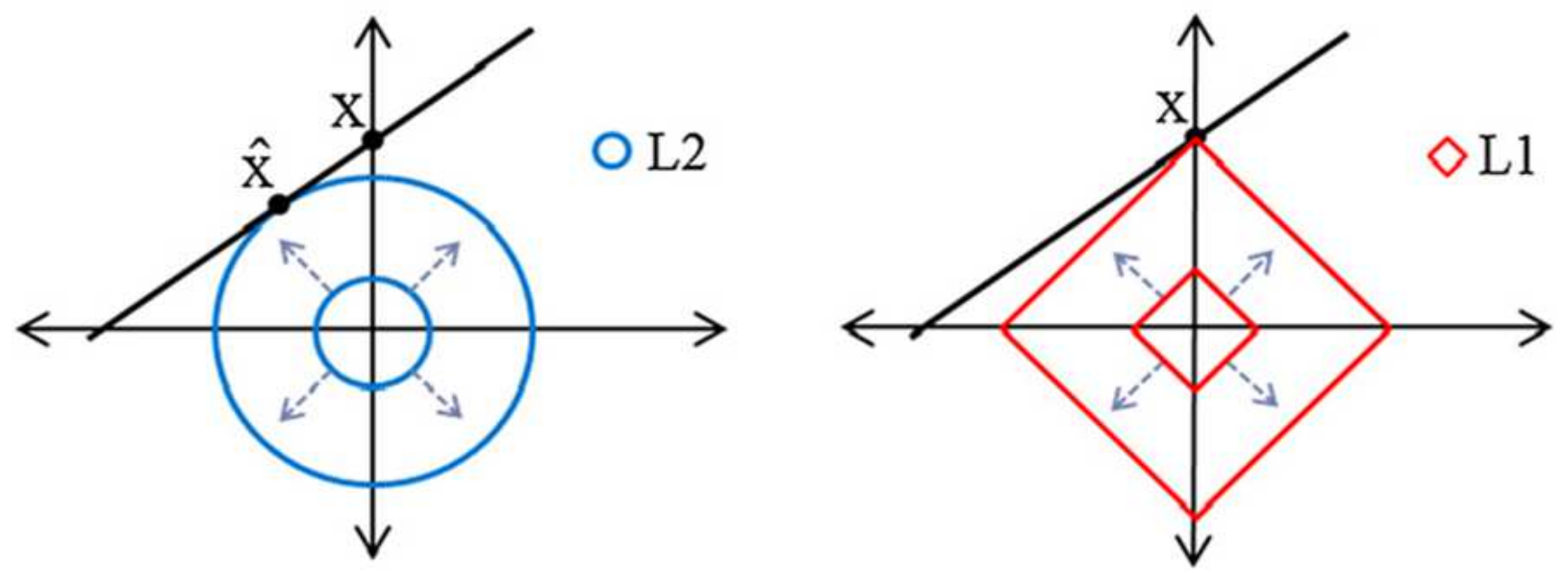

Figura 2.13: Comparativo entre normas L1 e L2. Com base na Figura 2.12, a norma $L_{2}$ coincide com a reta dos possíveis resultados fora dos eixos, o que implica em uma solução não esparsa. Já a norma $L_{1}$ encontra a reta exatamente sobre do eixo, justificando assim sua utilização. Adapatado de [2]

\subsubsection{Requisitos para o funcionamento do Compressive Sensing}

Para a perfeita reconstrução do sinal, devem ser atendidos dois critérios. O primeiro deles está relacionado com o uso do $C S$, que requer a existência de uma baixa coerência (Máxima Incoerência) entre as bases de amostragem e de esparsidade. A base binária contempla tal condição para o domínio da frequência, enquanto que o processo de amostragem aleatório atende com grande probabilidade todas as bases de esparsidade, sendo inclusive, considerada como o método universal de amostragem.

O segundo critério a ser atendido é denominado Princípio da Isometria Restrita (RIP). Con- 
sidere que da matriz de amostragem $\Phi$ ( $N_{\text {linhas }}$ x $\left.M_{\text {colunas }}\right)$, seja extraída uma segunda matriz, denominada $\Phi_{T}\left(N_{\text {linhas }} \times T_{\text {colunas }}\right)$, onde $\Phi_{T}$ é uma submatriz obtida pela extração de $\mathrm{T}$ colunas de $\Phi$. Defini-se a constante de restrição a $\mathrm{S}$, representada por $\delta_{S}$, como sendo o menor valor que satisfaz a equação

$$
\left(1-\delta_{S}\right)\|y\|_{2}^{2} \leq\left\|\Phi_{k y}\right\|_{2}^{2} \leq\left(1+\delta_{S}\right)\|y\|_{2}^{2}
$$

para todas as combinações de $\Phi_{k}$, em que K representa a esparsidade de Y. De forma simplificada, a propriedade RIP estabelece que qualquer conjunto de K colunas da matriz $\Phi$ se comportará como uma matriz ortonormal. Para que a reconstrução seja correta, é necessário que a matriz de amostragem satisfaça a RIP, o que acontece nos casos da matriz identidade e para matrizes aleatórias [35].

\subsubsection{Métrica $l_{p}<1$}

Além das normas tradicionais, existe a possibilidade de utilizar métricas $l_{p}<1$. Chartrand [31] é um dos autores que afirma que é possível a reconstrução de sinais através da minimização de uma métrica $<1$, uma vez que é demonstrado em seu artigo que estas métricas também atendem os critério da desigualdade triangular e podem ser utilizadas para reconstrução exata de sinais. Também é apresentado que o resultado se iguala, quando não é melhor, aos resultados obtidos para $l_{p}=1$. 


\section{Capítulo 3}

\section{Metodologia}

Neste capítulo será feito o detalhamento de cada uma das etapas do trabalho. Será explicado como foi feita a escolha do percentual de amostras, do intervalo máximo de reconstrução e da melhor norma.

\subsection{Introdução}

O trabalho foi realizado em duas grandes etapas. Na primeira, foi feita a adaptação do simulador de EMG-S desenvolvido por Farina e Merletti [3] para 2 dimensões, adicionando a possibilidade de descrição das camadas do volume condutor com funções matemáticas. Na segunda etapa, os sinais gerados com o simulador foram utilizados para avaliar a possibilidade de utilização do $C S$ no processamento de sinais de EMG-S.

Conforme visto na secção 2, para utilização do $C S$, é necessário que os sinais sejam esparsos, o que não acontece naturalmente com sinais de EMG-S. Entretanto, através da utilização de Banco de Filtros [15] é possível o fracionamento em sub-componentes, que atendem este requisito.

A Figura 3.1 apresenta o diagrama de blocos utilizado como referência para o desenvolvimento do trabalho. Nesta Figura ilustra-se como um sinal com perdas é recuperado através da metodologia proposta. Inicialmente é feita a decomposição em 32 sub-bandas de frequências através de um banco de filtros de análise. Em seguida, cada uma das componentes é submetida ao $C S$, de modo que as amostras sejam coletadas em pontos diferentes dos comprometidos. Posteriormente, cada sub-componente do sinal é filtrada com o banco de síntese, de modo a retornar ao domínio do Tempo. Por fim, todas as componentes são somadas, dando origem a um sinal semelhante ao sinal de entrada, porem corrigido nos pontos que estavam comprometidos.

Uma vez que o uso do $C S$ ainda está bastante incipiente quanto a sua aplicação em sinais de EMG, será executada uma rotina de testes, com objetivo de determinar quais os melhores parâmetros a serem utilizados na reconstrução de sinais comprometidos. Foi elaborado um laço de repetição para avaliar, em simultâneo, a influencias de parâmetros como o percentual de amostras, o tamanho máximo do intervalo de reconstrução e a melhor métrica $L_{p}$ a ser minimizada. Além disso, ao mesmo tempo em que os testes são realizados, será verificada a utilização de matrizes de 
amostragem ponderada em substituição à matriz binária.

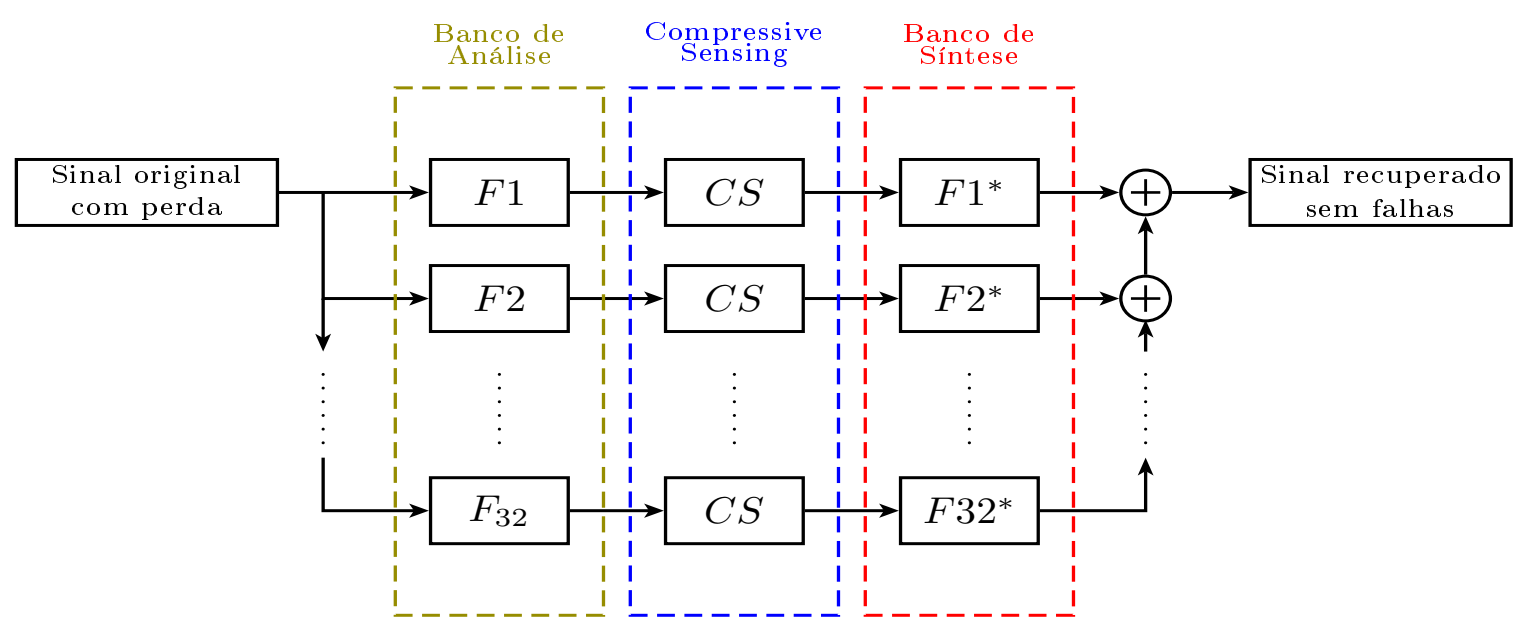

Figura 3.1: Diagrama de blocos das etapas de recuperação do sinal de EMG. O sinal é decomposto em 32 sub-bandas de frequências através de um banco de filtros de análise, processado com o uso do $C S$ e reconstruído com o uso do banco de filtros de síntese.

Considerando que ocorrem múltiplas falhas no sinal de EMG-S, será avaliada também a possibilidade de reconstrução de mais de um intervalo de pontos. Escolhidos os parâmetros que apresentaram melhores resultados e determinado qual o máximo intervalo que pode ser reconstruído, os novos trechos serão inseridos tendo essas informações como premissa.

\subsection{Simulador de EMG-S 2-D}

O simulador foi desenvolvido a partir do trabalho de Farina e Merletti [3], sendo uma adaptação para duas dimensões onde o volume condutor pode ser descrito por uma função especificada. O código do simulador original foi implementado em MatLab (Mathworks Inc., South Natick, MA, USA) e a configuração dos parâmetros, pele e gordura, segue o modelo de volume condutor descrito pela Figura 3.2(a).

Para que sinais de EMG-S fossem simulados em diferentes tipos de superfície, foi descrito um novo modelo para o volume condutor, tendo como fundamentação as informações apresentadas por Mesin [9] e Farina et al. [36]. A representação do novo volume condutor é apresentada na Figura 3.2(b). Foi considerado que em situações reais, as camadas de pele e de gordura não são planas, e por esse motivo a descrição apresentada na Figura 3.2(a) não seria suficiente.

\subsubsection{Adaptação do algoritmo}

A adaptação do algoritmo proposto em [3] consistiu na execução do código original $n$ vezes, onde $n$ é o número de colunas da matriz desejada. Em cada uma das iterações ocorria o deslocamento do sistema de eletrodo com relação à fibra muscular na direção $x$, de modo que o novo vetor de 


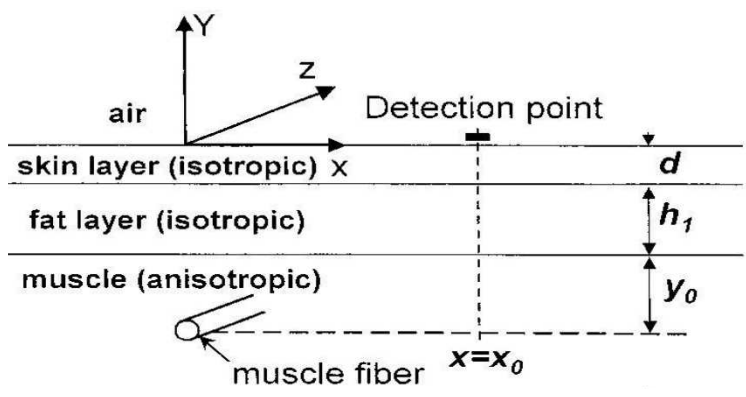

(a) Modelo para 1-D

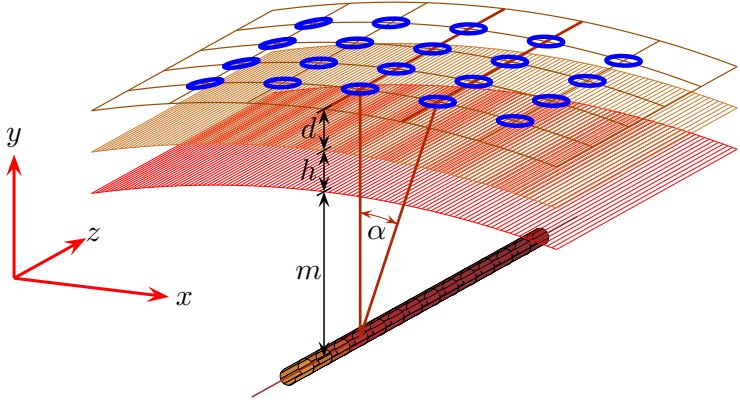

(b) Modelo para 2-D

Figura 3.2: (a) Volume condutor utilizado no simulador original. $\mathrm{O}$ eixo $\mathrm{x}$, que representa a camada onde estão posicionados os eletrodos, é considerado infinito e plano. As camadas $d$ e $h_{1}$ são fixas e independem da posição do eletrodo. Adaptado de [3]. (b) Volume condutor utilizado como referência para elaboração do simulador. As camadas de pele e gordura são descritas como funções do angulo $\alpha$ e variam conforme o eletrodo se distância horizontalmente da fibra muscular.

eletrodos fosse posicionado paralelamente ao vetor anterior. Desta maneira, cada vetor de eletrodos se tornava uma coluna, e o conjunto de todas as colunas formaria a matriz desejada.

Para cada iteração foi feita a manutenção dos parâmetros globais e avaliado o efeito da distância sobre as camadas do volume condutor. O modelo apresentado na Figura 3.2(b) considera não apenas a distância na direção $x$, como também a curvatura das superfícies.

Foi observado que o código original funcionava baseado em funções, que faziam uso de números e sequências aleatórias gerados no início de cada simulação. Foi realizada então uma alteração para que a função RNG disponível no MatLab fosse utilizada. Esta permite que, a partir de uma semente numérica, o gerador de números aleatórios do MatLab repita uma sequência pseudoaleatória toda vez que for utilizado. Este comando foi implementado no começo de cada iteração, de modo que cada coluna compartilha as mesmas configurações que a as colunas vizinhas. Toda vez que o programa é iniciado, uma nova sequencia é gerada.

\subsubsection{Configuração dos parâmetros}

Todos os parâmetros usados na simulação são configurados em um arquivo separado, de modo a permitir que o usuário altere apenas este arquivo antes de iniciar uma nova simulação. Nesse arquivo é possível estabelecer as especificações do eletrodo, espessura das camadas de pele e de gordura, além de todas as outras configurações gerais, que estão apresentadas na Tabela 3.1. Dada a adaptação do simulador para duas dimensões, foram adicionadas variáveis relacionadas com o número de linhas e de colunas da matriz desejada.

\subsubsection{Descrição do novo volume condutor}

No projeto original as camadas da pele e gordura são descritas como superfícies planas e infinitas, que se propagam nas direções $x$ e $z$. Durante o processo de modificação do algoritmo 
Tabela 3.1: Parâmetros utilizados na simulação

\begin{tabular}{|l|c|c|}
\hline Parâmetros & Valor & Unidade \\
\hline Espessura da camada de gordura & 3 & $\mathrm{~mm}$ \\
\hline Espessura da camada de pele & 1 & $\mathrm{~mm}$ \\
\hline Velocidade de condução das fibas da MU & 5 & $\mathrm{~m} / \mathrm{s}$ \\
\hline Raio da MU & 1.5 & $\mathrm{~mm}$ \\
\hline Disposição dos eletrodos para aquisição & Diferencial simples & - \\
\hline Distância inter-eletrodo & 3 & $\mathrm{~mm}$ \\
\hline Raio do eletrodo & 1.5 & $\mathrm{~mm}$ \\
\hline Número de canais & 4 & - \\
\hline Número de colunas & 5 & - \\
\hline Frequência de amostragem & 2048 & $\mathrm{~Hz}$ \\
\hline Tipo de eletrodo & Pontual & - \\
\hline Distância entre colunas & 3 & $\mathrm{~mm}$ \\
\hline Máxima contração voluntária (MVC) & 30 & $\%$ \\
\hline
\end{tabular}

descrito em [3], optou-se por fazer a descrição das camadas através de uma função $f(\alpha)$, onde $\alpha$ é o ângulo formado entre a reta perpendicular à fibra muscular, que passa pela origem do sistema de eletrodos, e o eletrodo em questão. Desta maneira, é possível considerar a influência da inclinação nos parâmetros $d$ e $h$, que correspondem às espessuras das camadas de pele e gordura, respectivamente.

Para teste, foi utilizado como músculo de referência o bíceps braquial, por ser amplamente utilizado em eletromiografia e possuir uma anatomia simples de ser trabalhada. Após análise da secção transversal do braço humano apresentado por Perotto [37], buscou-se uma função matemática que descrevesse a superfície do músculo. Dentre as possibilidades, uma função simplificada foi escolhida para representar as duas camadas (pele, gordura), alem de representar a secção transversal da fibra muscular como uma circunferência. Esta descrição está ilustrada na Figura 3.3. Foi observado que a porção central do volume condutor é menor do que as partes laterais. Desta forma, as camadas $d$ e $h$ tendem a aumentar conforme o eletrodo é afastado da origem. Uma função senoidal arbitrária foi escolhida por se assemelhar à curvatura do músculo, simplificando a etapa de testes. Através da multiplicação da função $f(\alpha)=1+0.2 \cdot \sin (\alpha)$ com os parâmetros $d$ e $h$, os parâmetros atingem nas laterais do músculo um valor que é 1.2 vezes maior que na porção central.

Para realização dos testes, foi estipulado que o maior valor absoluto permitido para o ângulo $\alpha$ seria $\frac{\pi}{2}$. Isto permitiu que a função apresentada na Figura 3.3 fosse aplicada. Os valores dos parâmetros principais utilizados para os testes estão representados na Tabela 3.1. No caso particular deste artigo foi criado uma matriz com dimensão $4 \times 5$, sendo as especificações adotadas com base em valores típicos apresentadas na literatura. Foi estabelecido que os sinais deveriam ser correspondentes à $30 \%$ da máxima contração volutária (MVC), com duração de 10 segundos. 


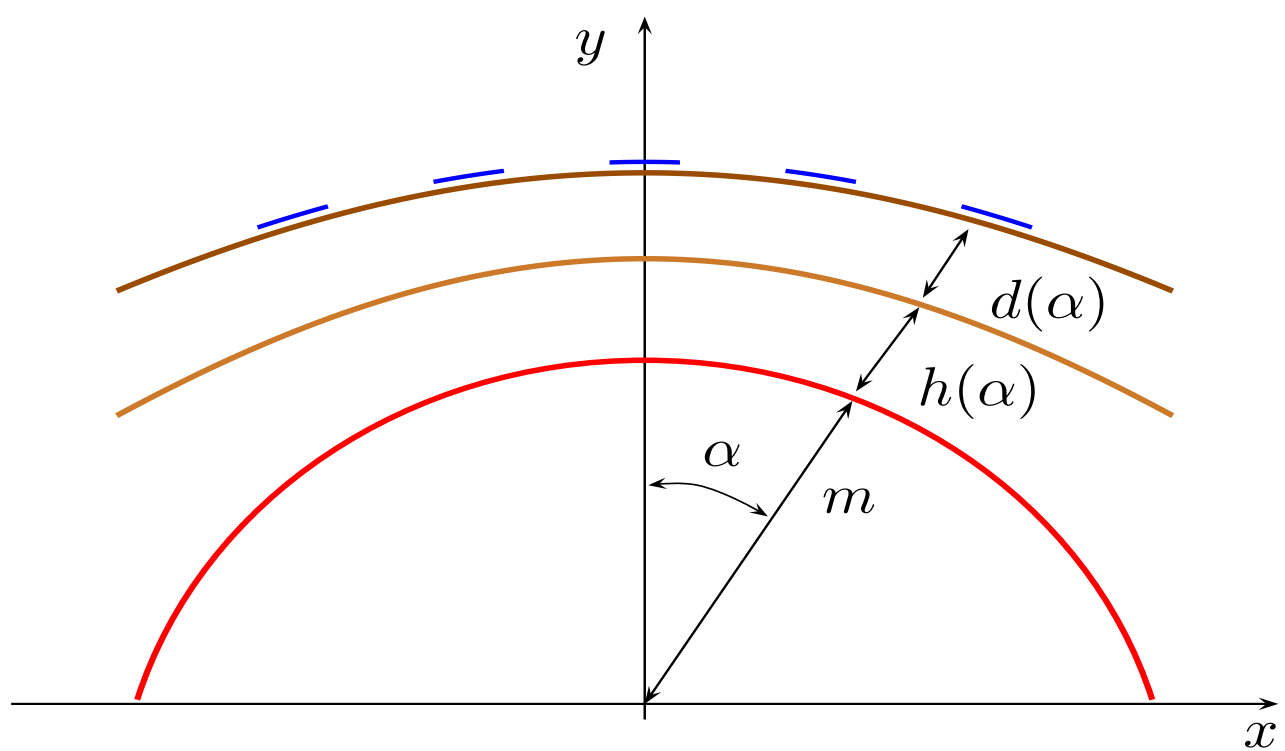

Figura 3.3: Função que descreve o comportamento das camadas de pele e de gordura. Na origem do sistema, os parâmetros $d$ e $h$ tem o valor original, que foi estabelecido pelo usuário. Conforme a coluna de eletrodo é deslocada na direção $x$, os parâmetros são alterados seguindo a função que descreve o volume condutor a ser simulado, considerando assim o efeito da distância na captação dos sinais.

\subsection{Processamento de Sinais de EMG-S com $C S$}

Este trabalho tem como objetivo avaliar a utilização do CS para o processamento e recuperação de sinais de EMG-S. Um dos sinais de EMG-S simulados foi utilizado como referência para os experimentos, sendo aplicado sobre este os procedimentos apresentados na Figura 3.1. Nesta seção, cada uma das etapas ilustradas na Figura 3.1 será detalhada, mostrando como foram implementadas no Matlab e os testes realizados para determinação das melhores opções para o percentual de amostras, número máximo de pontos e norma Lp.

\subsubsection{Banco de Filtros de Análise}

Conforme visto na secção 2, um dos requisitos para a aplicação do $C S$ em um sinal é que este seja esparso em pelo menos 1 domínio. Pela teoria de sinais apresentada por Oppenheim [12], um sinal senoidal puro no tempo possui representação no domínio da frequência dado por um impulso. Sabe-se também da teoria de análise de Fourier[12] que um sinal pode ser representado como o somatório de diversas senoides, conforme visto na secção 2.3.3.

A utilização de filtros passa-faixa, conforme apresentado na seção 2.5, permite delimitar o espectro de frequências do sinal. Quanto mais estreita for a banda passante do filtro, mais próximo de uma representação impulsional será a resposta no domínio transformado. Abarcado por esse conhecimento, foi projetado um banco de filtros responsável por decompor o sinal original em 32 sub-bandas, cuja representação no domínio da frequência pode ser considerada esparsa. O filtro projetado está distribuído em uma matriz com 32 linhas e 192 colunas. Cada linha representa uma 
sub-banda de frequência, enquanto que as colunas são os coeficientes do filtro, que levam o sinal para o domínio de Fourier. A resposta do filtro pode ser visualizada na Figura 3.4

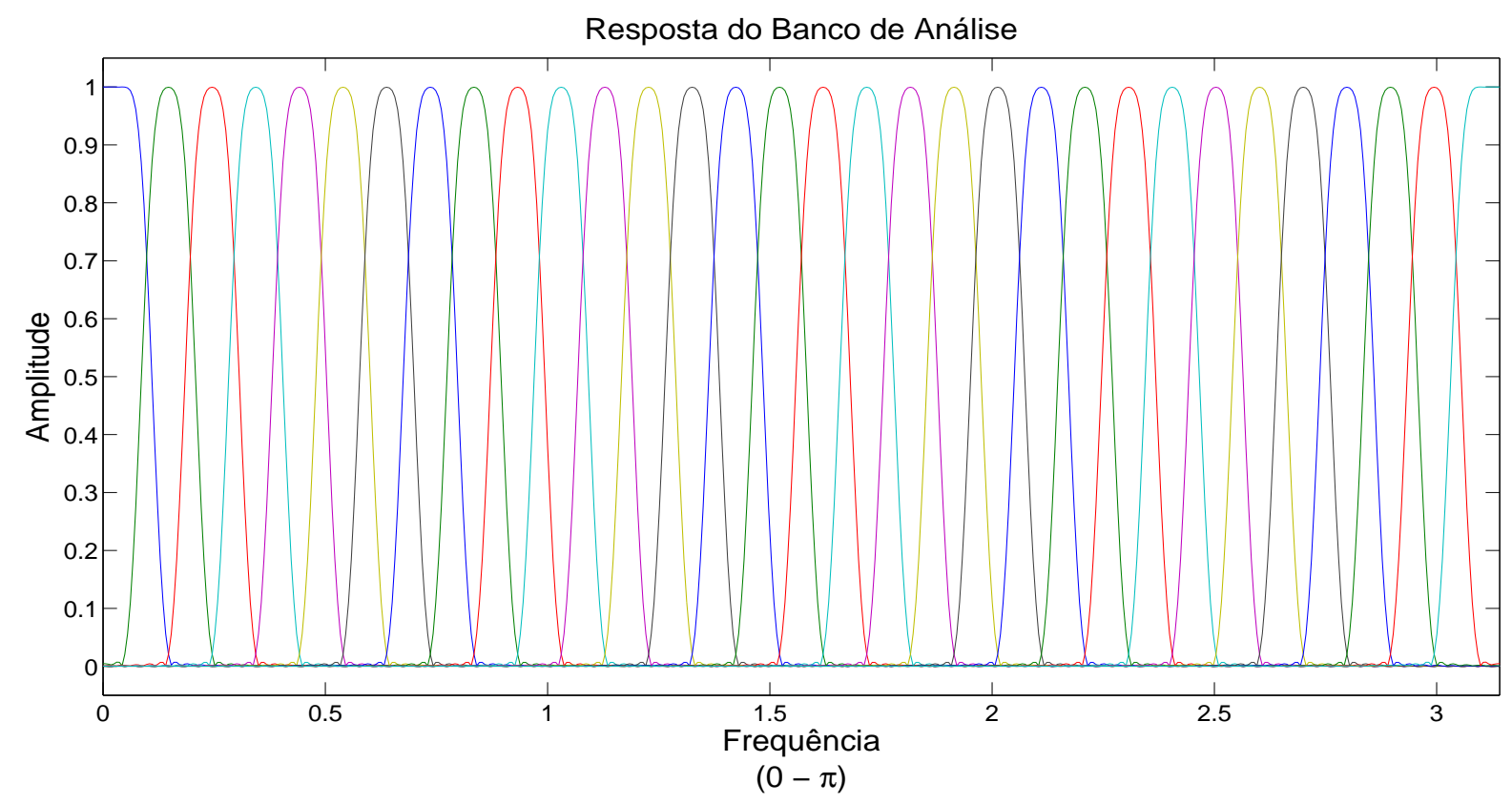

Figura 3.4: Resposta do banco de análise projetado. Na figura estão representados os 32 filtros passa-banda que compõem o banco de filtros. Observa-se que existe grande atenuação fora da banda de passagem.

Considerando que o filtro possui uma resposta dada por $h(n, i)$, onde $i$ representa a sub-banda de filtragem, a decomposição do sinal de EMG-S pelo banco de filtro se dá pela convolução do sinal com cada um dos filtros, conforme a fórmula

$$
\text { Componente }_{(i)}=E M G(i) * h(n, i)
$$

\subsubsection{Compressive Sensing}

Após garantir que o sinal foi decomposto em 32 sub-bandas esparsas no domínio de Fourier, a etapa seguinte foi a aplicação do $C S$ em cada uma das componentes do sinal. Entretanto, foi observado que existiam diversas combinações possíveis para os três parâmetros que estão sendo analisados:

- Intervalo máximo de pontos comprometidos

- Percentual de amostras que serão utilizadas para reconstrução

- Norma $L_{p}$

Tendo em vista que a determinação dos melhores parâmetros era um dos objetivos desta dissertação, elaborou-se uma rotina que pudesse avaliar o comportamento dos três em simultâneo. 
Para isso, fez-se uso de três laços de repetição, conforme está ilustrado no fluxograma da Figura 3.5 , onde todas as combinações puderam ser executadas.

Ademais, após a realização de um embasamento teórico, observou-se que a amostragem do sinal poderia ser realizada de duas maneiras distintas. Na primeira, a matriz de aquisição é formada por 1 e 0 , o que significa em termos práticos que, feita a multiplicação desta matriz com o sinal a ser amostrado, o resultado é a seleção de pontos de posições específicas. A matriz

$$
M_{\text {Tradicional }}=\left[\begin{array}{ccccc}
1 & 0 & 0 & \ldots & 0 \\
0 & 0 & 1 & \ldots & 0 \\
\vdots & \vdots & \vdots & \ddots & \vdots \\
0 & 1 & 0 & \ldots & 0
\end{array}\right]
$$

ilustra o processo tradicional. Entretanto, conforme apresentado por Baraniuk [35], a utilização de matrizes de aquisição geradas com certo grau de aleatoriedade vêm sendo empregada em processamento de sinais, inclusive para aplicações envolvendo Compressive Sensing. As dimensões desta matriz são semelhantes às apresentadas pela de aquisição tradicional, entretanto apresenta a característica de ter os elementos aleatórios. Considerando que não apenas um elemento é não nulo dentro de uma mesma linha, utilizar essa matriz significa realizar uma amostragem ponderada, em que o resultado é uma composição de diversos outros pontos. Um exemplo de matriz aleatória com esse tipo de configuração é apresentado a seguir:

$$
M_{\text {Ponderada }}=\left[\begin{array}{ccccc}
0.1 & 0.3 & 0 & \ldots & 0.3 \\
0.45 & 0.2 & 0.1 & \ldots & 0.05 \\
\vdots & \vdots & \vdots & \ddots & \vdots \\
0.01 & 0.27 & 0.6 & \ldots & 0.05
\end{array}\right]
$$

As simulações possuem tempo de execução variável, porém tendem a aumentar a medida que o tamanho do sinal é elevado. Por se tratar de ações computacionais, a melhor opção seria realizar um número alto de repetições, contudo, testes preliminares indicaram que a execução das rotinas apresentadas na Figura 3.5 se alongariam por dias no computador disponível. A solução adotada foi a busca do menor número de amostras possível, garantindo que esse número seria representativo e demonstraria com qualidade o comportamento do CS quando utilizados os parâmetros escolhidos.

Conforme visto no Secção 2.3.9, a realização de no mínimo 30 amostras permite aproximar os resultados para uma distribuição normal, sendo o valor da média significativa e representativa do universo populacional. Com base nesta informação, para cada percentual de amostras foram calculadas 30 medições, sendo este processo repetido para cada uma das possíveis combinações de norma e intervalo de pontos. Isto permitiu gerar as Tabelas 4.1 a 4.7 apresentadas na Secção 4, utilizadas para escolha dos parâmetros que seriam empregados posteriormente. 


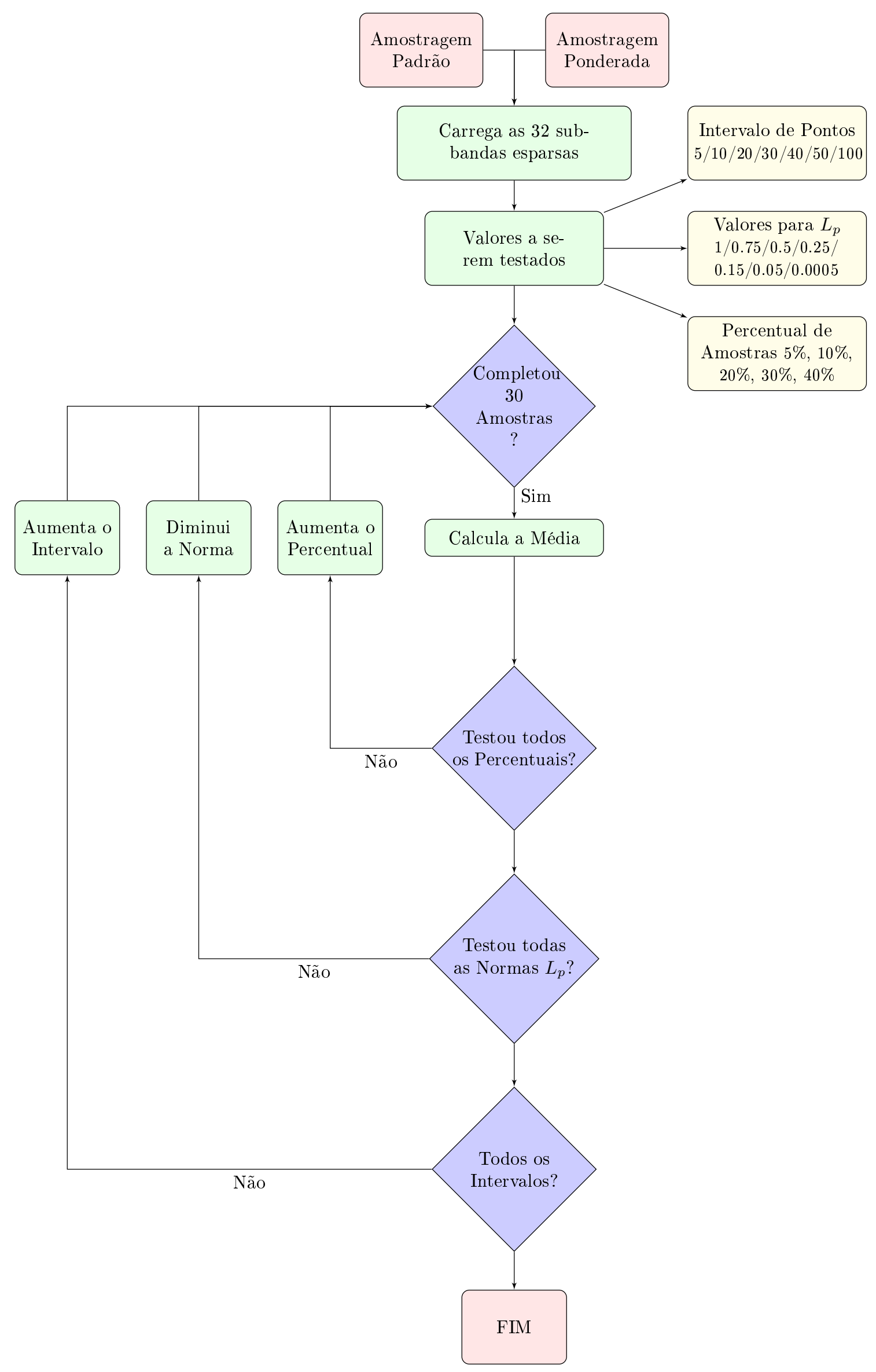

Figura 3.5: Fluxograma utilizado como referência para determinação dos melhores parâmetros 


\subsubsection{Signal to Signal Rate (SSR)}

Com objetivo de padronizar os resultados e possibilitar a comparação entre os valores obtidos, a solução adotada foi o cálculo de uma métrica entre os sinais recuperados e o sinal original. De cálculo semelhante ao praticado para o SNR (Signal-Noise Rate), o SSR pode ser utilizado para avaliar a proximidade entre dois sinais. Seu cálculo é dado por

$$
S S R_{(d B)}=20 \cdot \log _{10}\left(\frac{\| \text { Sinal }_{\text {Original }} \|}{\| \text { Sinal }_{\text {Original }}-\text { Sinal }_{\text {Recuperado }} \|}\right)
$$

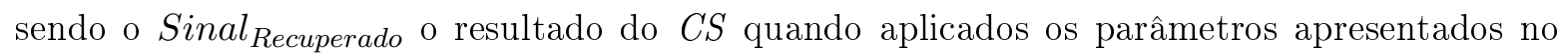
Fluxograma da Figura 3.5.

\subsubsection{Banco de Filtros de Síntese}

A obtenção do filtro de síntese se dá pela inversão horizontal dos coeficientes do filtro de análise, ou seja, se torna a versão espelhada do original, onde o primeiro coeficiente passa a ser o último e o último passa a ser o primeiro. A aplicação deste filtro se dá de maneira semelhante à anterior, no entanto, o sinal de entrada são as componentes já processadas com o CS. É feita a convolução de cada componente do sinal de EMG-S com os coeficientes do filtro de síntese, resultando em uma matriz com 32 linhas e N-1 colunas, onde N é o somatório das dimensões do sinal e da ordem do filtro. Para fim de testes, foi escolhido um sinal com 1025 amostras.

\subsubsection{Reconstrução do sinal}

Finalizado o processo de filtragem, o resultado é uma matriz com dimensões de 32 linhas e 1216 colunas, que correspondem aos 32 canais do filtro e as 1025 amostras de cada componente. A diferença de 191 pontos apresentada é um atraso temporal inserido em função da ordem dos filtros ultilizados. A reconstrução do sinal se dá pela soma linear de todos os elementos de uma mesma coluna, de modo que o sinal final possui 1 linha e 1216 colunas. Para remoção do atraso cada amostra teve sua posição acrescida em 191 pontos, de modo que o valor apresentado na posição $i$ se torna $i+191$. Com isso, as primeiras 191 amostras do sinal recuperado são descartadas, resultando em um sinal com 1025 pontos. 


\subsection{Reconstução de Multiplos Intervalos}

Uma vez definido qual o máximo de pontos que pode ser recuperado através do CS, outros intervalos de mesmo tamanho foram inseridos no sinal, com objetivo de avaliar a possibilidade de reconstrução mesmo na presença de falhas espalhadas ao longo do sinal. Para fins de teste, foram utilizados 2, 3, 4 e 5 intervalos, mantendo-se o sinal inalterado. As Figuras 3.6 a 3.9 ilustram a presença destes intervalos no sinal. Em cada uma das figuras, está em destaque a posição do trecho de falhas, obtida pela atribuição do valor zero às amostras. A posição de cada intervalo é apresentada na Tabela 3.2.

Tabela 3.2: Posição dos intervalos de perdas

\begin{tabular}{cc}
\hline Número de Intervalos & Posição \\
\hline 1 & $680-720$ \\
2 & $200-240 \mid 680-720$ \\
3 & $200-240|440-480| 680-720$ \\
4 & $200-240|440-480| 680-720 \mid 920-960$ \\
5 & $160-200|360-400| 560-600|760-800| 960-1000$ \\
\hline
\end{tabular}

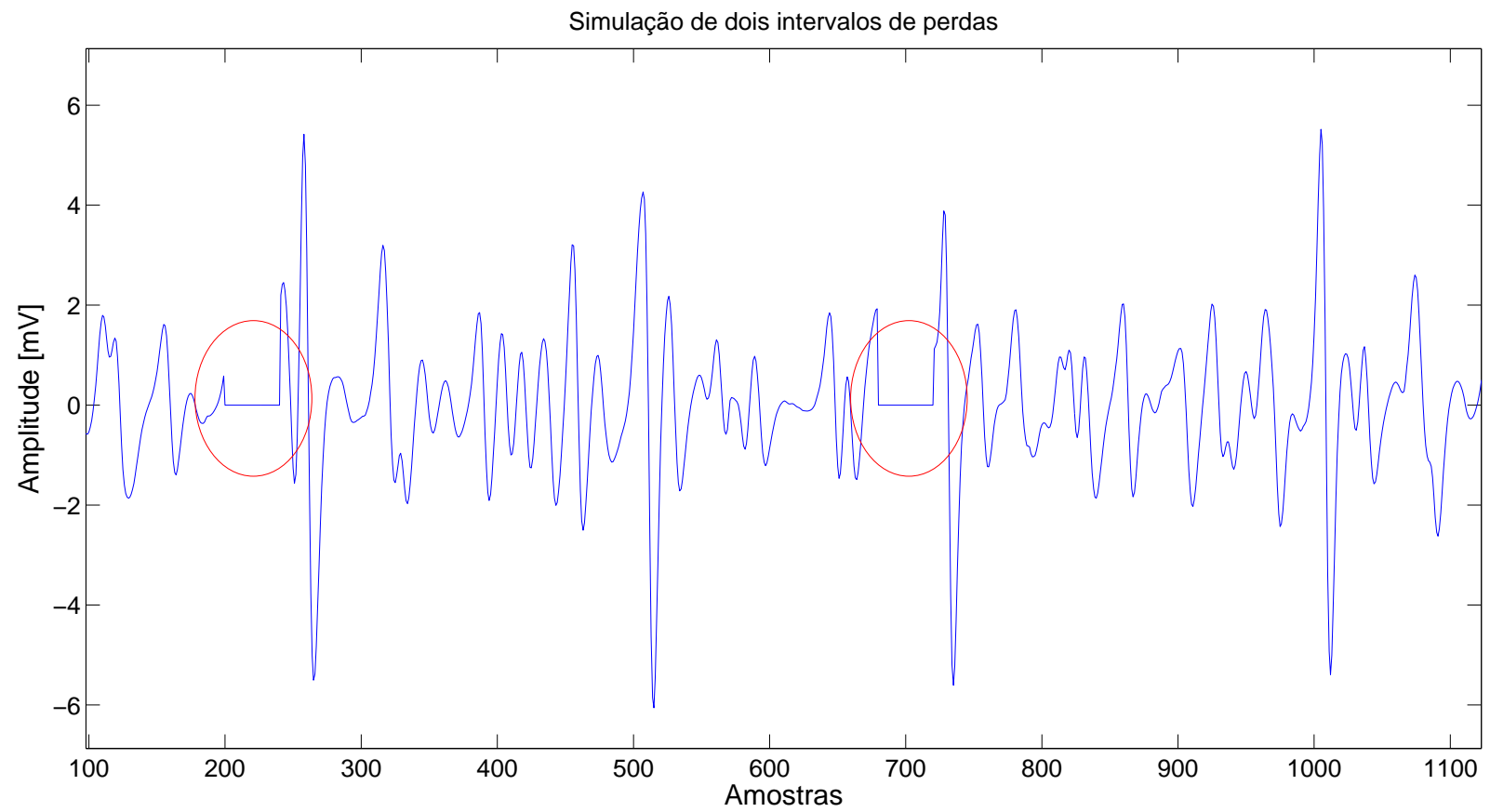

Figura 3.6: Simulação de dois intervalos de perdas no sinal. Estão circuladas as 2 falhas inseridas no sinal, localizadas entre os pontos 200-240 e entre 680-720. Cada trecho foi substituído por 40 elementos nulos. 


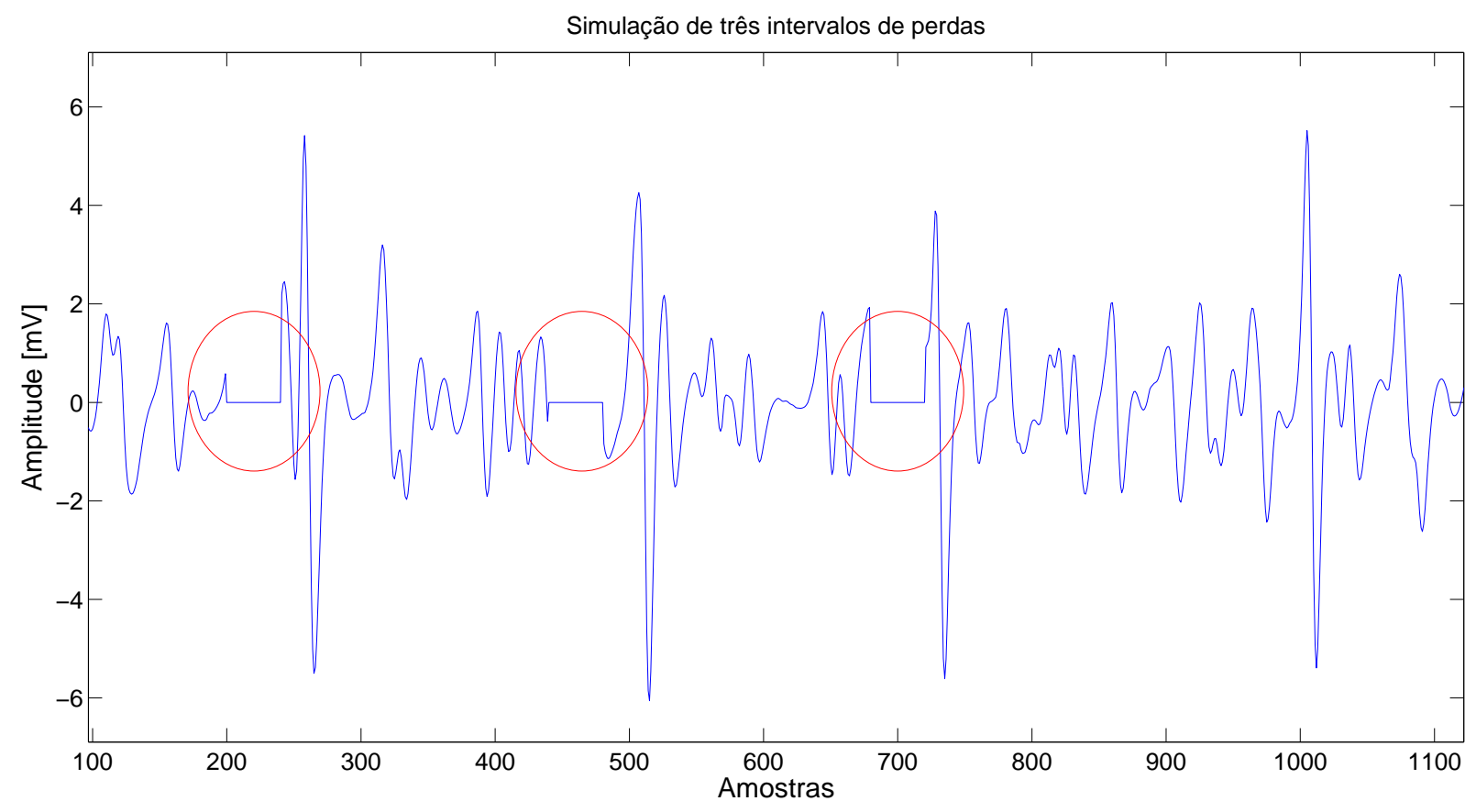

Figura 3.7: Simulação de três intervalos de perdas no sinal. Estão circuladas as 3 falhas inseridas no sinal, localizadas entre os pontos 200-240, 440-480 e entre 680-720. Cada trecho foi substituído por 40 elementos nulos.

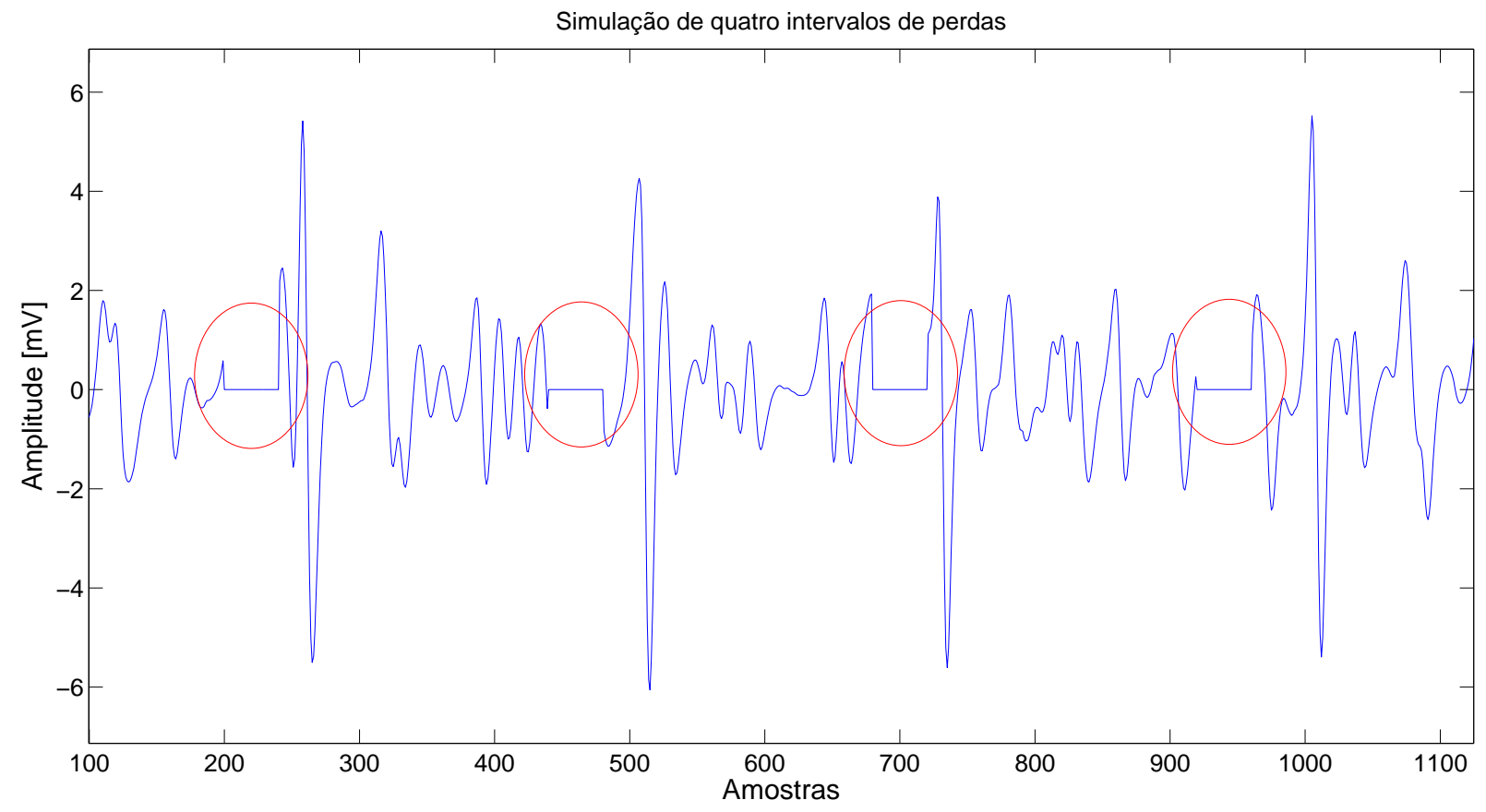

Figura 3.8: Simulação de quatro intervalos de perdas no sinal. Estão circuladas as 4 falhas inseridas no sinal, localizadas entre os pontos 200-240, 440-480, 680-720 e entre 920-960. Cada trecho foi substituído por 40 elementos nulos. 


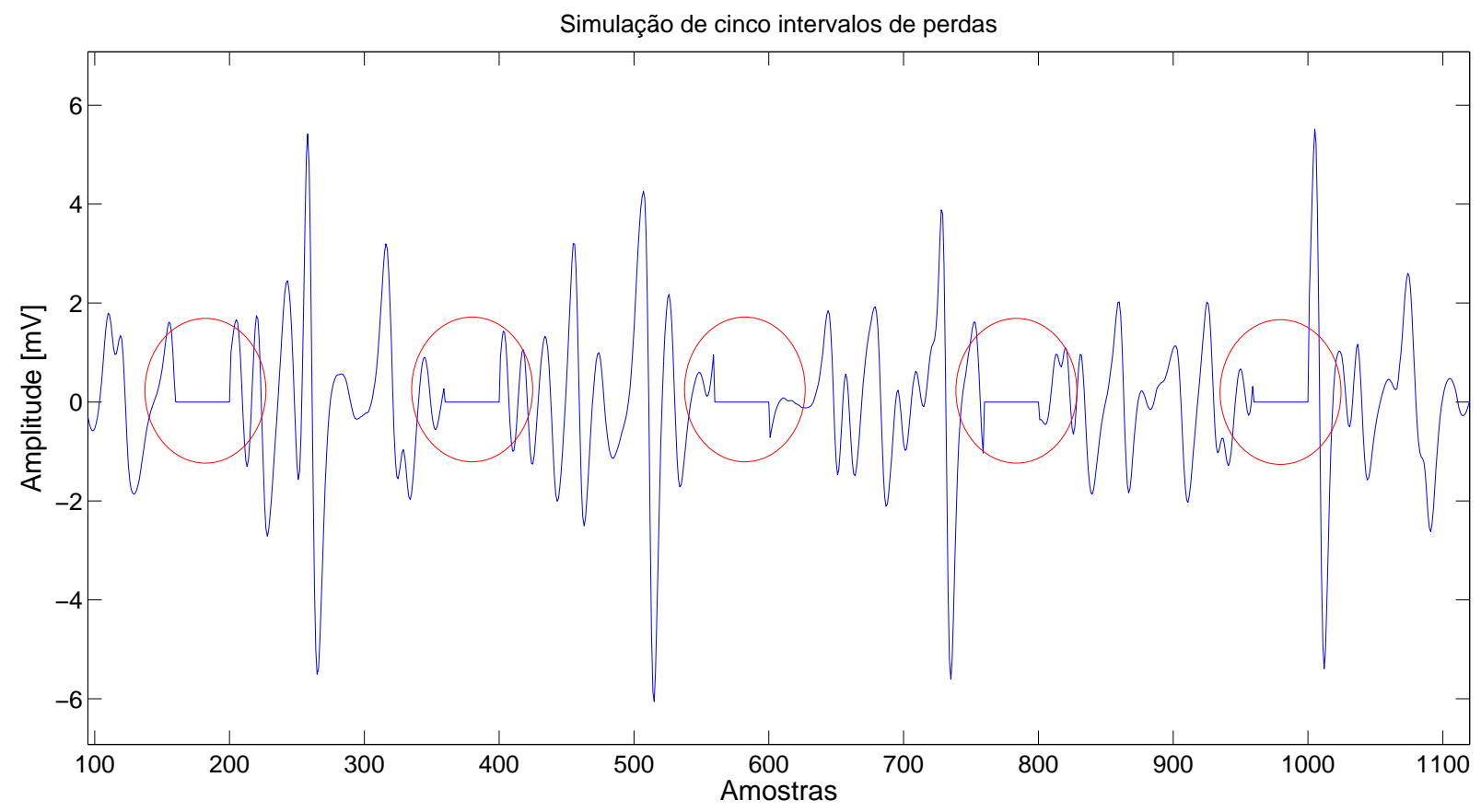

Figura 3.9: Simulação de cinco intervalos de perdas no sinal. Estão circuladas as 5 falhas inseridas no sinal, localizadas entre os pontos 160-200, 360-400, 560-600, 760-800 e entre 960-1000. Cada trecho foi substituído por 40 elementos nulos. 


\section{Capítulo 4}

\section{Resultados Experimentais}

Neste capitulo serão apresentados os resultados dos testes realizados com o CS e a determinação dos parâmetros, demonstrando também os resultados do simulador de EMG-S

\subsection{Introdução}

Este capítulo apresenta os resultados obtidos e como foram tomadas as decisões relacionadas com os parâmetros utilizados para recuperação dos sinais. Para apresentar o conteúdo e fazer a conexão entre os resultados, estes serão elencados na seguinte ordem:

1. Resultados da Simulação Bidimensional

2. Sinal utilizado para testes

3. Decomposição do sinal em 32 sub-bandas de frequência.

4. Resultados da rotina apresentada pelo fluxograma da Figura 3.5

5. Aplicação do Compressive Sensing nas Sub-bandas

6. Reconstrução do sinal e correção do atraso

7. Relação SSR entre o sinal original e o reconstruído

8. Reconstrução de Múltiplos intervalos

\subsection{Resultados da Simulação Bidimensional}

As simulações foram realizadas com os parâmetros listados na secção anterior por meio de um computador com processador de quatro núcleos, com velocidade de clock $2.4 \mathrm{GHz}$, e memória ram de 8 GB. O tempo total de simulação foi de 8 minutos. Verificou-se que a diminuição da distância inter-eletrodo e das dimensões físicas do eletrodo não provocam aumento significativo no tempo de simulação. No entanto, o aumento da densidade de pontos de aquisição eleva consideravelmente 
a duração do processo. Matrizes com grandes dimensões (exemplo 50x50) e alta concentração de pontos por $\mathrm{cm}^{2}$ demandam elevado poder computacional, sendo recomendado a utilização de máquinas melhores que a utilizada.

As Figuras 4.1, 4.2, 4.3 e 4.4 apresentam os resultados da simulação de uma matriz 4x5, semelhante à observada na Figura 3.2(b). Nestas figuras é possível verificar a propagação dos sinais, ao mesmo tempo que nota-se o decaimento da amplitude do sinal com o aumento das camadas do volume condutor. A Figura 4.1 apresenta os resultados da primeira coluna de eletrodos, posicionada paralelamente à fibra muscular e sobre o eixo z. De forma semelhante, a Figura 4.2 ilustra o efeito do deslocamento perpendicular à fibra, apresentando os resultados da primeira linha de eletrodos. Em função de variações no volume condutor, a amplitude do sinal é afetada. A Figura 4.3 apresenta os resultados de todas as colunas sobrepostos, enquanto a Figura 4.4 mostra individualmente cada linha de eletrodos. São expostos quatro planos, sendo cada um deles correspondente à uma linha da matriz de eletrodos. Em cada uma das imagens, observa-se a propagação dos sinais de EMG-S no tempo, que são captados por cinco eletrodos que estão espaçados com distância estabelecida na Tabela 3.1.

Os resultados mostram um decaimento da amplitude do sinal em função do deslocamento na direção $x$, que é perpendicular à fibra muscular. Este fato era esperado, uma vez que o aumento do volume condutor dificulta a propagação do sinal e reduz a sua captação pelos eletrodos [8].

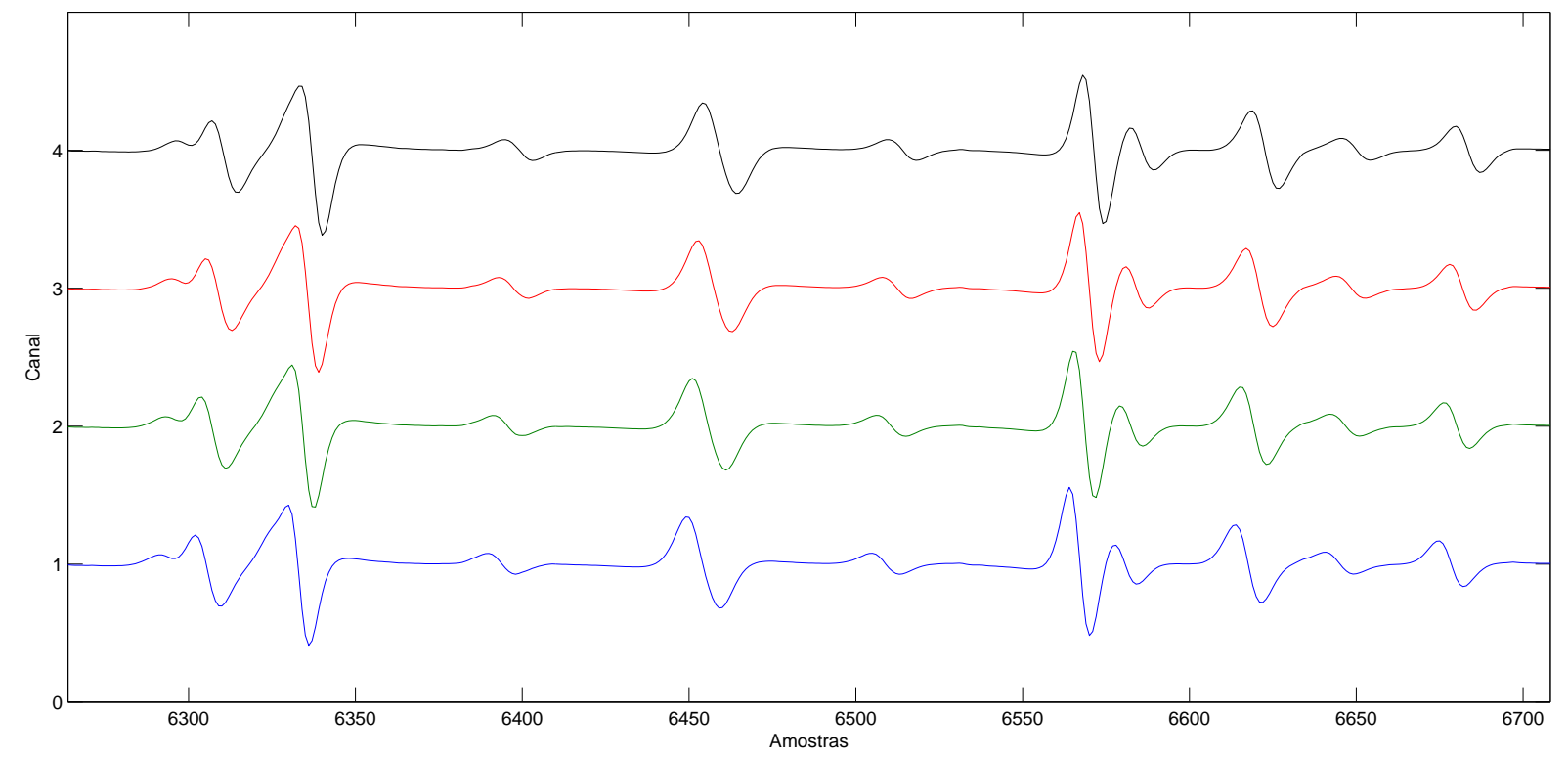

Figura 4.1: Representação dos resultados para a primeira coluna de eletrodos, posicionada paralela às fibras musculares e sobre o eixo Z. Existe pouca variação na amplitude e ocorre atraso em função da distância entre os eletrodos. 


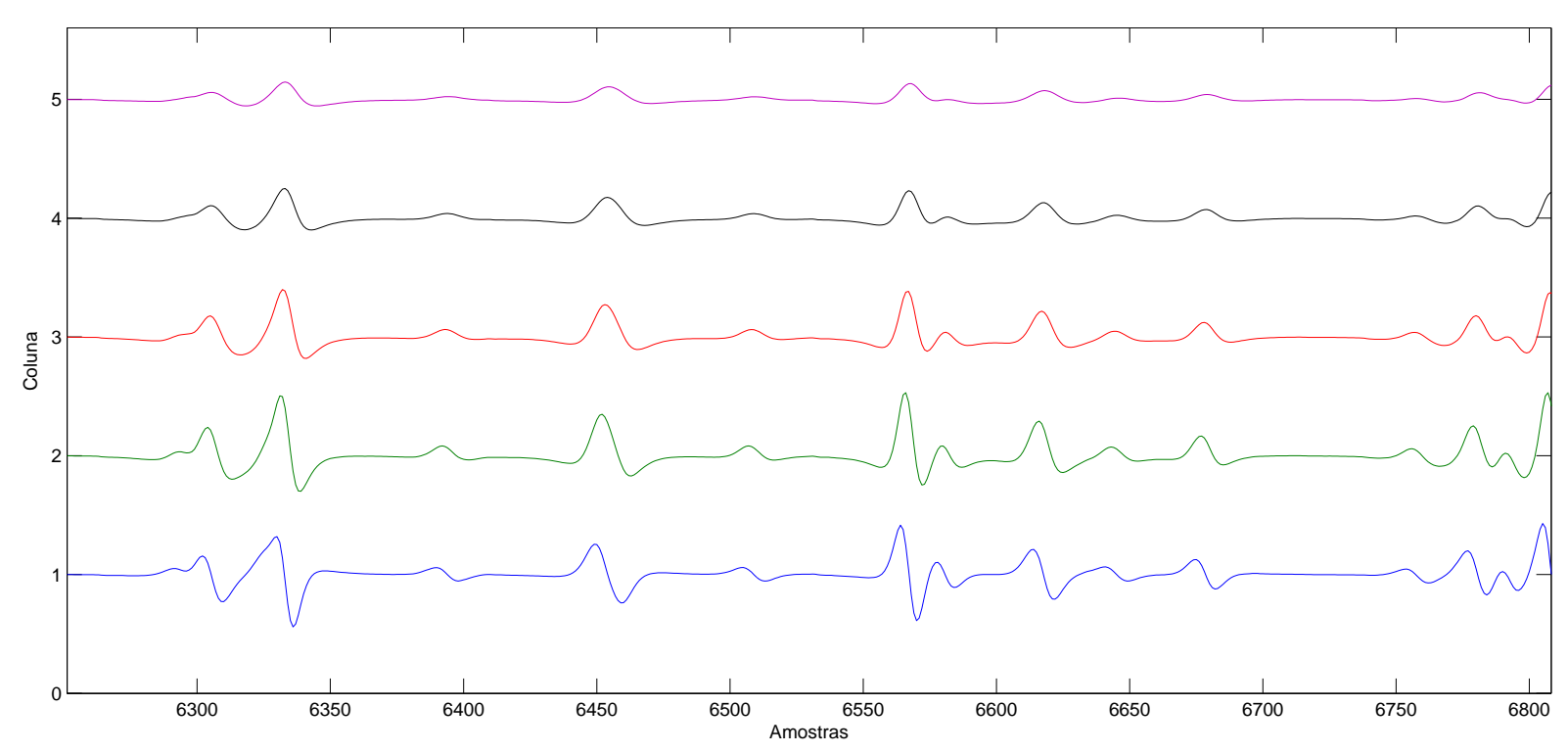

Figura 4.2: Representação dos resultados para a primeira linha de eletrodos, posicionada perpendicular às fibras musculares e sobre o eixo x. Existe grande variação na amplitude em função das variações no volume condutor.

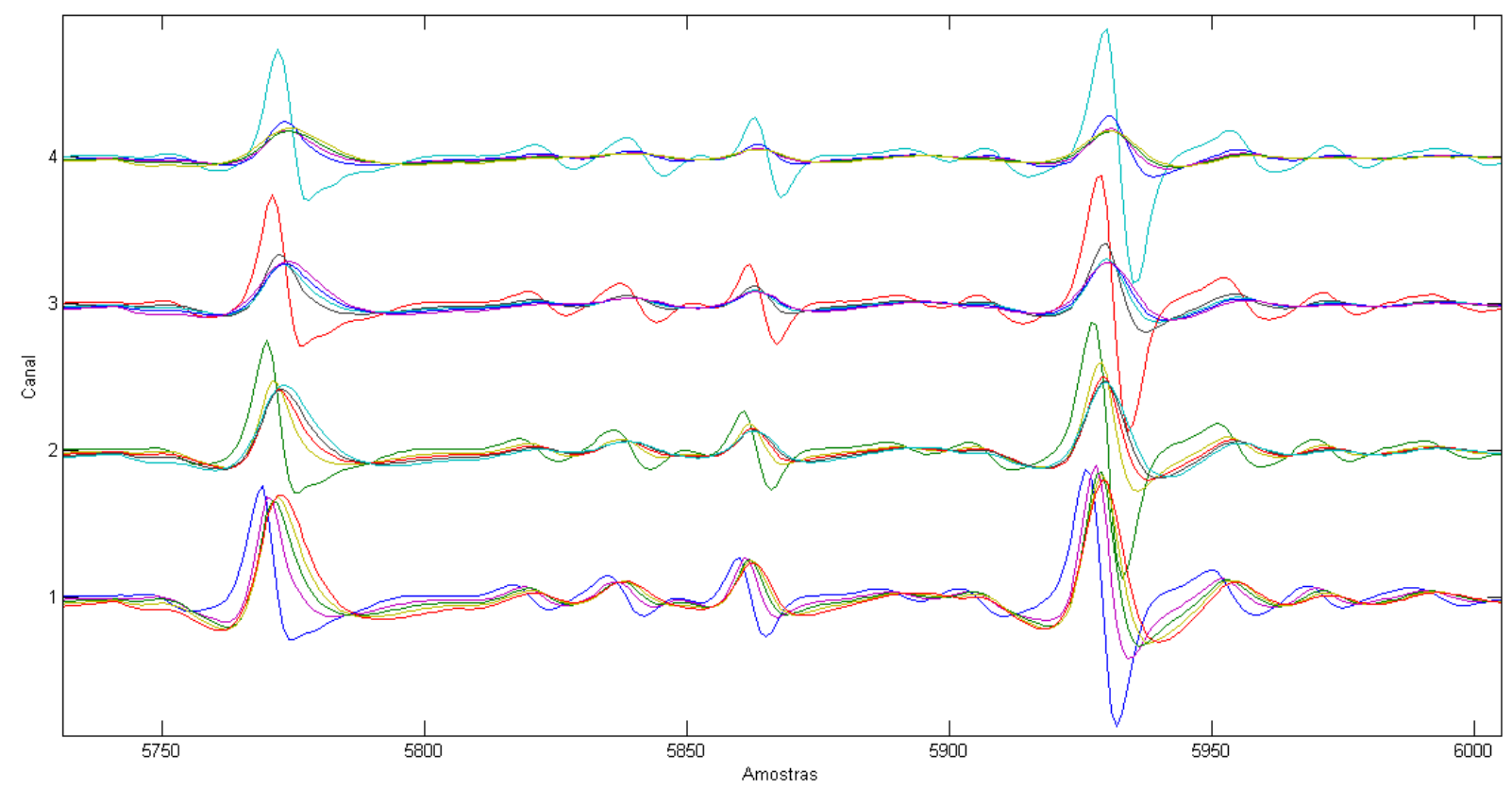

Figura 4.3: Representação 2-D da simulação de uma matriz 4x5, utilizando os parâmetros estabelecidos na Tabela 3.1. Cada conjunto de sinais representa uma mesma linha de eletrodos, onde os sinais das 5 colunas estão reunidos. Os sinais de maior amplitude são os posicionados diretamente sobre a fibra muscular. 


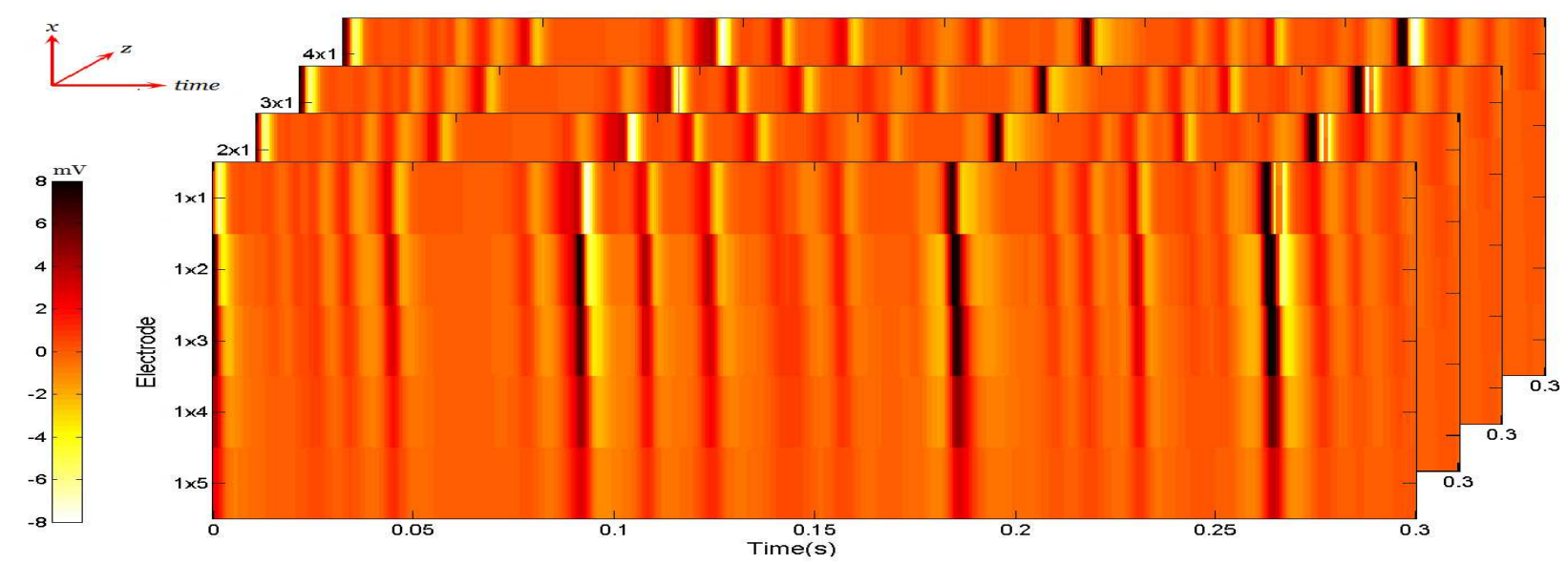

Figura 4.4: Resultados da simulação de uma matriz 4x5, utilizando os parâmetros estabelecidos na Tabela 3.1. Cada plano apresenta o resultado de um linha de cinco eletrodos, onde o primeiro está posicionado com distância horizontal nula, enquanto o quinto elemento está a $12 \mathrm{~mm}$ na direção $x$. O decaimento da amplitude do sinal é resultado da variação das camadas do volume condutor em função do angulo $\alpha$. A tonalidade escura indica os pontos em que a amplitude do sinal de EMG é máxima, enquanto a cor branca indica os pontos de mínimo. Os potenciais de ação estão se propagando da esquerda para a direita.

\subsection{Sinal utilizado para testes}

Para a execução dos testes, foi realizada a escolha arbitrária de um dos canais de EMG-S simulados. O sinal possui 1025 amostras e foi gerado com as configurações estabelecidas na Tabela 3.1. O sinal é apresentado pela Figura 4.5. O sinal foi filtrado com o banco de filtros de análise, conforme apresentado na secção 4.4

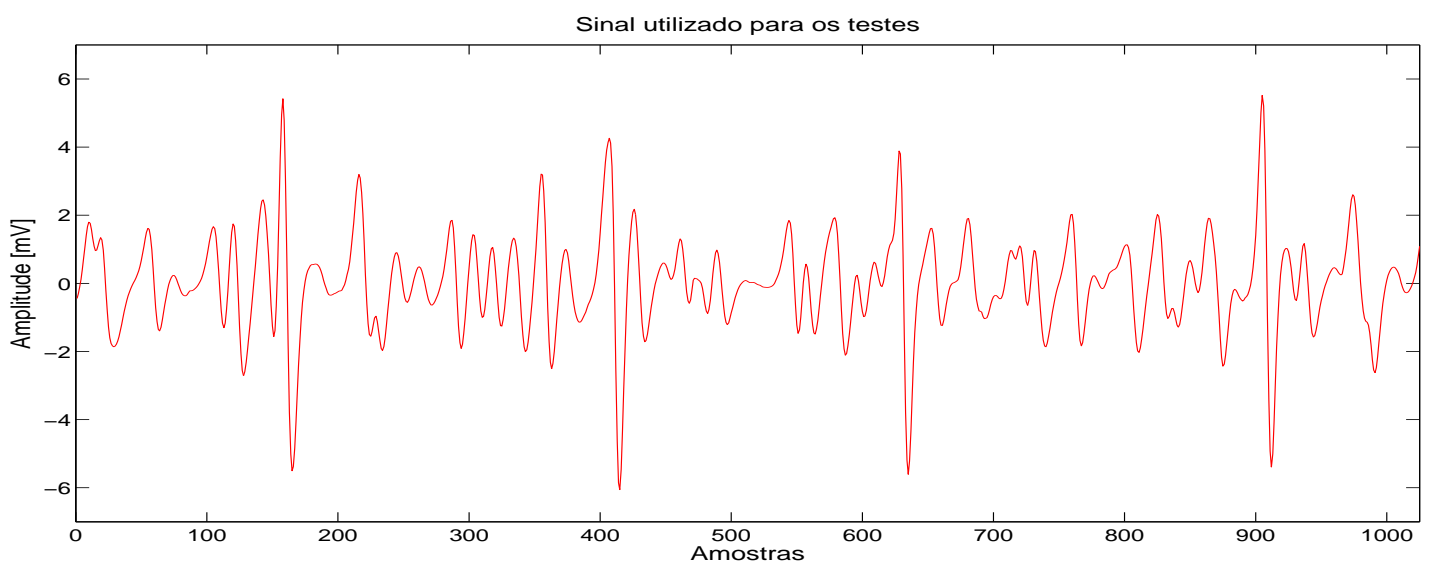

Figura 4.5: Sinal utilizado como referência para os testes. O sinal possui 1025 amostras e foi obtido através de simulação. Os parâmetros característicos do sinal estão apresentados na Tabela 3.1 


\subsection{Decomposição do sinal em 32 sub-bandas de frequência.}

A convolução do sinal ilustrado na Figura 4.5 com o banco de filtros resultou na decomposição em 32 sub-bandas esparsas no domínio da frequência. Este processo está representado pelas Figuras 4.6(a) e 4.6(b), que apresentam o resultado das 15 primeiras sub-bandas. Para cada uma, é mostrado sua representação temporal e o respectivo espectro em frequência.
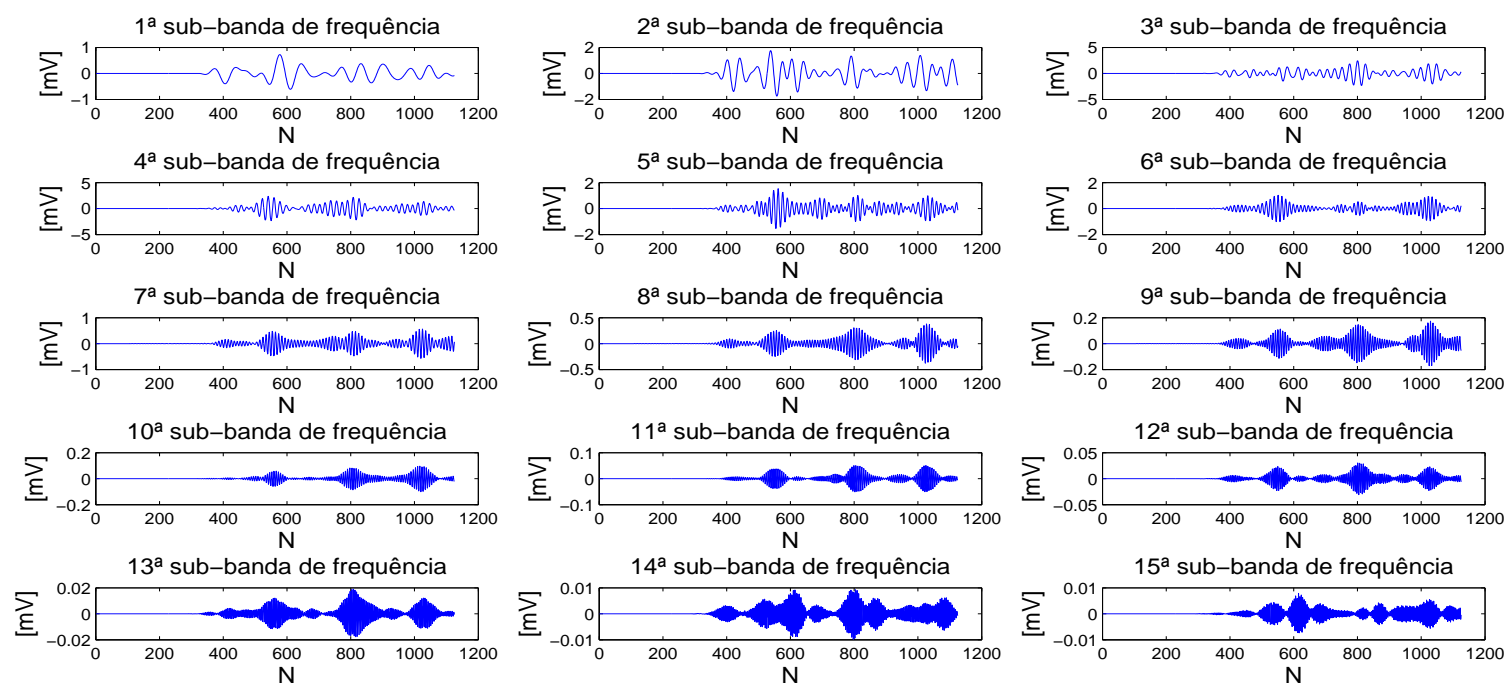

(a) Tempo
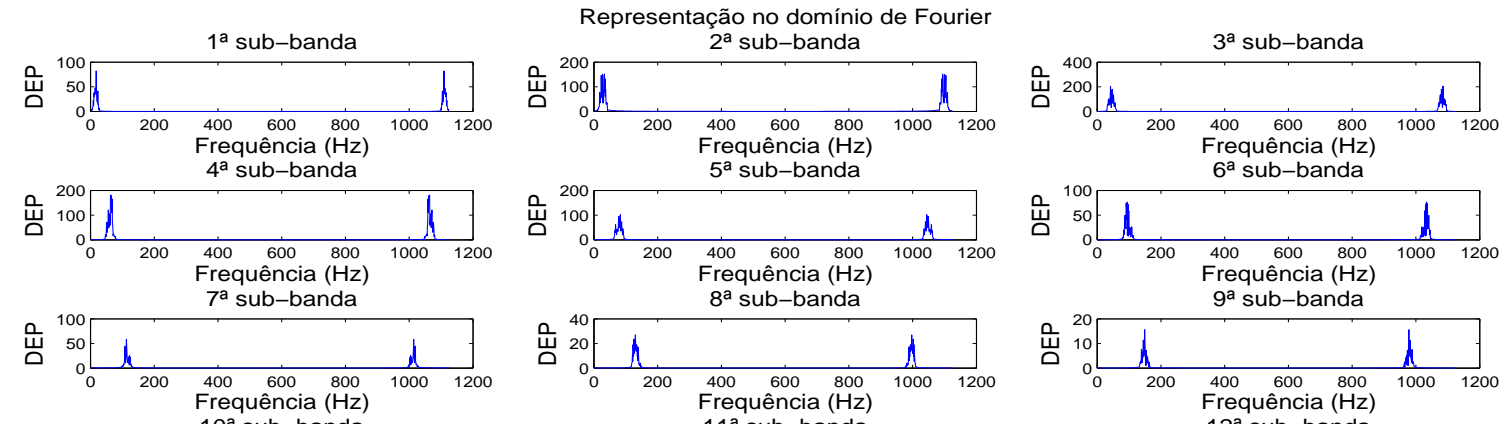

$11^{\text {a }}$ sub-banda
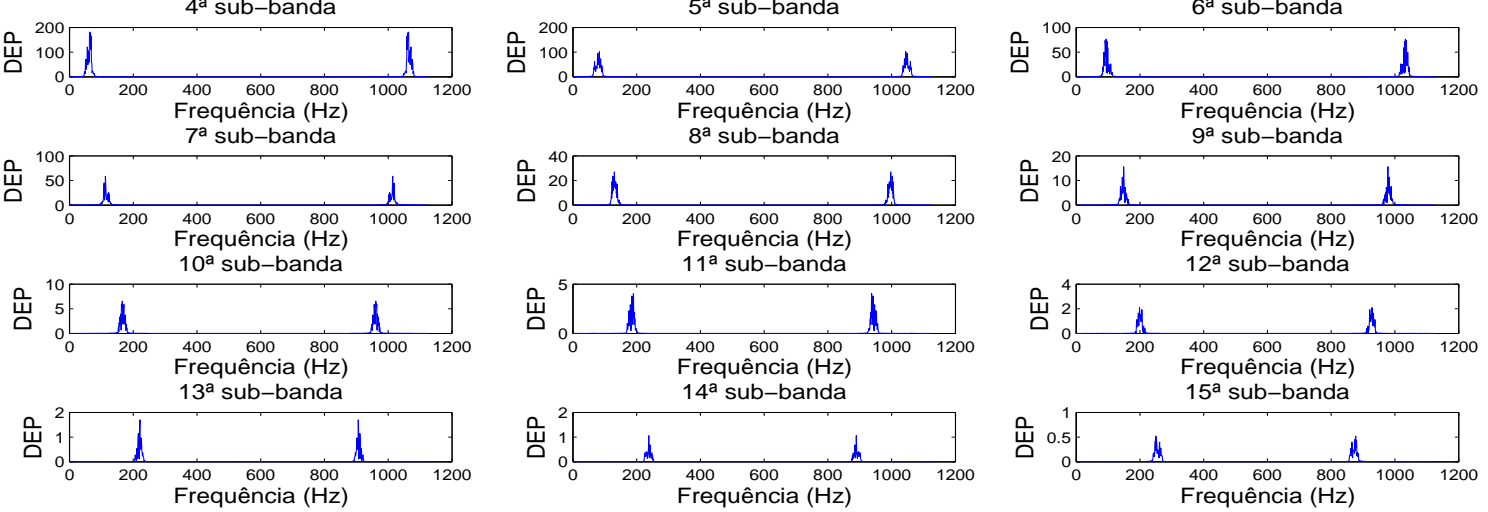

(b) Frequência

Figura 4.6: Decomposição do sinal em sub-bandas de frequência para esparsificação. Cada componente equivale a uma largura de banda de $15 \mathrm{~Hz}$. a) Representação temporal das primeiras 15 sub-bandas do sinal de EMG-S. b) Representação no domínio da frequência, onde é possível observar que a resposta se aproxima de um impulso, que pode ser assumido como esparso. 


\subsection{Resultados da rotina apresentada no fluxograma da Figura 3.5}

A rotina apresentada na Figura 3.5 foi implementada através de laços de repetição. Todas as combinações possíveis foram executadas 30 vezes e o resultado foi disposto nas Tabelas 4.1 a 4.7. A amostragem foi realizada primeiramente de maneira padrão, utilizando a matriz tradicional apresentada na seç̧ão 3.3.2. Após a execução de todas as iterações, o processo foi repetido, porém a matriz de aquisição foi substituída por uma matriz gerada aleatoriamente. Para fins de comparação, os resultados também estão dispostos nas Tabelas 4.1 a 4.7. 
Tabela 4.1: Resultados da rotina apresentada na Figura 3.5 para um intervalo de 5 pontos

\begin{tabular}{|c|c|c|c|}
\hline & & Amostragem Padrão & Amostragem Ponderada \\
\hline Norma & Amostras & $\mathrm{SSR}(\mathrm{dB})$ & $\mathrm{SSR}(\mathrm{dB})$ \\
\hline \multirow{5}{*}{$\mathrm{L}=1$} & 0.05 & 2.12 & 1.59 \\
\hline & 0.1 & 8.16 & 7.92 \\
\hline & 0.2 & 23.75 & 24.26 \\
\hline & 0.3 & 32.32 & 33.11 \\
\hline & 0.4 & 37.60 & 38.44 \\
\hline \multirow{5}{*}{$L_{p}=0.75$} & 0.05 & 2.31 & 1.26 \\
\hline & 0.1 & 13.86 & 13.71 \\
\hline & 0.2 & 30.46 & 31.10 \\
\hline & 0.3 & 36.41 & 36.97 \\
\hline & 0.4 & 39.60 & 40.61 \\
\hline \multirow{5}{*}{$L_{p}=0.5$} & 0.05 & 1.75 & 1.41 \\
\hline & 0.1 & 16.98 & 16.10 \\
\hline & 0.2 & 28.81 & 31.75 \\
\hline & 0.3 & 36.97 & 37.35 \\
\hline & 0.4 & 40.13 & 40.79 \\
\hline \multirow{5}{*}{$L_{p}=0.25$} & 0.05 & 2.08 & 0.72 \\
\hline & 0.1 & 16.64 & 17.85 \\
\hline & 0.2 & 29.39 & 32.19 \\
\hline & 0.3 & 36.01 & 37.30 \\
\hline & 0.4 & 39.51 & 40.81 \\
\hline \multirow{5}{*}{$L_{p}=0.15$} & 0.05 & 1.34 & 0.77 \\
\hline & 0.1 & 16.15 & 17.90 \\
\hline & 0.2 & 29.44 & 32.05 \\
\hline & 0.3 & 35.44 & 37.43 \\
\hline & 0.4 & 39.24 & 40.54 \\
\hline \multirow{5}{*}{$L_{p}=0.05$} & 0.05 & 1.07 & 0.88 \\
\hline & 0.1 & 16.40 & 17.29 \\
\hline & 0.2 & 29.64 & 31.96 \\
\hline & 0.3 & 35.43 & 37.23 \\
\hline & 0.4 & 38.85 & 40.71 \\
\hline \multirow{5}{*}{$L_{p}=0.0005$} & 0.05 & 1.27 & 0.62 \\
\hline & 0.1 & 18.65 & 16.91 \\
\hline & 0.2 & 25.97 & 32.22 \\
\hline & 0.3 & 27.84 & 37.17 \\
\hline & 0.4 & 29.75 & 40.66 \\
\hline
\end{tabular}


Tabela 4.2: Resultados da rotina apresentada na Figura 3.5 para um intervalo de 10 pontos

\begin{tabular}{|c|c|c|c|}
\hline & & Amostragem Padrão & Amostragem Ponderada \\
\hline Norma & Amostras & $\mathrm{SSR}(\mathrm{dB})$ & $\mathrm{SSR}(\mathrm{dB})$ \\
\hline \multirow{5}{*}{$\mathrm{L}=1$} & 0.05 & 1.38 & 1.42 \\
\hline & 0.1 & 8.49 & 7.58 \\
\hline & 0.2 & 22.43 & 22.31 \\
\hline & 0.3 & 31.25 & 31.85 \\
\hline & 0.4 & 34.76 & 36.48 \\
\hline \multirow{5}{*}{$L_{p}=0.75$} & 0.05 & 1.54 & 1.57 \\
\hline & 0.1 & 12.45 & 12.10 \\
\hline & 0.2 & 28.18 & 31.04 \\
\hline & 0.3 & 34.75 & 37.06 \\
\hline & 0.4 & 38.99 & 40.65 \\
\hline \multirow{5}{*}{$L_{p}=0.5$} & 0.05 & 1.99 & 1.78 \\
\hline & 0.1 & 15.97 & 16.02 \\
\hline & 0.2 & 29.31 & 31.95 \\
\hline & 0.3 & 36.24 & 37.44 \\
\hline & 0.4 & 38.58 & 40.64 \\
\hline \multirow{5}{*}{$L_{p}=0.25$} & 0.05 & 1.24 & 0.47 \\
\hline & 0.1 & 15.92 & 16.60 \\
\hline & 0.2 & 28.83 & 32.39 \\
\hline & 0.3 & 34.66 & 37.04 \\
\hline & 0.4 & 39.21 & 40.42 \\
\hline \multirow{5}{*}{$L_{p}=0.15$} & 0.05 & 0.79 & 1.10 \\
\hline & 0.1 & 16.32 & 15.86 \\
\hline & 0.2 & 29.79 & 31.77 \\
\hline & 0.3 & 35.67 & 37.32 \\
\hline & 0.4 & 37.84 & 40.50 \\
\hline \multirow{5}{*}{$L_{p}=0.05$} & 0.05 & 0.84 & 0.49 \\
\hline & 0.1 & 15.47 & 16.48 \\
\hline & 0.2 & 29.70 & 31.79 \\
\hline & 0.3 & 35.77 & 37.19 \\
\hline & 0.4 & 37.83 & 40.26 \\
\hline \multirow{5}{*}{$L_{p}=0.0005$} & 0.05 & 1.47 & 0.68 \\
\hline & 0.1 & 18.82 & 17.09 \\
\hline & 0.2 & 26.26 & 32.06 \\
\hline & 0.3 & 28.73 & 37.06 \\
\hline & 0.4 & 30.34 & 40.22 \\
\hline
\end{tabular}


Tabela 4.3: Resultados da rotina apresentada na Figura 3.5 para um intervalo de 20 pontos

\begin{tabular}{|c|c|c|c|}
\hline & & Amostragem Padrão & Amostragem Ponderada \\
\hline Norma & Amostras & $\mathrm{SSR}(\mathrm{dB})$ & $\mathrm{SSR}(\mathrm{dB})$ \\
\hline \multirow{5}{*}{$\mathrm{L}=1$} & 0.05 & 1.29 & 1.31 \\
\hline & 0.1 & 6.73 & 6.42 \\
\hline & 0.2 & 18.72 & 17.63 \\
\hline & 0.3 & 23.24 & 22.96 \\
\hline & 0.4 & 24.01 & 24.57 \\
\hline \multirow{5}{*}{$L_{p}=0.75$} & 0.05 & 1.31 & 1.23 \\
\hline & 0.1 & 11.12 & 10.56 \\
\hline & 0.2 & 23.42 & 27.24 \\
\hline & 0.3 & 28.03 & 30.05 \\
\hline & 0.4 & 29.91 & 31.33 \\
\hline \multirow{5}{*}{$L_{p}=0.5$} & 0.05 & 0.81 & 1.15 \\
\hline & 0.1 & 12.52 & 12.79 \\
\hline & 0.2 & 26.65 & 30.99 \\
\hline & 0.3 & 30.43 & 34.50 \\
\hline & 0.4 & 34.60 & 36.30 \\
\hline \multirow{5}{*}{$L_{p}=0.25$} & 0.05 & 1.19 & 0.47 \\
\hline & 0.1 & 15.06 & 14.76 \\
\hline & 0.2 & 27.91 & 31.74 \\
\hline & 0.3 & 32.97 & 35.67 \\
\hline & 0.4 & 35.56 & 37.54 \\
\hline \multirow{5}{*}{$L_{p}=0.15$} & 0.05 & 0.31 & 0.35 \\
\hline & 0.1 & 14.84 & 15.08 \\
\hline & 0.2 & 27.30 & 31.82 \\
\hline & 0.3 & 33.04 & 36.30 \\
\hline & 0.4 & 33.46 & 37.50 \\
\hline \multirow{5}{*}{$L_{p}=0.05$} & 0.05 & 0.88 & 0.63 \\
\hline & 0.1 & 14.32 & 15.47 \\
\hline & 0.2 & 26.74 & 31.59 \\
\hline & 0.3 & 31.58 & 35.65 \\
\hline & 0.4 & 35.09 & 37.74 \\
\hline \multirow{5}{*}{$L_{p}=0.0005$} & 0.05 & 1.13 & 0.80 \\
\hline & 0.1 & 18.25 & 14.70 \\
\hline & 0.2 & 24.54 & 31.73 \\
\hline & 0.3 & 26.77 & 36.02 \\
\hline & 0.4 & 28.04 & 37.94 \\
\hline
\end{tabular}


Tabela 4.4: Resultados da rotina apresentada na Figura 3.5 para um intervalo de 30 pontos

\begin{tabular}{|c|c|c|c|}
\hline & & Amostragem Padrão & Amostragem Ponderada \\
\hline Norma & Amostras & $\mathrm{SSR}(\mathrm{dB})$ & $\mathrm{SSR}(\mathrm{dB})$ \\
\hline \multirow{5}{*}{$\mathrm{L}=1$} & 0.05 & 1.28 & 0.96 \\
\hline & 0.1 & 6.58 & 5.85 \\
\hline & 0.2 & 14.81 & 14.85 \\
\hline & 0.3 & 16.77 & 17.05 \\
\hline & 0.4 & 17.46 & 17.76 \\
\hline \multirow{5}{*}{$L_{p}=0.75$} & 0.05 & 1.35 & 1.06 \\
\hline & 0.1 & 10.67 & 10.14 \\
\hline & 0.2 & 19.22 & 21.01 \\
\hline & 0.3 & 20.82 & 21.75 \\
\hline & 0.4 & 21.03 & 22.15 \\
\hline \multirow{5}{*}{$L_{p}=0.5$} & 0.05 & 1.47 & 1.07 \\
\hline & 0.1 & 12.34 & 13.15 \\
\hline & 0.2 & 22.32 & 24.15 \\
\hline & 0.3 & 24.11 & 25.65 \\
\hline & 0.4 & 25.58 & 26.17 \\
\hline \multirow{5}{*}{$L_{p}=0.25$} & 0.05 & 1.09 & 0.90 \\
\hline & 0.1 & 13.84 & 14.67 \\
\hline & 0.2 & 25.49 & 26.47 \\
\hline & 0.3 & 26.50 & 27.41 \\
\hline & 0.4 & 28.12 & 28.33 \\
\hline \multirow{5}{*}{$L_{p}=0.15$} & 0.05 & 0.60 & 0.93 \\
\hline & 0.1 & 12.81 & 13.54 \\
\hline & 0.2 & 24.93 & 26.90 \\
\hline & 0.3 & 26.39 & 29.80 \\
\hline & 0.4 & 29.08 & 28.87 \\
\hline \multirow{5}{*}{$L_{p}=0.05$} & 0.05 & 0.59 & 0.92 \\
\hline & 0.1 & 12.27 & 14.79 \\
\hline & 0.2 & 24.66 & 26.73 \\
\hline & 0.3 & 27.29 & 28.89 \\
\hline & 0.4 & 28.20 & 30.31 \\
\hline \multirow{5}{*}{$L_{p}=0.0005$} & 0.05 & 1.33 & 0.92 \\
\hline & 0.1 & 17.24 & 13.84 \\
\hline & 0.2 & 24.04 & 28.41 \\
\hline & 0.3 & 24.92 & 28.96 \\
\hline & 0.4 & 25.63 & 29.41 \\
\hline
\end{tabular}


Tabela 4.5: Resultados da rotina apresentada na Figura 3.5 para um intervalo de 40 pontos

\begin{tabular}{|c|c|c|c|}
\hline & & Amostragem Padrão & Amostragem Ponderada \\
\hline Norma & Amostras & $\mathrm{SSR}(\mathrm{dB})$ & $\mathrm{SSR}(\mathrm{dB})$ \\
\hline \multirow{5}{*}{$\mathrm{L}=1$} & 0.05 & 0.93 & 1.28 \\
\hline & 0.1 & 6.15 & 5.80 \\
\hline & 0.2 & 13.89 & 14.30 \\
\hline & 0.3 & 14.89 & 15.27 \\
\hline & 0.4 & 15.23 & 15.56 \\
\hline \multirow{5}{*}{$L_{p}=0.75$} & 0.05 & 1.47 & 0.65 \\
\hline & 0.1 & 11.09 & 9.13 \\
\hline & 0.2 & 18.07 & 18.29 \\
\hline & 0.3 & 18.20 & 18.67 \\
\hline & 0.4 & 18.31 & 18.69 \\
\hline \multirow{5}{*}{$L_{p}=0.5$} & 0.05 & 1.16 & 1.08 \\
\hline & 0.1 & 12.37 & 12.84 \\
\hline & 0.2 & 20.11 & 21.22 \\
\hline & 0.3 & 20.24 & 21.05 \\
\hline & 0.4 & 20.89 & 20.73 \\
\hline \multirow{5}{*}{$L_{p}=0.25$} & 0.05 & 0.88 & 0.65 \\
\hline & 0.1 & 13.91 & 14.18 \\
\hline & 0.2 & 22.04 & 22.80 \\
\hline & 0.3 & 21.68 & 22.11 \\
\hline & 0.4 & 22.01 & 21.19 \\
\hline \multirow{5}{*}{$L_{p}=0.15$} & 0.05 & 0.74 & 0.78 \\
\hline & 0.1 & 12.40 & 14.12 \\
\hline & 0.2 & 22.19 & 23.63 \\
\hline & 0.3 & 21.48 & 22.10 \\
\hline & 0.4 & 21.59 & 21.38 \\
\hline \multirow{5}{*}{$L_{p}=0.05$} & 0.05 & 1.09 & 0.72 \\
\hline & 0.1 & 14.00 & 14.37 \\
\hline & 0.2 & 22.40 & 23.33 \\
\hline & 0.3 & 21.61 & 23.49 \\
\hline & 0.4 & 21.32 & 21.63 \\
\hline \multirow{5}{*}{$L_{p}=0.0005$} & 0.05 & 1.33 & 0.60 \\
\hline & 0.1 & 18.38 & 14.34 \\
\hline & 0.2 & 23.53 & 22.89 \\
\hline & 0.3 & 24.24 & 23.13 \\
\hline & 0.4 & 24.62 & 20.79 \\
\hline
\end{tabular}


Tabela 4.6: Resultados da rotina apresentada na Figura 3.5 para um intervalo de 50 pontos

\begin{tabular}{|c|c|c|c|}
\hline & & Amostragem Padrão & Amostragem Ponderada \\
\hline Norma & Amostras & $\mathrm{SSR}(\mathrm{dB})$ & $\mathrm{SSR}(\mathrm{dB})$ \\
\hline \multirow{5}{*}{$\mathrm{L}=1$} & 0.05 & 0.80 & 1.01 \\
\hline & 0.1 & 4.76 & 3.95 \\
\hline & 0.2 & 12.20 & 12.46 \\
\hline & 0.3 & 14.51 & 14.89 \\
\hline & 0.4 & 15.16 & 15.48 \\
\hline \multirow{5}{*}{$L_{p}=0.75$} & 0.05 & 1.02 & 0.81 \\
\hline & 0.1 & 8.23 & 7.07 \\
\hline & 0.2 & 16.45 & 17.91 \\
\hline & 0.3 & 17.61 & 18.40 \\
\hline & 0.4 & 18.22 & 18.46 \\
\hline \multirow{5}{*}{$L_{p}=0.5$} & 0.05 & 0.53 & 0.78 \\
\hline & 0.1 & 10.79 & 11.01 \\
\hline & 0.2 & 19.90 & 20.73 \\
\hline & 0.3 & 19.56 & 20.70 \\
\hline & 0.4 & 20.24 & 20.49 \\
\hline \multirow{5}{*}{$L_{p}=0.25$} & 0.05 & 0.96 & 0.67 \\
\hline & 0.1 & 11.71 & 12.91 \\
\hline & 0.2 & 20.45 & 22.29 \\
\hline & 0.3 & 22.11 & 21.51 \\
\hline & 0.4 & 21.70 & 21.79 \\
\hline \multirow{5}{*}{$L_{p}=0.15$} & 0.05 & 0.29 & 0.015 \\
\hline & 0.1 & 11.91 & 12.57 \\
\hline & 0.2 & 20.91 & 22.19 \\
\hline & 0.3 & 21.78 & 21.91 \\
\hline & 0.4 & 22.63 & 21.48 \\
\hline \multirow{5}{*}{$L_{p}=0.05$} & 0.05 & 0.87 & 0.089 \\
\hline & 0.1 & 12.50 & 12.07 \\
\hline & 0.2 & 21.32 & 22.22 \\
\hline & 0.3 & 22.31 & 23.13 \\
\hline & 0.4 & 21.70 & 21.66 \\
\hline \multirow{5}{*}{$L_{p}=0.0005$} & 0.05 & 0.99 & 0.46 \\
\hline & 0.1 & 17.35 & 11.73 \\
\hline & 0.2 & 23.50 & 22.39 \\
\hline & 0.3 & 24.55 & 22.97 \\
\hline & 0.4 & 25.65 & 22.12 \\
\hline
\end{tabular}


Tabela 4.7: Resultados da rotina apresentada na Figura 3.5 para um intervalo de 100 pontos Amostragem Padrão Amostragem Ponderada

\begin{tabular}{|c|c|c|c|}
\hline Norma & Amostras & $\mathrm{SSR}(\mathrm{dB})$ & $\mathrm{SSR}(\mathrm{dB})$ \\
\hline \multirow{5}{*}{$\mathrm{L}=1$} & 0.05 & 0.91 & 0.76 \\
\hline & 0.1 & 3.29 & 3.00 \\
\hline & 0.2 & 6.10 & 6.29 \\
\hline & 0.3 & 6.95 & 7.18 \\
\hline & 0.4 & 7.36 & 7.43 \\
\hline \multirow{5}{*}{$L_{p}=0.75$} & 0.05 & 0.35 & 0.49 \\
\hline & 0.1 & 5.25 & 4.22 \\
\hline & 0.2 & 9.62 & 10.89 \\
\hline & 0.3 & 10.26 & 11.11 \\
\hline & 0.4 & 10.73 & 11.27 \\
\hline \multirow{5}{*}{$L_{p}=0.5$} & 0.05 & 0.58 & 0.54 \\
\hline & 0.1 & 6.08 & 6.73 \\
\hline & 0.2 & 12.59 & 12.84 \\
\hline & 0.3 & 12.73 & 12.82 \\
\hline & 0.4 & 12.89 & 12.77 \\
\hline \multirow{5}{*}{$L_{p}=0.25$} & 0.05 & 0.56 & 0.025 \\
\hline & 0.1 & 7.12 & 8.38 \\
\hline & 0.2 & 12.62 & 13.09 \\
\hline & 0.3 & 12.78 & 12.80 \\
\hline & 0.4 & 12.75 & 12.75 \\
\hline \multirow{5}{*}{$L_{p}=0.15$} & 0.05 & 0.53 & 0.40 \\
\hline & 0.1 & 6.46 & 7.40 \\
\hline & 0.2 & 12.78 & 12.76 \\
\hline & 0.3 & 12.74 & 12.66 \\
\hline & 0.4 & 12.72 & 12.54 \\
\hline \multirow{5}{*}{$L_{p}=0.05$} & 0.05 & 0.36 & 0.17 \\
\hline & 0.1 & 7.45 & 8.35 \\
\hline & 0.2 & 12.58 & 12.63 \\
\hline & 0.3 & 12.81 & 12.64 \\
\hline & 0.4 & 12.80 & 12.59 \\
\hline \multirow{5}{*}{$L_{p}=0.0005$} & 0.05 & 1.10 & 0.26 \\
\hline & 0.1 & 12.36 & 8.86 \\
\hline & 0.2 & 15.96 & 12.76 \\
\hline & 0.3 & 16.61 & 12.60 \\
\hline & 0.4 & 15.99 & 12.50 \\
\hline
\end{tabular}




\subsubsection{Escolha dos parâmetros}

Após a realização de todas as combinações possíveis, o preenchimento das Tabelas 4.1 a 4.7 permitiu observar o comportamento dos parâmetros mencionados. Com objetivo de tornar a interpretação mais intuitiva, gráficos foram gerados para ilustrar tal comportamento. As Figuras 4.7(a) a 4.7(n) apresentam a relação SSR do sinal recuperado e do sinal original, em função do intervalo de pontos recuperado e do percentual de amostras utilizado. Para cada valor de norma $L_{p}$, representa-se na coluna da esquerda o SSR obtido com a matriz de aquisição tradicional, enquanto na coluna direita estão os resultados da matriz ponderada.

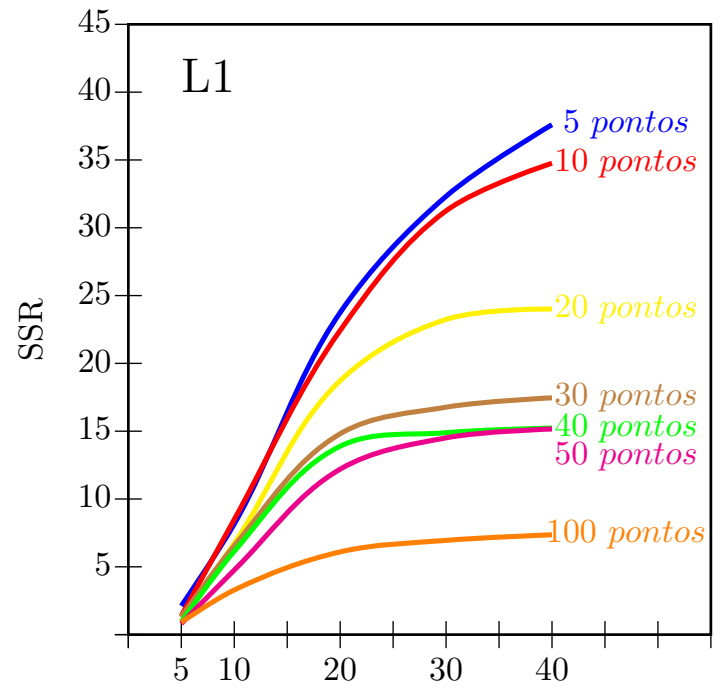

$\%$ de Amostras

(a)

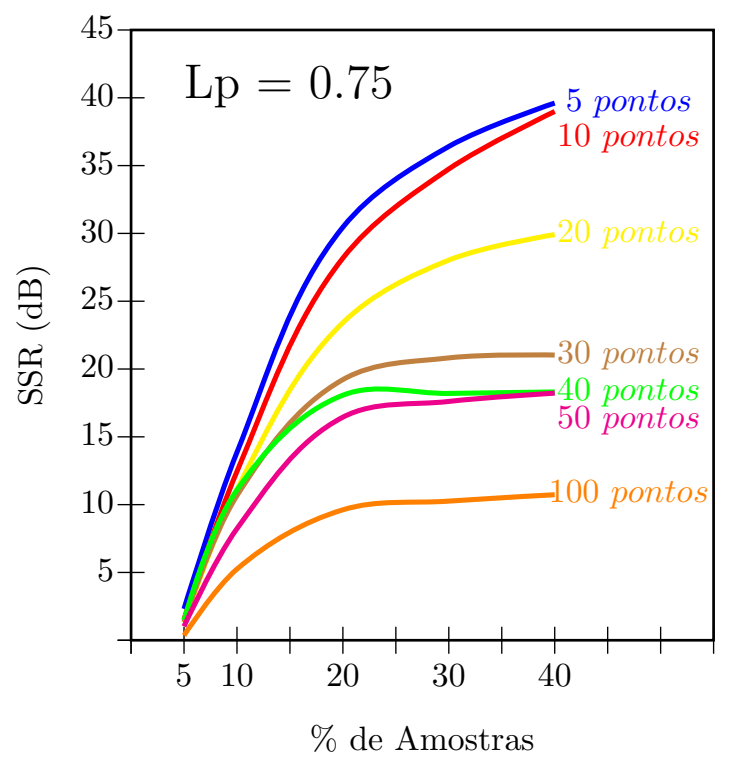

(c)

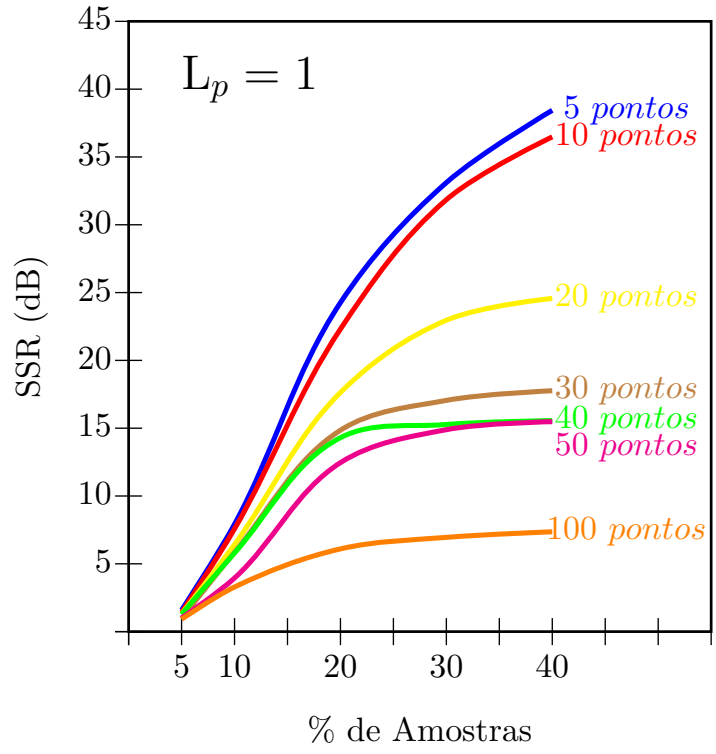

(b)

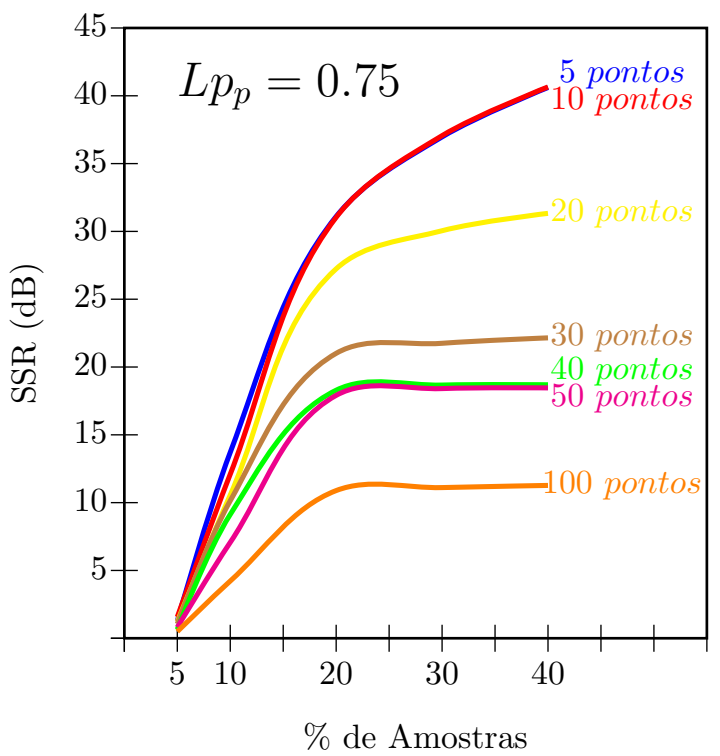

(d) 


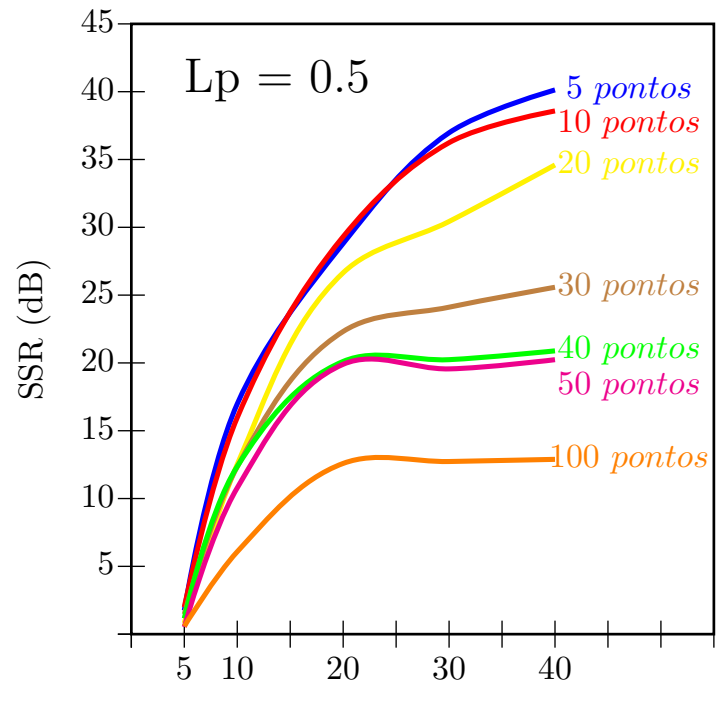

$\%$ de Amostras

(e)

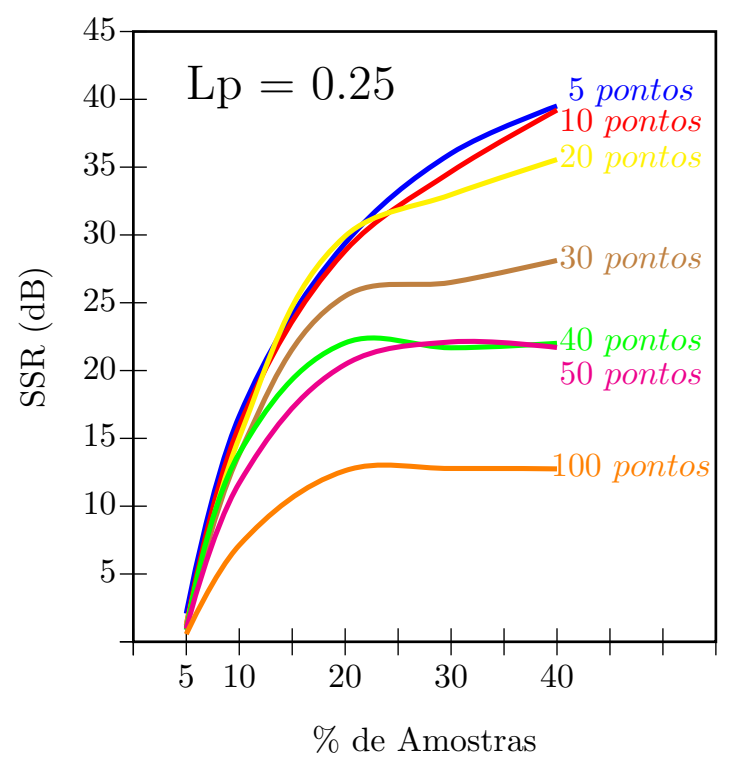

(g)

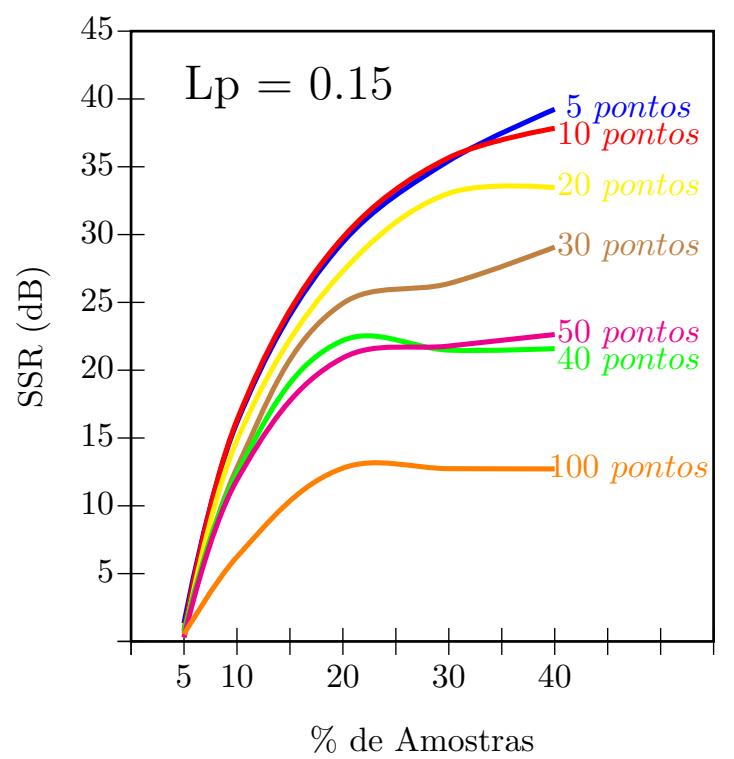

(i)

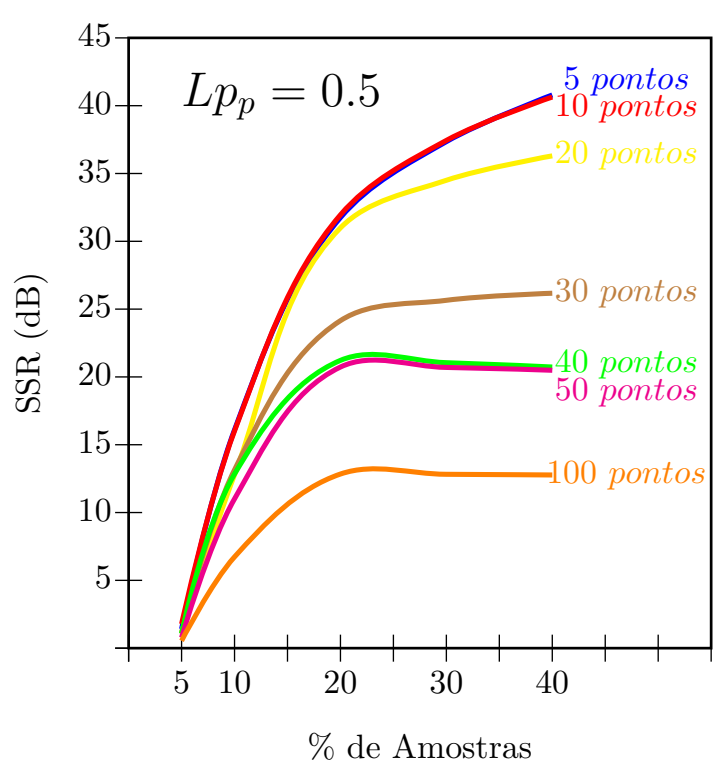

(f)

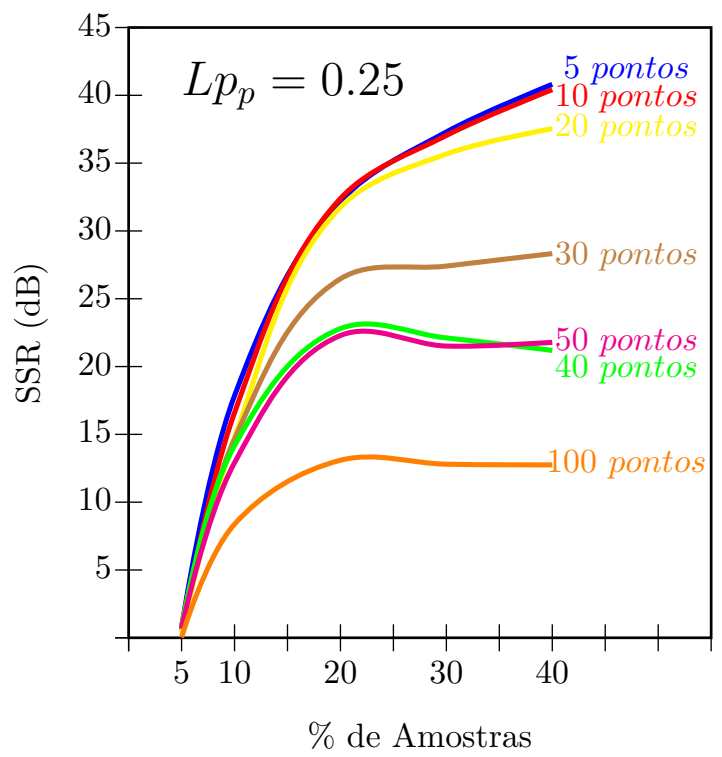

(h)

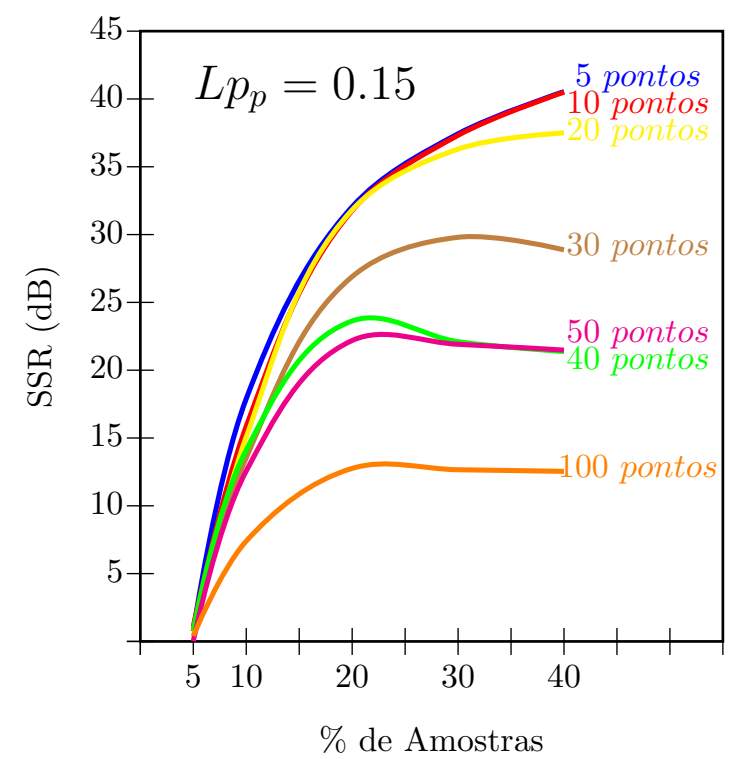

(j) 


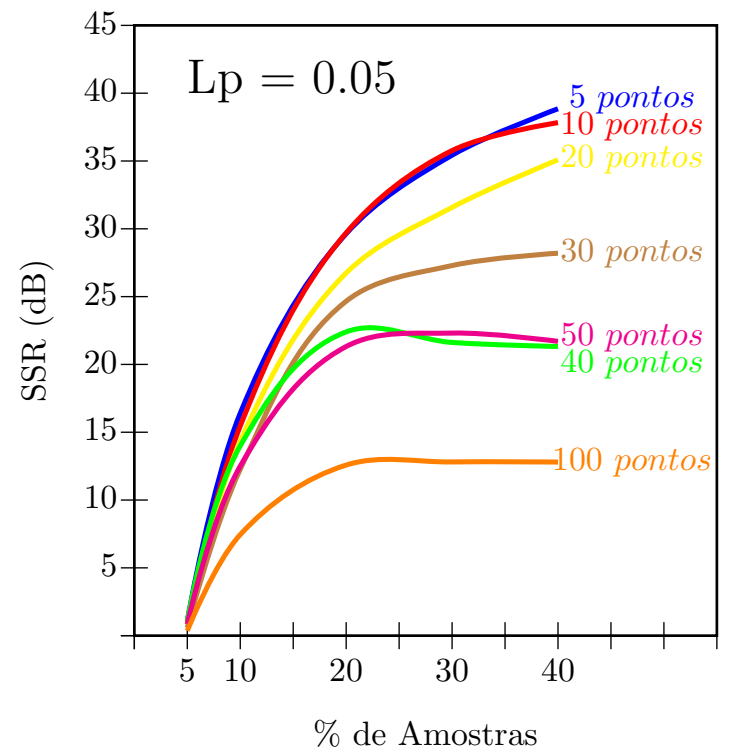

$(\mathrm{k})$

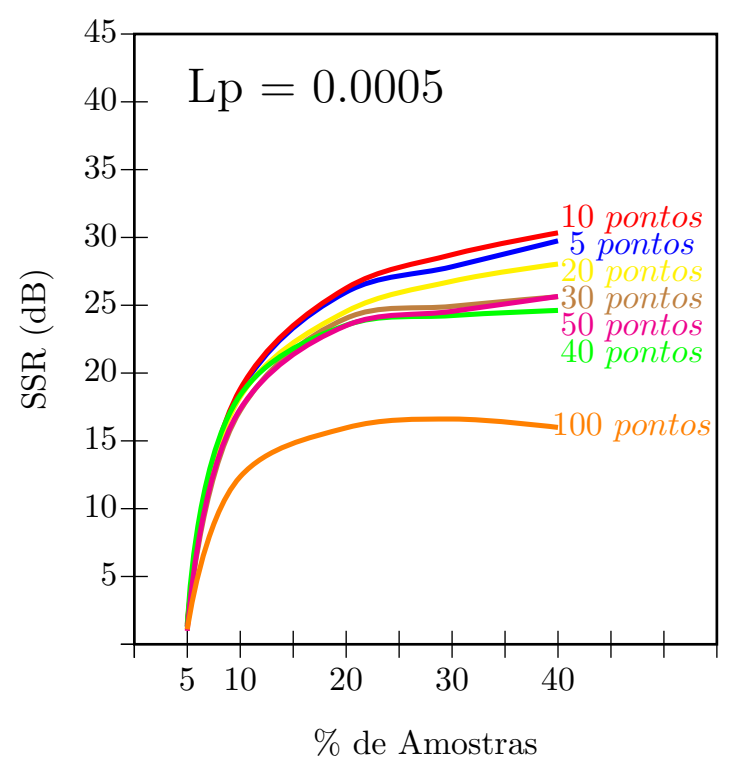

$(\mathrm{m})$

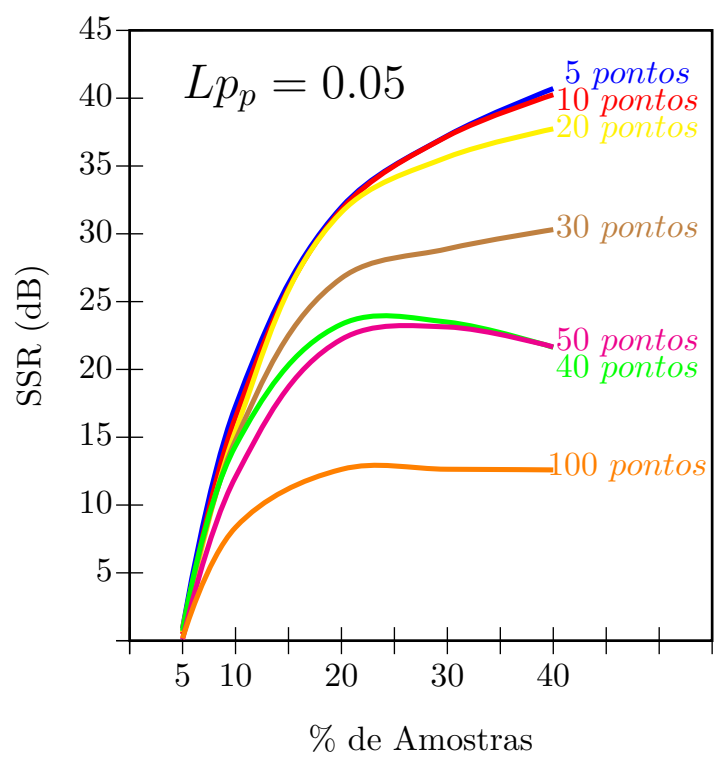

(1)

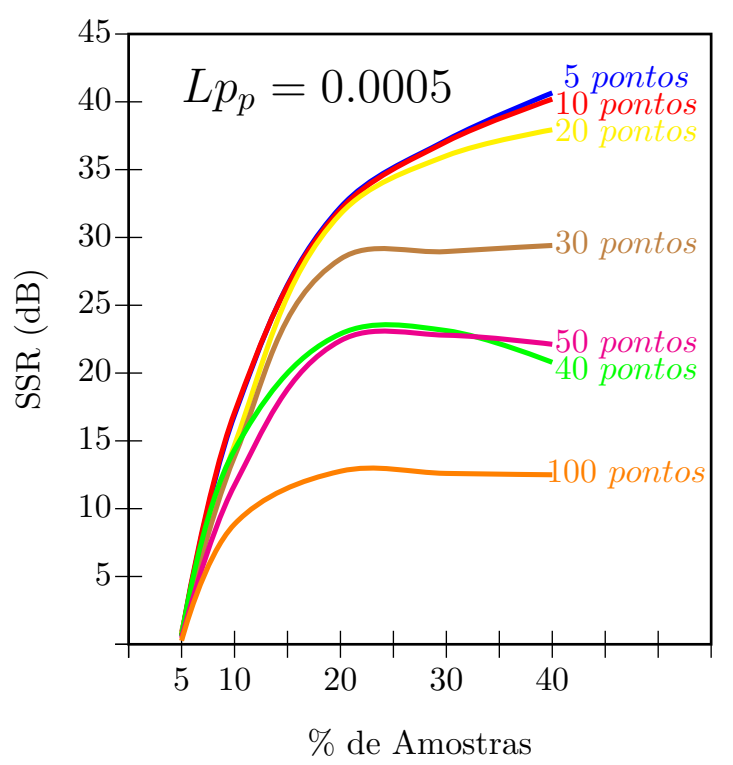

(n)

Figura 4.7: Representação do comportamento da medida de SSR em função do percentual de amostras utilizada. Representa-se também em cada uma das figuras, o efeito do aumento do numero de pontos perdidos. As Figuras a,c,e,g,i,k,m representam os resultados obtidos com a amostragem padrão, enquanto as Figuras b,d,f,h,j,l,n apresentam os resultados da amostragem ponderada. 
As figuras apresentadas nas Figuras 4.7(a) a 4.7(n) foram utilizadas para a decisão do intervalo de pontos que seria reconstruído. Para a escolha da norma $L_{p}$, novas figuras foram geradas. Desta vez, optou-se por utilizar como eixo horizontal a quantidade de pontos, de modo a observar como seria o comportamento das normas $L_{p}$ para os possíveis intervalos. Os resultados estão apresentados nas Figuras 4.8(a) a 4.8(e).

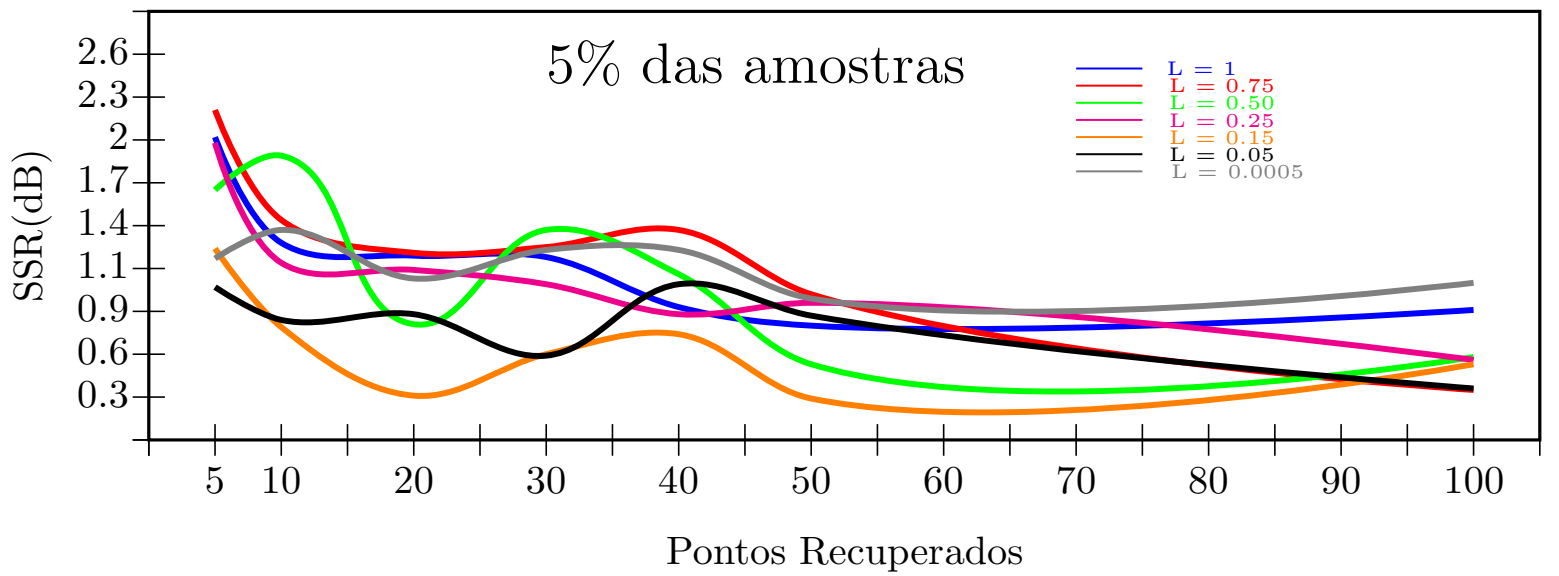

(a)

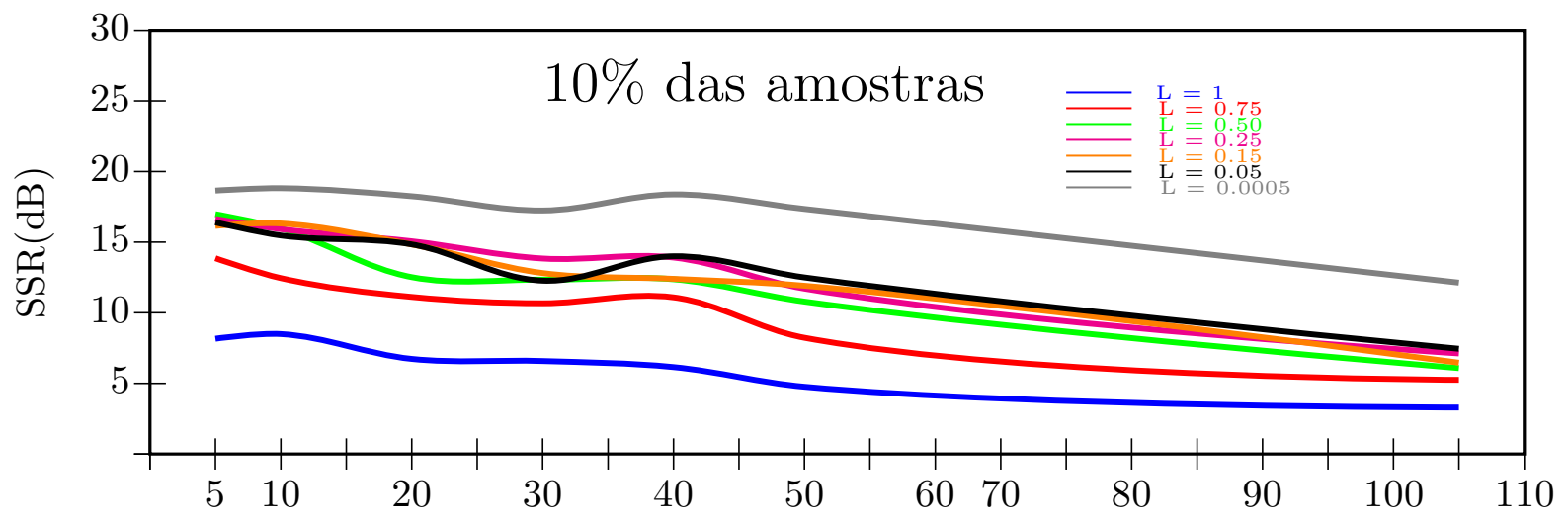

Pontos Recuperados

(b)

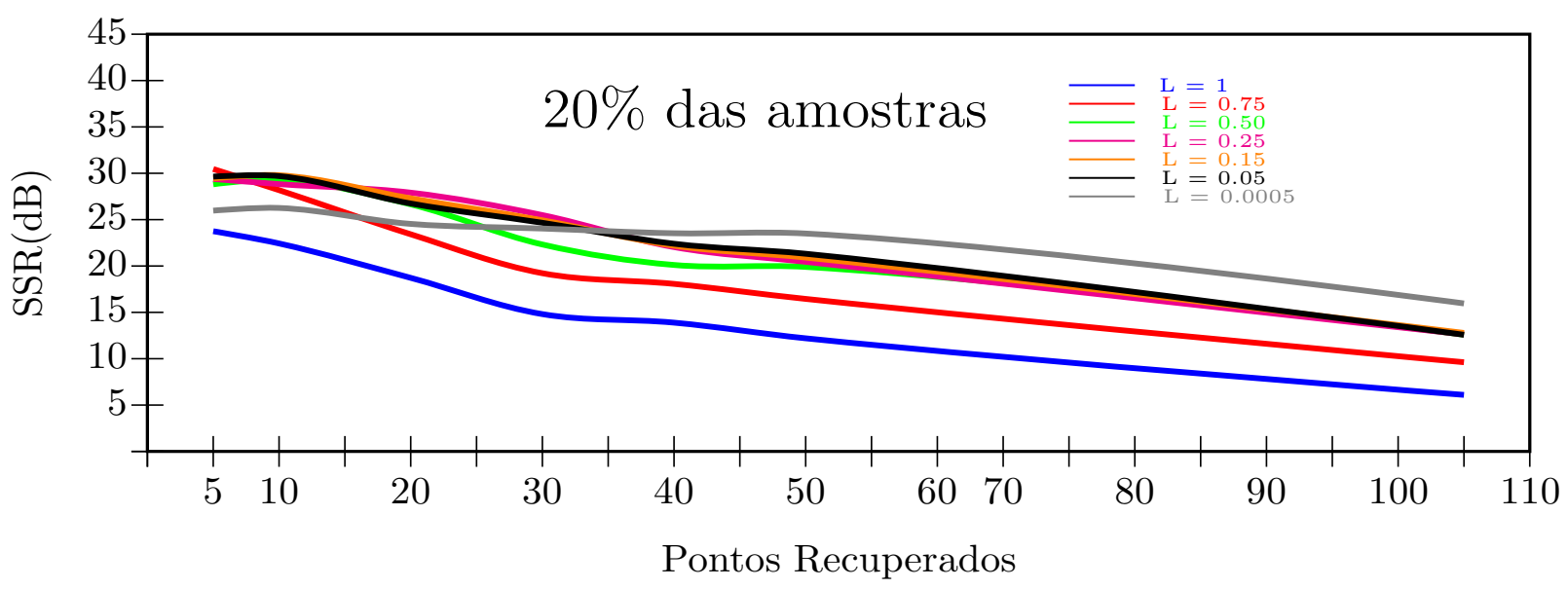

(c) 


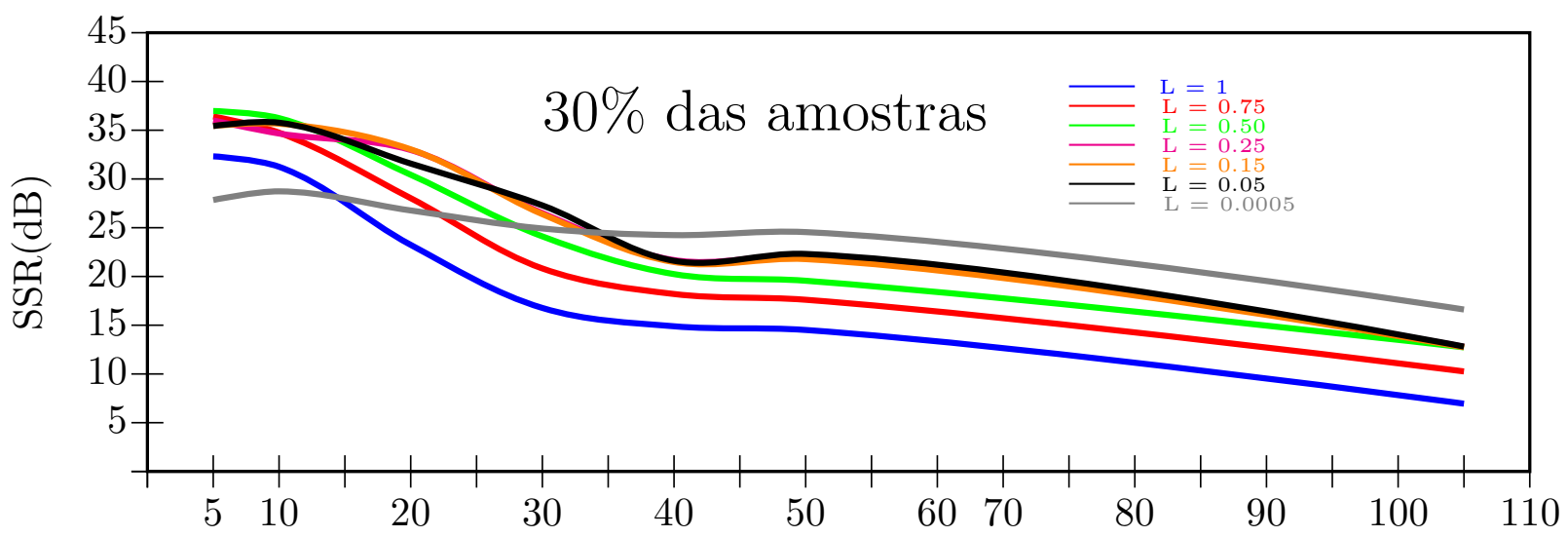

Pontos Recuperados

(d)

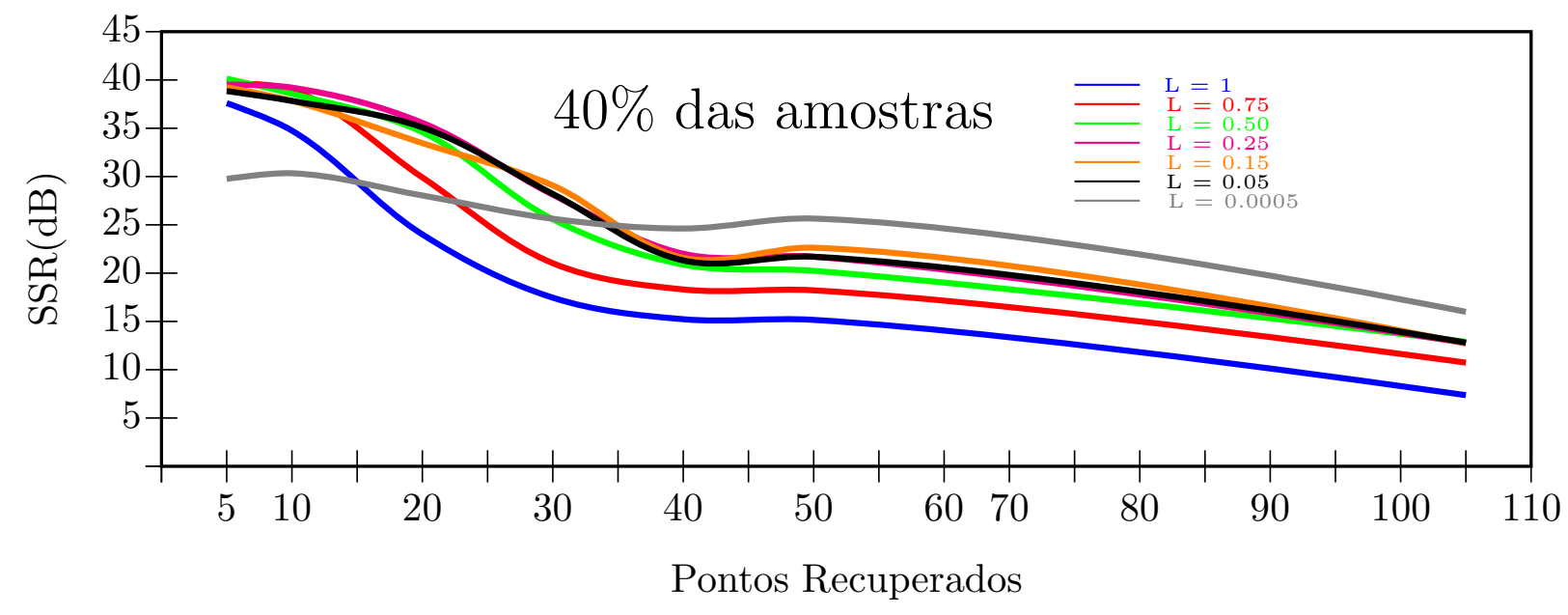

(e)

Figura 4.8: Visualização do comportamento das normas em função do aumento do número de pontos reconstruídos. A metrica $L_{p}=0.0005$ apresenta os melhores resultados em quase todos os casa, com exceção do caso em que é utilizado $5 \%$ das amostras. Neste caso, não existe definição clara do comportamento em decorrência do baixo numero de pontos utilizados e da reconstrução não ser ter qualidade satisfatória. 


\subsubsection{Definição dos parâmetros utilizados para uso no CS}

Os parâmetros adotados para os testes são apresentados na Tabela 4.8. Estas escolhas foram feitas com base nos resultados apresentados na simulação executada. A justificativa será feita na secção 6, porem oa valores são desde já apresentado para dar continuidade à execução dos testes.

Tabela 4.8: Parâmetros escolhidos após o fim dos testes experimentais

\begin{tabular}{cc}
\hline Parâmetro & Escolha realizada \\
\hline Percentual de Amostras & $20 \%$ \\
Norma $L_{p}$ & 0.005 \\
Intervalo de Reconstrução & 40 \\
Tipo de amostragem & Ponderada \\
\hline
\end{tabular}

\subsection{Aplicação do $C S$ nas Sub-bandas}

Após a definição dos parâmetros, aplicou-se o CS em cada uma das sub-bandas de frequência. Estas foram processadas e o resultado de cada componente é apresentado na Figura 4.9. Ainda não foi realizada a filtragem dos sinais reconstruídos, sendo a próxima etapa ilustrada na secção 4.7 .

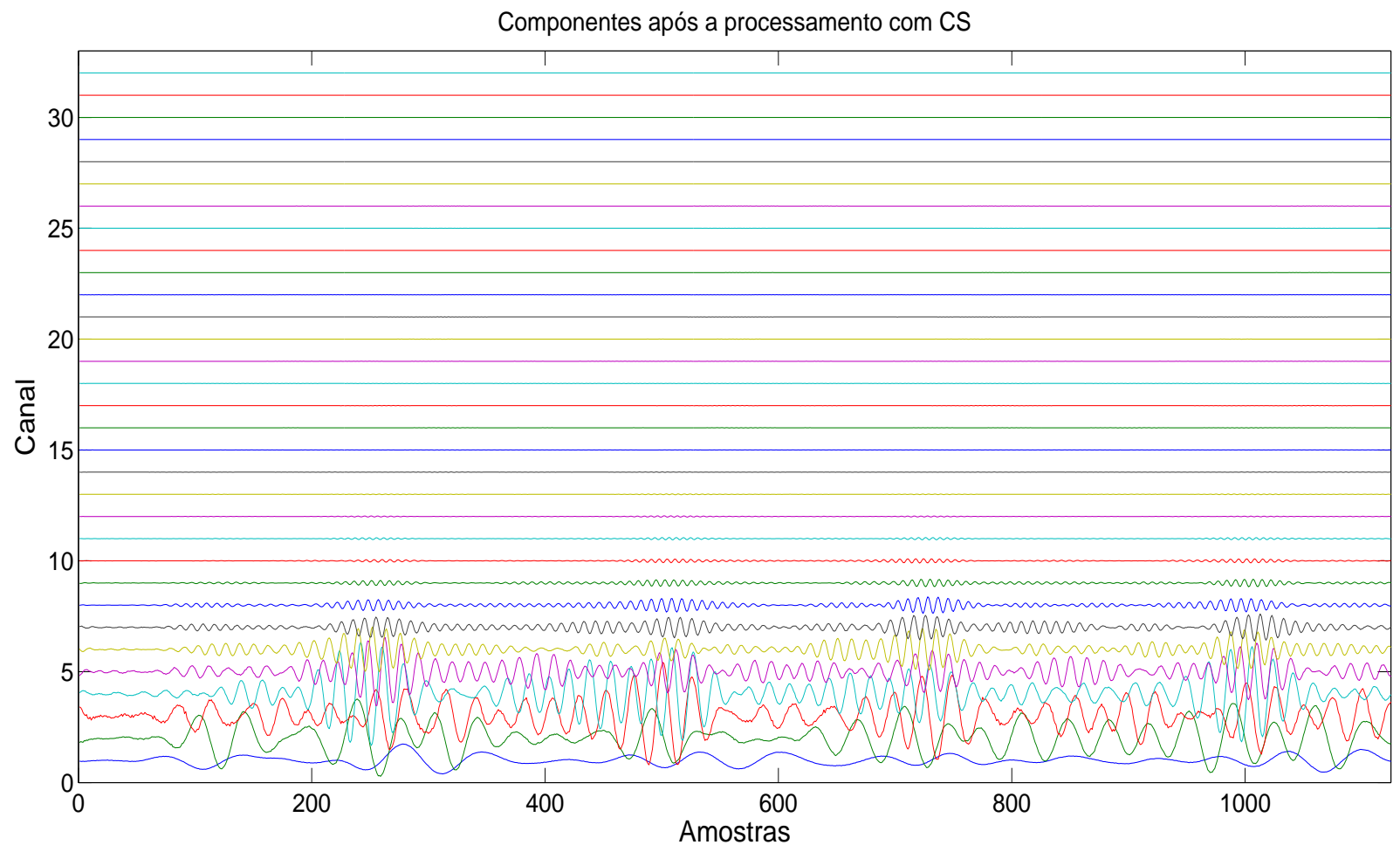

Figura 4.9: 32 sub-bandas processadas com o $C S$. Nesta etapa as componentes apresentam atraso em função do filtro de análise utilizado. Nota-se que as componentes iniciais possuem a maior parte das informações, enquanto que as últimas pouco influenciam. 


\subsection{Filtragem com o banco de síntese}

A aplicação do banco de síntese consiste na convolução das componentes com o inverso do banco de análise. Considerando que o banco é de reconstrução perfeita, não existem perdas associadas a este processo. A Figura 4.10 apresenta o resultado deste processo. Apesar de ser semelhante à Figura 4.9, nota-se a remoção de partes do sinal e a presença de um atraso.

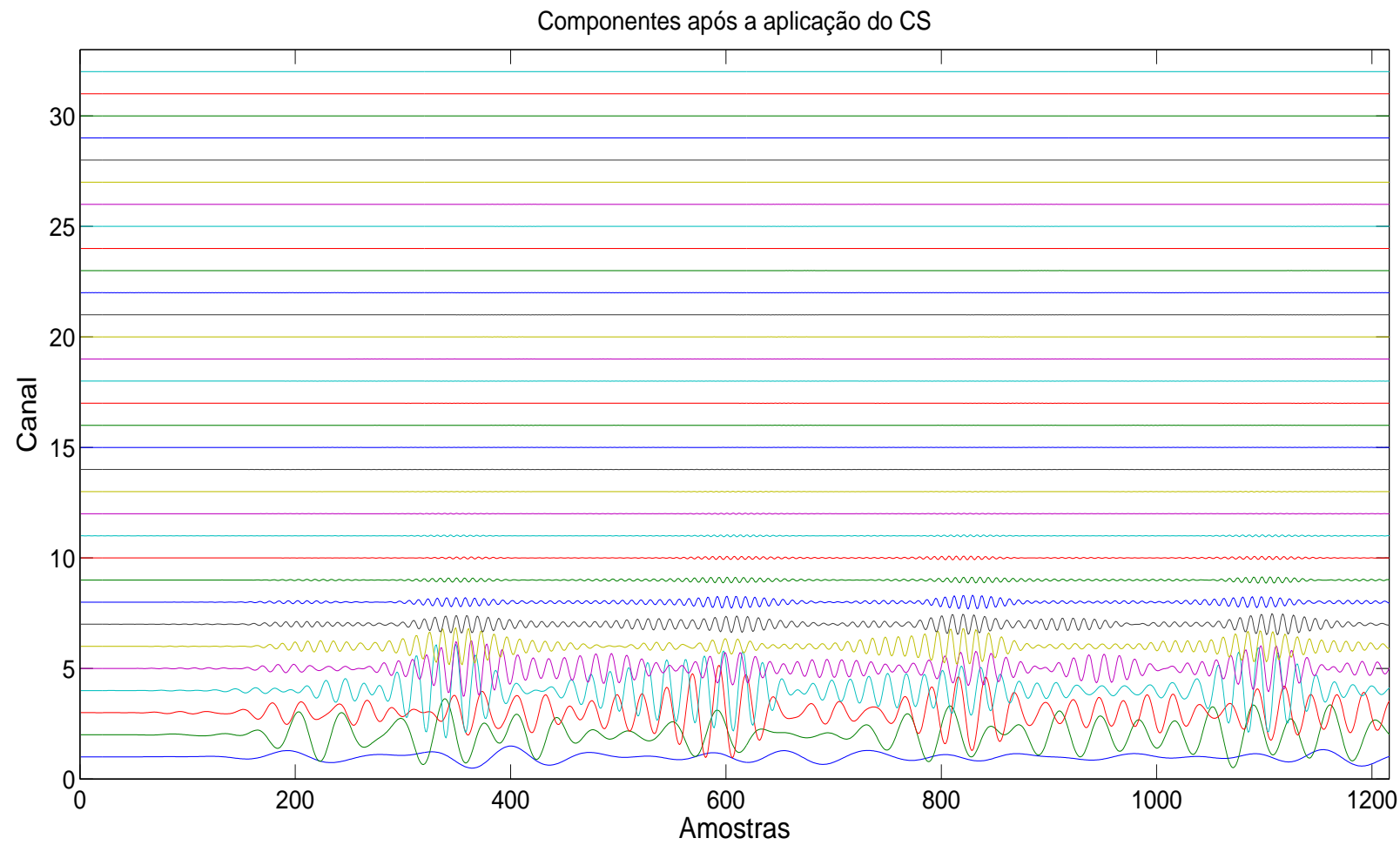

Figura 4.10: 32 sub-bandas processadas com o $C S$ e convoluídas com o filtro de síntese. Após essa etapa, o sinal está pronto para ser reconstruído, sendo este processo a soma linear de todas as componentes. O atraso ainda não é corrigido.

\subsection{Reconstrução do sinal e correção do atraso}

A recuperação do sinal se dá pela soma linear de todas as componentes já filtradas. Entretanto, ainda é necessário corrigir o atraso introduzido pelo banco de filtro. Este processo se dá por meio do deslocamento das amostras em 191 pontos, conforme visto na seç̧ão 3.3.3.1. A Figura 4.11(a) ilustra a reconstrução do sinal em vermelho, apresentando um atraso de 191 amostras em relação ao sinal original (azul). Já a Figura 4.11(b), apresenta o resultado do deslocamento dos pontos e a correção. 


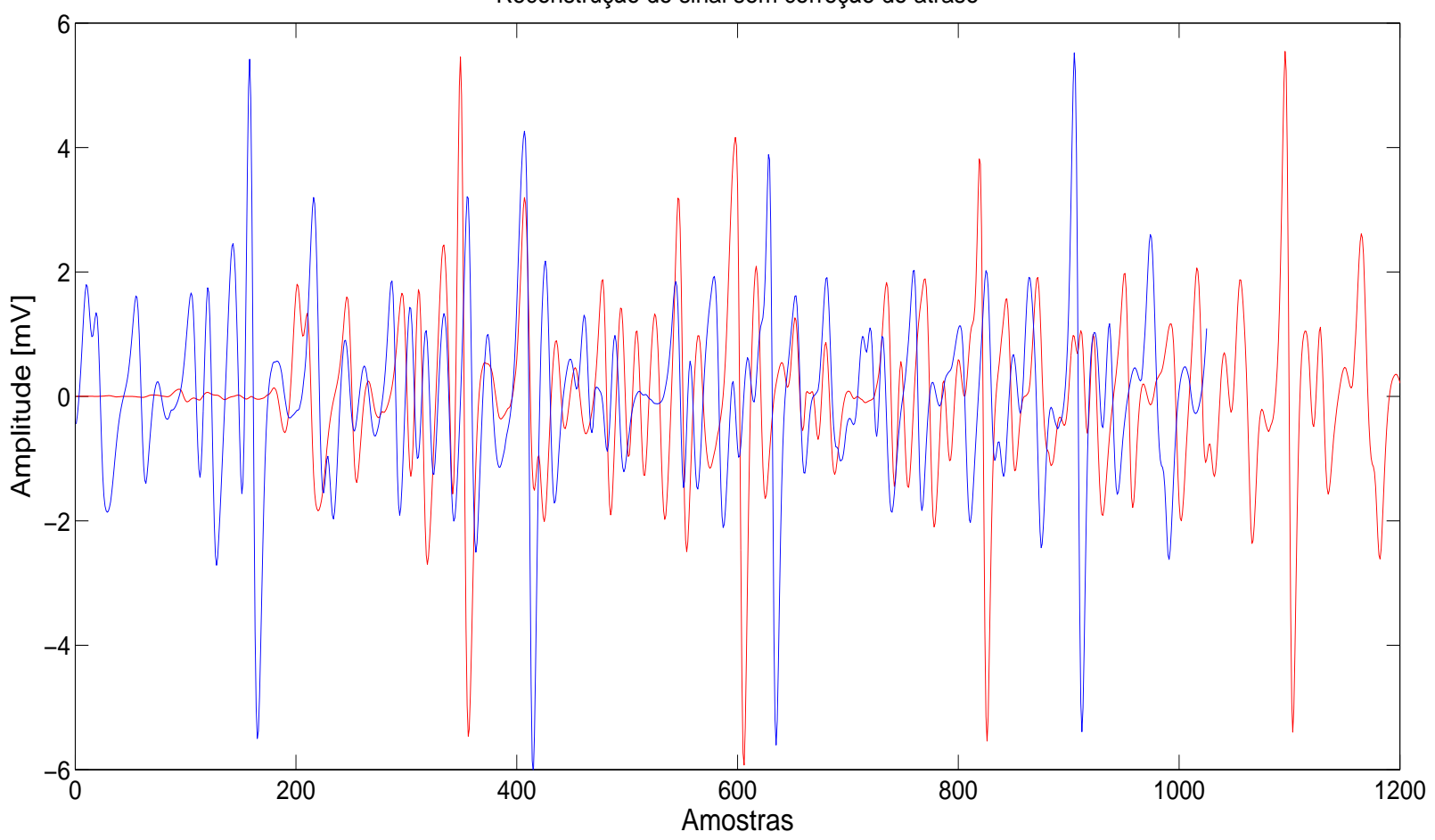

(a)

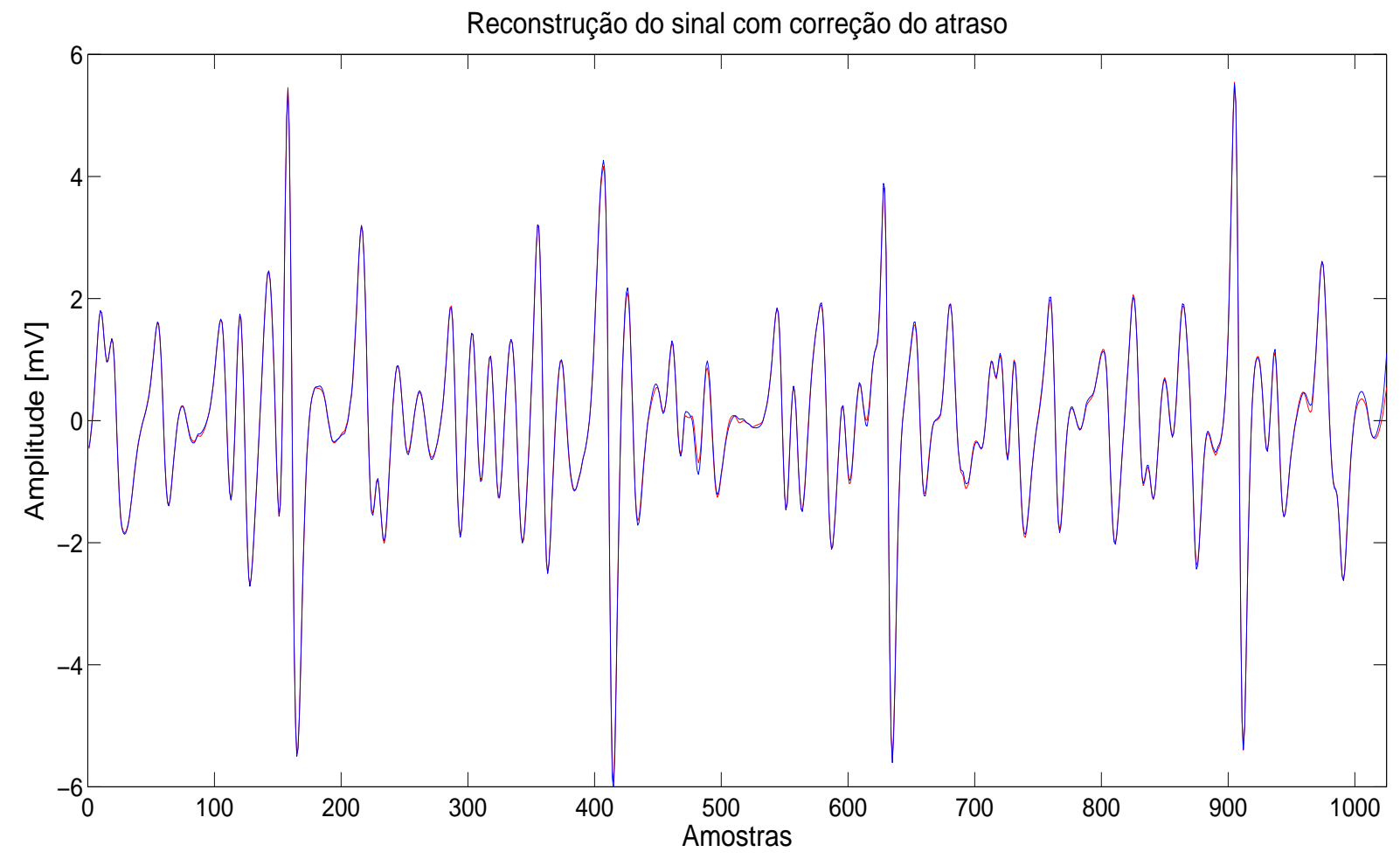

(b)

Figura 4.11: Reconstrução sinal e correção do atraso inserido pelo banco de filtros. O sinal original é representado em azul, enquanto que o reconstruído está em vermelho.a) Antes da remoção do atraso. b) Sinal recuperado e deslocado em 191 pontos para remoção do atraso introduzido pelo banco de filtros. 


\subsection{Reconstrução de Múltiplos intervalos}

Conforme relatado na secção 3.4, foram inseridos múltiplos intervalos de falhas no sinal. As Figuras 4.12(a) a 4.12(d) ilustram a recuperação do sinal. Na etapa de configuração, optou-se por distribuir os intervalos de forma uniforme dentro do sinal, conforme apresentado pela Tabela 3.2.

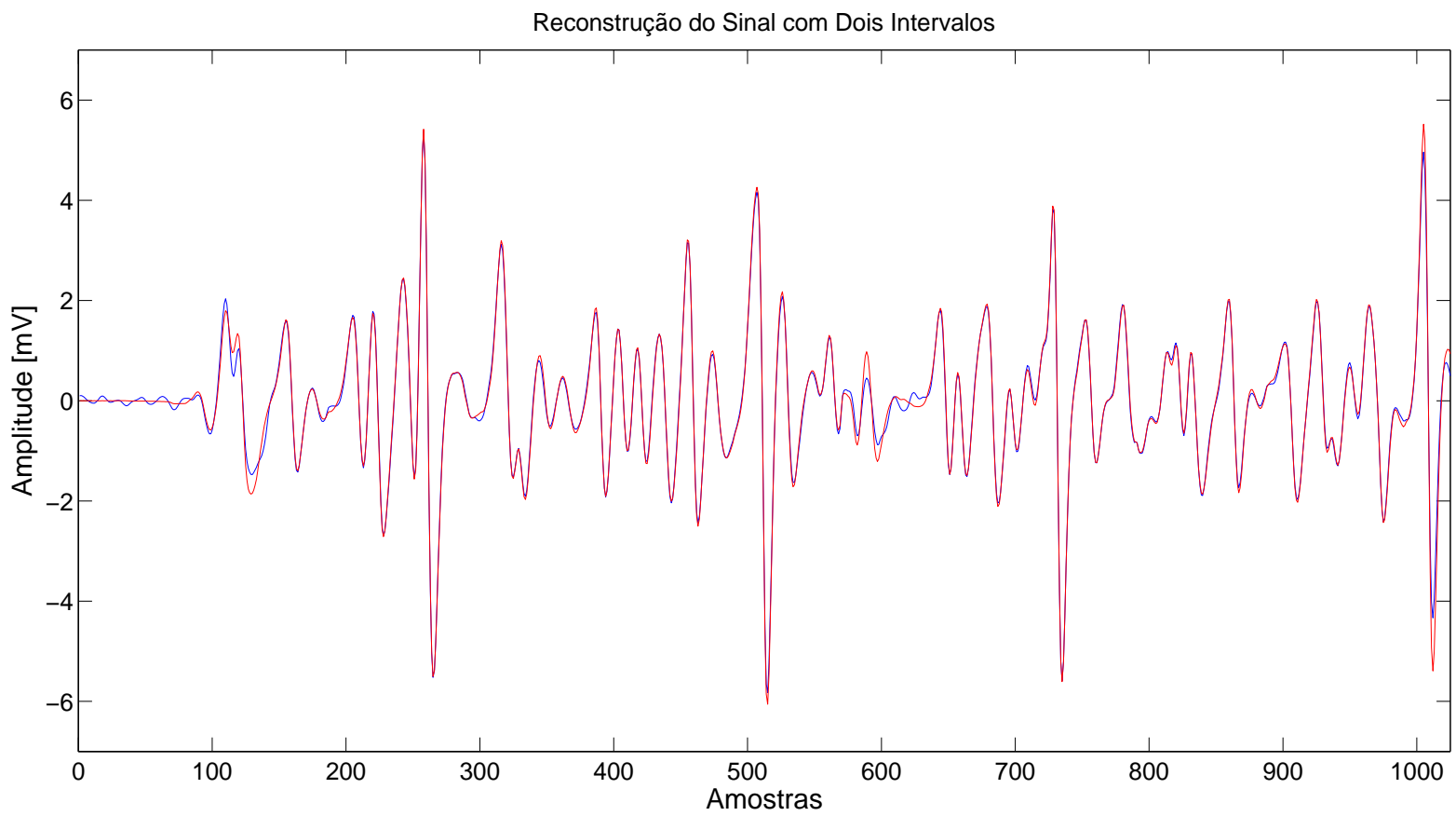

(a)

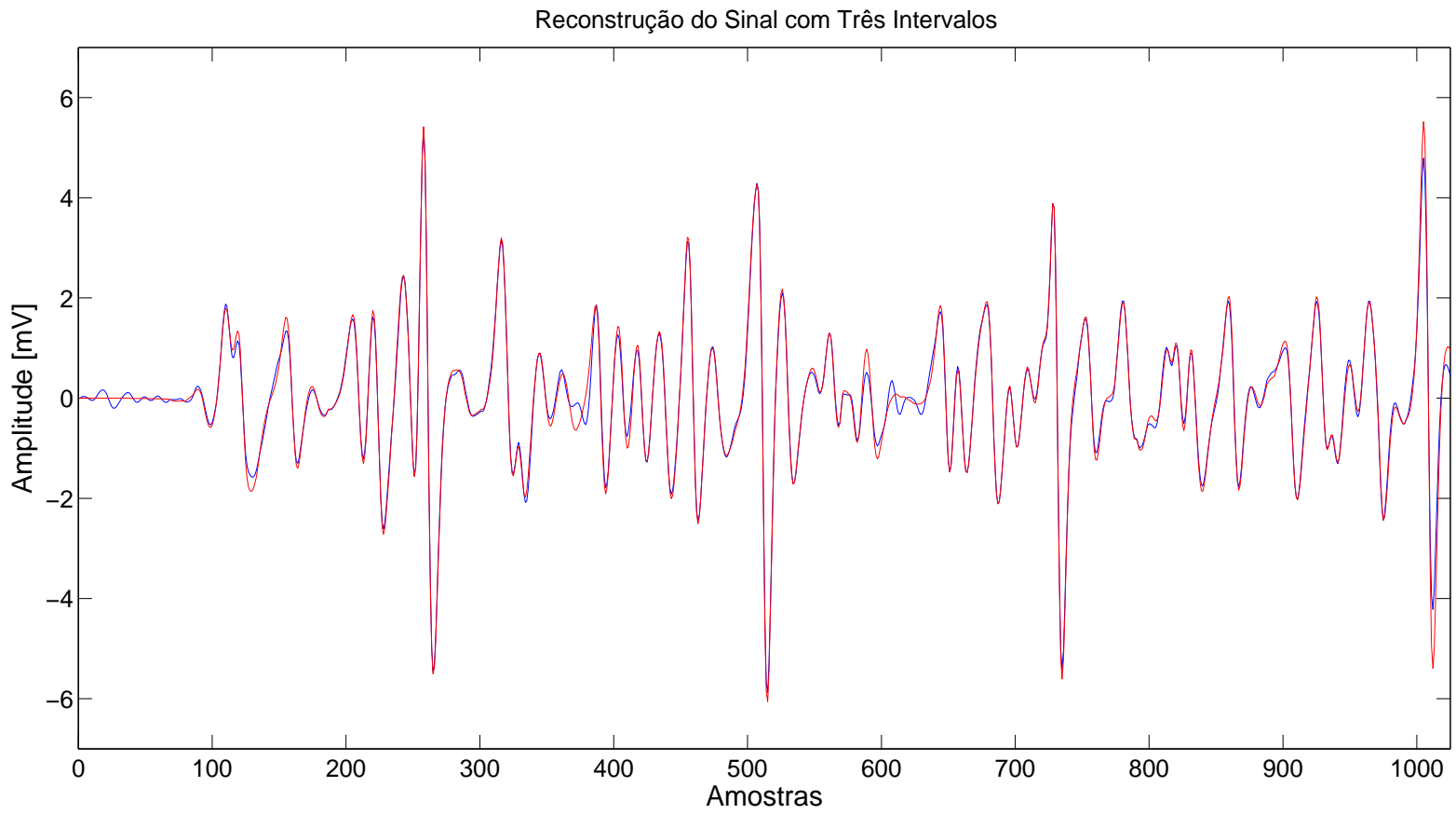

(b) 


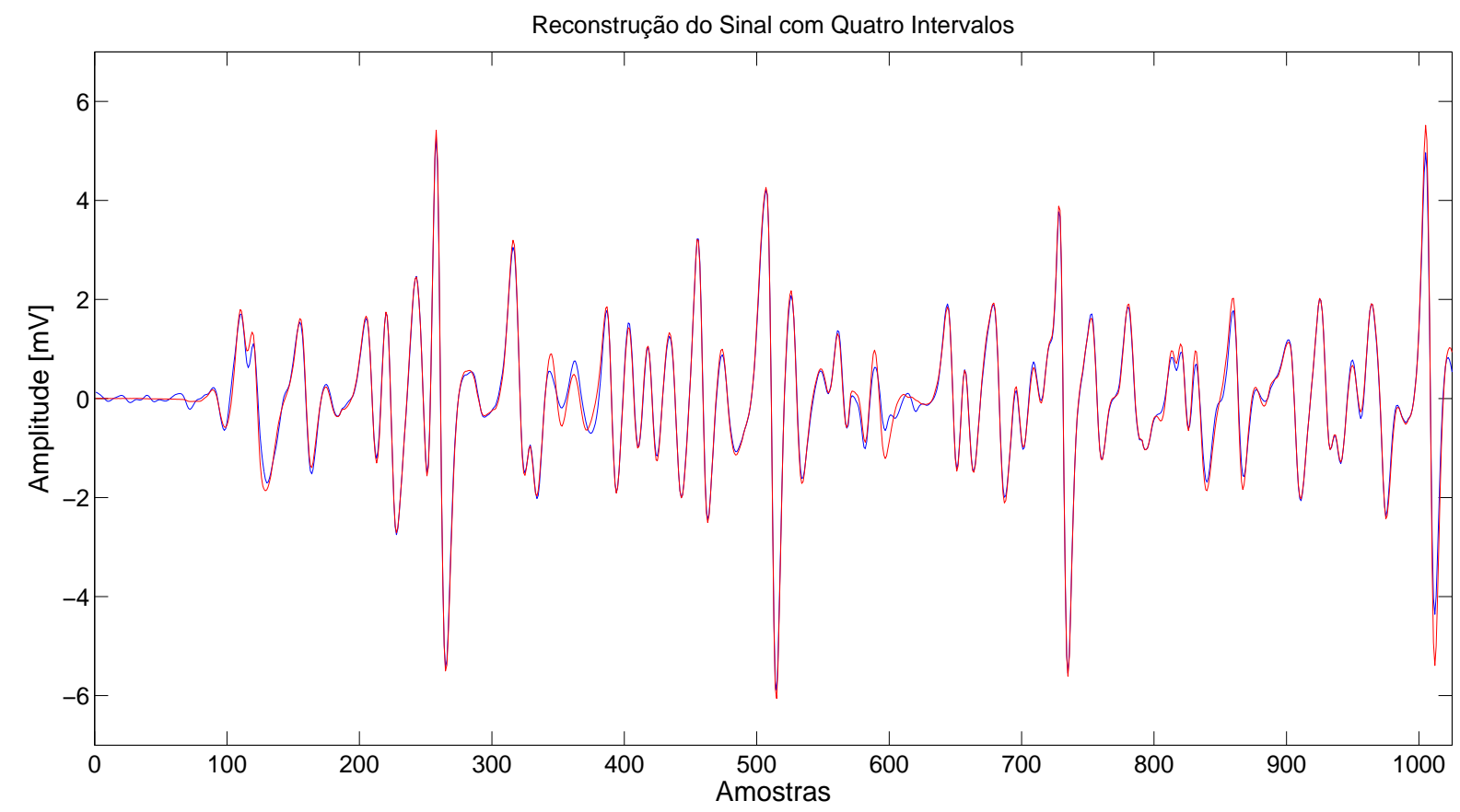

(c)

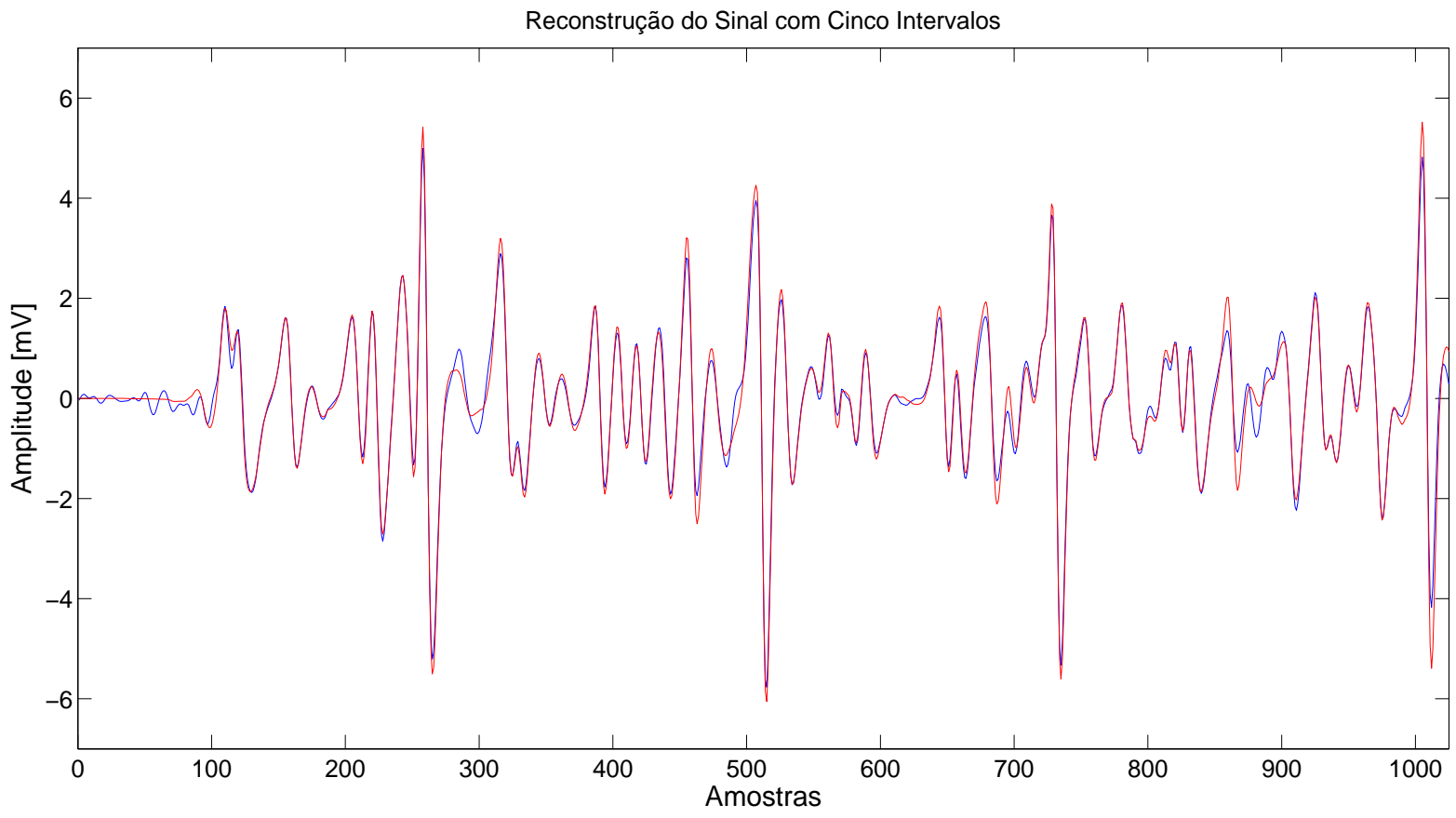

(d)

Figura 4.12: Recuperação do sinal com múltiplos intervalos de falhas, com posições estabelecidas na Tabela 3.2. Cada intervalo representa 40 pontos de perda de informações. a) Dois intervalos. b) Três intervalos. c) Quatro intervalos. d) Cinco intervalos. 


\subsection{Relação SSR entre o sinal original e o reconstruído}

O cálculo do SSR, apresentado pela Equação 3.2 e obtido através da execução de 30 vezes da simulação, resultou nos valores apresentados na Tabela 4.9.

Tabela 4.9: Resultados dos cálculos de SRR do sinal reconstruído e o do sinal original para múltiplos intervalos

\begin{tabular}{cc}
\hline Número de Intervalos & SSR do Sinal Reconstruído \\
\hline 1 & 29.59 \\
2 & 26.37 \\
3 & 25.74 \\
4 & $25.92 \mathrm{~dB}$ \\
5 & $25.01 \mathrm{~dB}$ \\
\hline
\end{tabular}




\section{Capítulo 5}

\section{Discussão}

\subsection{Discussão sobre o simulador de EMG-S bidimensional}

Por meio dos experimentos realizados, verificou-se a possibilidade de utilização do modelo proposto para geração de sinais com características específicas, podendo este ser empregado, por exemplo, na validação e calibração de equipamentos médicos.

A possibilidade de descrição das camadas do volume condutor através de funções mostra-se relevante, uma vez que permite que diversas superfícies sejam avaliadas. Com a escolha da função característica que melhor descreve o volume condutor desejado, o usuário pode tornar a simulação mais precisa, e ter resultados mais condizentes com a realidade. No caso deste trabalho, optouse por simplificar as descrições feitas no volume condutor, sendo as camadas de pele e gordura descritas como uma função senoidal arbitrária, que pode vir a ser substituída de acordo com os interesses do pesquisador.

Por se tratar de um simulador, foi possível atingir dimensões que atualmente estão limitadas por questões físicas e econômicas. Desta forma, novas pesquisas podem fazer uso dos sinais gerados e não ter seu progresso limitado pelo estado atual da fabricação de eletrodos. Este fato mostra-se de grande relevância, por exemplo, no cenário do controle de active phrostetic limbs, onde uma distinção mais precisa dos sinais possa resultar em um controle mais eficiente.

\subsection{Utilização do Banco de Filtros}

Em um primeiro momento, o estudo foi direcionado para a esparsificação de sinais. Verificou-se que os sinais fisiológicos normalmente não apresentam quebra de continuidade e que a representação no domínio de Fourier seria adequada para o desenvolvimento da pesquisa. No estudo preliminar de Compressive Sensing, verificou-se a necessidade de trabalhar com sinais esparsos, o que motivou a busca por alternativas para transformar os de EMG-S.

A solução adotada foi a utilização de Banco de Filtros. A partir dos conhecimentos prévios sobre EMG-S, era sabido que a banda espectral deste tipo de sinal biológico está concentrada na 
faixa de 20 a $500 \mathrm{~Hz}$. Observou-se também que, para ser considerado esparso, é necessário que o sinal possua representação no domínio transformado dado por um número pequeno de amostras, o que para o caso de Fourier, se dá por uma representação próxima à impulsional.

A divisão da banda de $480 \mathrm{~Hz}$ em 32 sub-bandas mostrou-se satisfatória, onde cada sub-banda ficou responsável por acomodar um espectro com largura de $15 \mathrm{~Hz}$. No domínio de Fourier, este espectro apresenta como curva característica uma onda com formato de sino bastante estreito, o que para os fins desta pesquisa, foi aceito como impulsional e considerado como esparso.

Outro fator que motivou a escolha de 32 canais foi o tempo gasto com o processamento envolvendo o CS. Por terem sido utilizados filtros digitais, não havia limitação teórica para o número de sub-bandas. Entretanto, o tempo gasto para o processamento de 32 canais durante a rotina de testes indicou que a utilização de um número maior de sub-bandas resultaria em um tempo muito elevado.

Os banco de síntese apresentou resultados bastantes satisfatórios na reconstrução do sinal. Após a correção do atraso introduzido, a diferença em relação ao original foi extremamente baixa, resultando em uma relação SSR próxima a 30dB. Levando em consideração que nos estudos de envolvendo eletromiografia a curva do sinal é apenas uma das várias características observadas, tal resultado indica uma reconstrução extremamente próxima ao original.

\subsection{Rotina para delimitação dos parâmetros}

A execução do laço de repetição permitiu avaliar o comportamento dos três parâmetros em simultâneo. O primeiro avaliado foi o percentual de amostras, que é uma das principais justificativas para a utilização do CS. Estipulou-se que este não poderia ser superior a $40 \%$ to total de pontos e que a posição das amostras deveriam ser aleatórias. Os testes indicaram em todas os casos que, para os percentuais de $5 \%$ e $10 \%$, a diferença entre o sinal reconstruído e o original foi extremamente elevada, comprometendo completamente os resultados. Por outro lado, os resultados apresentados para os percentuais de 20\%, 30\% e 40\% foram muito próximos entre si e reconstruíram com qualidade o sinal na maior parte dos casos. A diferença do SSR apresentada entre os resultados não justifica a escolha dos dois valores mais elevados (30\% e 40\%), uma vez que o tempo de processamento é maior e não há melhora significativa em relação ao sinal reconstruído com $20 \%$.

O segundo parâmetro avaliado foi a métrica $L_{p}$. Em teoria, a minimização da métrica $L_{0}$ seria a melhor solução para o problema, entretanto, sabe-se que a solução é computacionalmente impraticável. Por outro lado, muito trabalhos vêm utilizando a minimização da norma $L_{1}$ junto com o $C S$ e têm obtido excelentes resultados. Esta apresenta a desvantagem de não oferecer a solução mais esparsa possível em todos os casos. Situado este problema, buscou-se então a utilização de métrica intermediária $\left(0 \leq L_{p} \leq 1\right)$, com objetivo de obter as vantagens de cada uma. Os valores não foram escolhidos aleatoriamente pois desejava-se observar a influência da métrica sobre o SRR, sendo os valores escolhidos os mais comumente citados na literatura.

Nos gráficos gerados, os demais parâmetros foram fixados e foi possível observar que, com a 
diminuição da métrica $L_{p}$ ocorria a elevação dos valores médios de SSR. Este fato deixou de ocorrer apenas para o caso em que $L_{p}=0.0005$ e a matriz de amostragem era binária, o que provavelmente indica um ponto crítico onde a característica da métrica $L_{0}$ está predominante. Por outro lado, a utilização da matriz de aquisição com coeficientes ponderados apresentou resultados melhores. Este resultado era esperado, uma vez que pontos ao longo de todo o sinal têm contribuição sobre o valor da amostra adquirida, diferentemente do que ocorre na matriz binária.

O terceiro parâmetro analisado e objeto foco deste trabalho foi o número máximo de pontos que poderia ser reconstruído. Como era esperado, os menores valores de intervalo apresentaram a melhor reconstrução. Contudo, a ideia era descobrir até que ponto a distância poderia ser aumentada sem comprometer a reconstrução no trecho. A partir do desenvolvimento de outros trabalhos científicos, era previamente conhecida a informação sobre o SNR em sinais de EMG-S, em que valores iguais ou superiores a $30 \mathrm{~dB}$ são considerados muito bons. Fazendo uma comparação com o valor de SSR utilizado neste trabalho, estipulou-se inicialmente que seriam considerados válidos e aceitáveis os sinais reconstruídos que apresentassem relação SSR igual ou superior a 30 dB. Os testes foram executados em apenas uma sub-banda do sinal, e foi observado que a partir da métrica $L_{p}=0.25$, o intervalo de 30 pontos tendia a manter-se sempre próximo de $30 \mathrm{db}$.

Escolhido então a métrica $L_{p}=0.0005$, o intervalo de 30 pontos e o percentual de $20 \%$, os testes com o $C S$ tiveram início e foi executada a reconstrução do sinal com o banco de síntese. Neste momento foi constatado que o intervalo de 40 pontos também oferecia relação SSR próxima de 30dB. Para verificar esta diferença e definir qual seria a melhor escolha, uma nova rotina de testes foi executada, porém desta vez o algorítimo de testes foi executado para todas as sub-bandas do sinal de EMG-S e o SRR calculado a partir do sinal final. Foram realizados trinta testes e os resultados indicaram que para um intervalo de 40 pontos, o SSR seria de aproximadamente 29.59 dB. Este valor é muito próximo dos $30 \mathrm{~dB}$ estipulados inicialmente e analisando o contexto em que está inserido, foi considerado como aceitável.

\subsection{Reconstrução de múltiplos intervalos}

Esse tópico não estava previsto inicialmente no escopo do trabalho, mas após a delimitação dos parâmetros e a análise dos resultados para um intervalo, decidiu-se fazer o teste com a adição de até 5 intervalos de falhas no mesmo sinal. Uma das razões para estes testes ocorrerem foi a quantidade de pontos inutilizados e que já seriam reconstruídos independente de outros fatores. Como foram utilizas apenas $20 \%$ dos pontos, os testes consistiram em zerar trechos do sinal (40 pontos) e realizar a amostragem fora destes intervalos. Os resultados surpreenderam e são um grande indicativo de que a técnica pode ser utilizada para outras aplicações e de maneira mais eficiente.

Um exemplo de situação que muito provavelmente será solucionada é a detecção automática de falhas através de pontos muito destoantes do sinal. Será possível, por exemplo, localizar no pósprocessamento os instantes em que usuário realizou um movimento fora do esperado e foi gerado um ruído de artefato. Outro tipo de falha é perda de contato eletrodo-pele, que gera impulsos de 
grande amplitude no sinal. Será possível descartar esse trecho e recuperá-lo através dos demais pontos.

No caso desta dissertação, o sinal de referência possuía 1025 amostras e o resultado para 5 intervalos falhos de 40 pontos ( 200 pontos no total $\approx 20 \%$ do sinal) foi muito satisfatório. Para trabalhos futuros, é muito provável que um maior número de trechos possa ser reconstruído. O desafio passa a ser a determinação da melhor técnica para realizar a amostragem. Neste trabalho a posição das amostras foi gerada aleatoriamente, respeitando apenas a condição de não coletar dados comprometidos. Acredita-se que seja possível alcançar uma recuperação entre 60 a $70 \%$ do sinal, utilizando para isso intervalos com dimensões variadas e uma regra de amostragem mais robusta.

\subsection{Compressive Sensing}

A utilização desta técnica mostrou-se bastante satisfatória quanto a reconstrução dos trechos comprometidos. A etapa mais demorada e difícil do processo foi a determinação dos melhores parâmetros, que foi obtida através de uma simulação que se estendeu por dias. Entretanto, uma vez determinados, a reconstrução do sinal de 1025 amostras utilizando o CS foi relativamente rápida, durando poucos segundos. Para pesquisas, tal intervalo de tempo é aceitável, uma vez que os resultados apresentam uma grande economia de tempo em refazer os experimentos.

Quando comparada à outras técnicas de reconstrução de sinais como a IDW (Inverse Distance Weighting), que utiliza os pontos vizinhos para a determinação de um ponto intermediário, o $C S$ apresenta a vantagem de utilizar informações do próprio sinal corrompido para reconstrução. 


\section{Capítulo 6}

\section{Conclusão}

Este trabalho teve como objetivo, o estudo de viabilidade da utilização do $C S$ na recuperação de sinais de EMG-S. Por ser um ramo de pesquisa relativamente novo, algumas aplicações para o $C S$ ainda estão incipientes e abertas para novas pesquisas. Após uma busca bibliográfica, foi observado que o Compressive Sensing já está oferecendo bons resultados em projetos, como os que envolvem ressonância magnética e o processamento de imagens. Entretanto, poucos trabalhos publicados versam sobre a recuperação de sinais de eletromiografia.

Por ser uma sinal susceptível a diversos tipos de interferências e perda de informações, a perfeita aquisição de sinais de EMG-S muitas vezes não ocorre ou é muito cara para ser executada, limitando o avanço de pesquisas. Ademais, pode ocorrer de os sinais serem captados e somente no pós processamento ser verificado o comprometimento das informações. Para tentar resolver essas situações, foi proposto neste trabalho a aplicação do $C S$ em intervalos de pontos comprometidos intencionalmente, de modo a realizar a comparação entre o sinal recuperado e o sinal original.

Após a delimitação do tema, verificou-se que os sinais de EMG-S são naturalmente não-esparsos, sendo necessária a utilização de um Banco de Filtros. Considerando que o espectro de frequência de sinais de EMG-S está concentrado na faixa de 20 a $500 \mathrm{~Hz}$, a utilização de um banco com 32 componentes mostrou-se suficiente, um vez que cada parcela compreende uma largura de banda de aproximadamente $15 \mathrm{~Hz}$. É muito provável que a utilização de bancos com um maior número de sub-bandas resulte em uma esparsificação mais robusta, entretanto esta escolha não foi realizada devido o tempo de processamento envolvido.

A proposta inicial do trabalho era a recuperação de um intervalo de pontos comprometidos, de modo que, utilizando apenas o restante do sinal, fosse possível recuperar o maior trecho possível. Pouco material foi encontrado relacionando o $C S$ e sinais de EMG-S, e em nenhum trabalhos lidos houve uma posição clara sobre qual os melhores procedimentos e parâmetros. Além disso, constatou-se que além do intervalo máximo, outras questões precisariam ser respondidas antes, pois estavam diretamente relacionadas com a aplicação do $C S$. Na minimização da métrica $L_{p}$, infinitos valores podem ser atribuídos à $p$, sendo necessário restringir os possíveis resultados. Além disso, nos processo envolvendo $C S$ é desejado a redução do número de amostras, caso contrário não haveria razão para utilização da técnica. De maneira análoga à questão da norma $L_{p}$, vários 
percentuais de amostras podem vir a ser utilizados, sendo novamente necessária a delimitação dos resultados.

Além das três variáveis que geram várias combinações possíveis, outros fator importante foi observado. A amostragem de pontos no sinal poderia ser realizada de duas maneiras distintas. Na primeira delas, o processo tradicional seria utilizado, e a matriz de aquisição seria binária. Na segunda opção, a matriz de amostragem seria ponderada, onde cada componente teria um peso distinto e aleatório.

Para observação mais precisa e afim de verificar todas as combinações em simultâneo, a solução adotada foi a execução de um grande laço de repetições, onde os parâmetros seriam alterados em cada iteração. Tal processo foi executado em um computador com processador de quatro núcleos, velocidade de clock de $2.6 \mathrm{GHz}$ e 8 Gb de memória Ram, sendo que o tempo total de execução foi de aproximadamente 104 horas consecutivas. A disposição dos dados em tabelas em gráficos ajudou na interpretação dos resultados, e possibilitou a escolha dos parâmetros que seriam utilizados.

Uma vez definido quais parâmetros seriam utilizados, os testes foram realizados em um sinal de referência. O tempo de processamento de todas as etapas para um sinal com 1025 amostras foi de 47 segundos, o que é aceitável em processamentos sinais para fins de pesquisa. A matriz de aquisição ponderada se mostrou melhor em todos os testes realizados, apresentando média dos resultados superiores à apresentadas na amostragem binária. A reconstrução de um intervalo de 40 pontos se deu de maneira bastante satisfatória, analisando o contexto em que se aplica. Considerando que na análise de sinais de EMG-S micro-oscilações na curva do sinal não são comprometedoras, e que outros parâmetros/características possuem uma relevância muito maior (ex: RMS, ARV, MNF, MDF, CV), o objetivo foi alcançado e a utilização do $C S$ mostrou-se bastante promissor.

Após a delimitação do tamanho máximo do intervalo e dos testes iniciais indicarem uma boa qualidade na reconstrução, novos intervalos de falhas foram inseridos. Esta ação foi motivada pelo fato de ter sido estipulado que o $C S$ faria uso de $20 \%$ das amostras e que 40 pontos correspondem a apenas $3 \%$ do sinal. Uma vez que os $77 \%$ restantes do sinal também seriam reconstruídos, a ideia consistiu em inserir outros intervalos de 40 pontos, igualmente espaçados, e que os pontos utilizados pelo $C S$ fossem adquiridos fora destes espaços.

Os resultados obtidos apresentaram grande proximidade com o sinal original, o que indica que este procedimento pode ser aplicado, por exemplo, em rotinas de detecção automática de falhas e remoção de sinais espúrios. Feita uma varredura ao longo de todo o sinal, é possível que sejam identificados as partes comprometidas por algum agente, como ruído ou movimentação do eletrodo, e que a recuperação seja feita sem a necessidade de intervenção do pesquisador.

Para encontrar a melhor combinação de parâmetros, muito esforço computacional é exigido e o $C S$ pode não ser uma solução para casos simples. Entretanto, uma vez definido quais valores serão utilizados, a aplicação mostra-se bastante eficiente e de rápido processamento. Neste trabalho foi feita uma busca sobre quais as melhores configurações para o uso do CS em sinais de EMG-S, e a mesma metodologia pode ser aplicada em outros sinais biológicos. 


\section{REFERÊNCIAS BIBLIOGRÁFICAS}

[1] MARRA, J. C. de O. CONTROLE HÍBRIDO DE VIBRAÇÕES EM ESTRUTURAS SOB EXCITAÇÃO DE BANDA LARGA, UTILIZANDO NEUTRALIZADOR VISCOELÁSTICO E FILTRO ADAPTATIVO. Dissertação (Mestrado) - Universidade Federal de Santa Catarina, 2007.

[2] SHIN, Y. et al. Sparse representation-based classification scheme for motor imagery-based brainâĂŞcomputer interface systems. Journal of Neural Engineering, v. 9, n. 5, p. 056002, 2012. Disponível em: <http://stacks.iop.org/1741-2552/9/i=5/a=056002>.

[3] FARINA, D.; MERLETTI, R. A novel approach for precise simulation of the emg signal detected by surface electrodes. Biomedical Engineering, IEEE Transactions on, v. 48, n. 6, p. 637-646, Jun 2001. ISSN 0018-9294.

[4] JIANG, N. et al. Myoelectric control of artificial limbs : Is there a need to change focus? [in the spotlight]. IEEE Signal Processing Magazine, Institute of Electrical \& Electronics Engineers (IEEE), v. 29, n. 5, p. 152âĂŞ150, Sep 2012. ISSN 1053-5888. Disponível em: <http://dx.doi.org/10.1109/MSP.2012.2203480>.

[5] DISSELHORST-KLUG, C.; SILNY, J.; RAU, G. Improvement of spatial resolution in surfaceemg: a theoretical and experimental comparison of different spatial filters. Biomedical Engineering, IEEE Transactions on, v. 44, n. 7, p. 567-574, July 1997. ISSN 0018-9294.

[6] FOUGNER, A. et al. Control of upper limb prostheses: Terminology and proportional myoelectric control 2014; a review. IEEE Trans. Neural Syst. Rehabil. Eng., Institute of Electrical \& Electronics Engineers (IEEE), v. 20, n. 5, p. 663âĂŞ677, Sep 2012. ISSN 1558-0210. Disponível em: <http://dx.doi.org/10.1109/TNSRE.2012.2196711>.

[7] INSTRUMENTS, N. Medical device testing with national instruments software and modular instruments. In: . [s.n.], 2012. Disponível em: <http://www.ni.com/white-paper/4530/en/>.

[8] MERLETTI, R.; PARKER, P. Electromyography: Physiology, Engineering, and Noninvasive Applications. [S.1.]: Wiley-IEEE Press, 2004. 520 pages.

[9] MESIN, L. Volume conductor models in surface electromyography: Computational techniques. Computers in Biology and Medicine, Elsevier BV, v. 43, n. 7, p. 942âĂŞ952, Aug 2013. ISSN 0010-4825. Disponível em: <http://dx.doi.org/10.1016/j.compbiomed.2013.02.002>. 
[10] REHBAUM, H.; FARINA, D. Adaptive common average filtering for myocontrol applications. Med Biol Eng Comput, Springer Science + Business Media, Nov 2014. ISSN 1741-0444. Disponível em: <http://dx.doi.org/10.1007/s11517-014-1215-1>.

[11] CANDèS, E. J.; WAKIN, M. B. An introduction to compressive sampling. IEEE SIGNAL PROCESSING MAGAZINE, 2008.

[12] OPPENHEIM, A. V.; SCHAFER, R. W.; BUCK, J. R. Discrete-Time Signal Processing. 2nd. ed. [S.1.]: Prentice Hall, 1999.

[13] CANDĖS, E. J.; ROMBERG, J.; TAO, T. Robust uncertainty principles: exact signal reconstruction from highly incomplete frequency information. IEEE Transactions on Information Theory, v. 52, n. 2, p. 489Ü509, 2006.

[14] DONOHO, D. L. Compressed sensing. IEEE Transactions on Information Theory, v. 52, n. 4, p. 1289 - 1306, April 2006.

[15] VAIDYANATHAN, P. Multirate Systems and Filter Banks. [S.1.]: Prentice Hall, 1993.

[16] CORREIA., P.; MIL-HOMENS, P. A. A eletromiografia no estudo do movimento humano. Cruz Quebrada. Faculdade de Motricidade Humana. 2004.

[17] SOARES, F. A.; SALOMONI, S. Simulador computacional de sinais Eletromiográficos invasivos por modelagem de Dipolo. Universidade de Brasília, Brasília, Brasil.: [s.n.], 2004.

[18] PIPER, H. Electrophusiologie Menschicher Muskeln. [S.1.]: Springer - Verlag, 1912.

[19] GASSER, H. S.; NEWCOMER, H. S. Physiological action currents in the phrenic nerve. An application of the thermionic vacuum tube to nerve physiology. [S.1.], 1921.

[20] CRAM, J. R. (Ed.). The History of the Surface Eletromiography. 2003.

[21] NYQUIST, H. Certain topics in telegraph transmission theory. Transactions of the American Institute of Electrical Engineers., v. 47, p. 617Ü644, 1928.

[22] SHANNON, C. E. Communication in the presence of noise. Proceedings of the Institute of Radio Engineers, v. 37, p. 10-21, 1949.

[23] JERRI, A. J. The shannon sampling theorem - its various extensions and applications : A tutorial review. Proceedings of the IEEE, v. 65, n. 11, p. 1565Û1596, 1977.

[24] LLAVE, B. C. Aplicação do método do gradiente espectral projetado ao problema de compressive sensing. Dissertação (Mestrado) - Instituto de matemática e estatítica da Universidade de São Paulo, 2012.

[25] DUARTE, M. et al. Single pixel imaging via compressed sensing. IEEE Signal Processing Magazine, v. 25, p. 83-91, march 2008. Digital Version.

[26] BARANIUK, R. G. Compressive Sensing. [S.1.], 2007. P.118-124. Disponível em: $<$ http://dsp.rice.edu/sites/dsp.rice.edu/files/cs/baraniukCSlecture07.pdf >. 
[27] LEE, K.; BRESLER, Y. Computing performance guarantees for compressed sensing. Proceedings IEEE International Conference on Acoustics, Speech and Signal Processing, p. 5129-5132, march 2008.

[28] FRANçA, R. dos S. OTIMIZAÇÃO E ESTIMAÇÃO DE PARÂMETROS PARA PROCESSAMENTO DE PADRÕES INTERFEROMÉTRICOS POR COMPUTAÇÃO EVOLUCIONÁ$R I A$. Tese (Doutorado) - Programa de Pós-Graduação em Engenharia Elétrica, COPPE, Universidade Federal do Rio de Janeiro,, 2015.

[29] BALOUCHESTANI, M.; KRISHNAN, S. Effective low-powerwearable wireless surface EMG sensordesign based on analog-compressed sensing. Sensors, MDPI AG, v. 14, n. 12, p. 2430524328, Dec 2014. ISSN 1424-8220. Disponível em: <http://dx.doi.org/10.3390/s141224305>.

[30] WANG, Q. et al. A novel pedestrian dead reckoning solution using motion recognition algorithm with wearable EMG sensors. Journal of Global Positioning Systems, International Association of Chinese Professionals in Global Positioning Systems, v. 10, n. 1, p. 39-49, Jun 2011. ISSN 1446-3164. Disponível em: <http://dx.doi.org/10.5081/jgps.10.1.39>.

[31] CHARTRAND, R. Exact reconstruction of sparse signals via nonconvex minimization. IEEE SIGNAL PROCESSING LETTERS, v. 14, n. 10, p. 707-710, OCTOBER 2007.

[32] MEDEIROS, R. J. V. de. Investigação Sobre Aplicação de Amostragem Compressiva a Sinais de Áudio. Dissertação (Mestrado) — Universidade Federal de Campina Grande, 2010.

[33] GUYTON, A. Fisiologia Humana. Guanabara Koogan, 1988. ISBN 9788527714129. Disponível em: <http://books.google.com.br/books?id=8Zg2HAAACAAJ $>$.

[34] LUCA, C. J. D. et al. Filtering the surface emg signal: Movement artifact and baseline noise contamination. Journal of Biomechanics, Elsevier BV, v. 43, n. 8, p. 1573âĂŞ1579, May 2010. ISSN 0021-9290. Disponível em: <http://dx.doi.org/10.1016/j.jbiomech.2010.01.027>.

[35] BARANIUK, R. et al. A simple proof of the restricted isometry property for random matrices. Constructive Approximation, Springer Science + Business Media, v. 28, n. 3, p. 253âĂ ̧263, Jan 2008. ISSN 1432-0940. Disponível em: <http://dx.doi.org/10.1007/s00365-007-9003-x>.

[36] FARINA, D. et al. A surface emg generation model with multilayer cylindrical description of the volume conductor. IEEE Trans. Biomed. Eng., Institute of Electrical \& Electronics Engineers (IEEE), v. 51, n. 3, p. 415âĂŞ426, Mar 2004. ISSN 0018-9294. Disponível em: $<$ http://dx.doi.org/10.1109/TBME.2003.820998>.

[37] Perotto, A. O. et al. Anatomical Guide For The Electromyographer: The Limbs And Trunk. 5ł. ed. [S.l.]: Charles C Thomas Pub Ltd, 2011. 